NIST Technical Note 1720

\title{
An Experimental and Computational Study of Reinforced Concrete Assemblies under a Column Removal Scenario
}

H.S. Lew

Yihai Bao

Fahim Sadek Joseph A. Main

Santiago Pujol

Mete A. Sozen

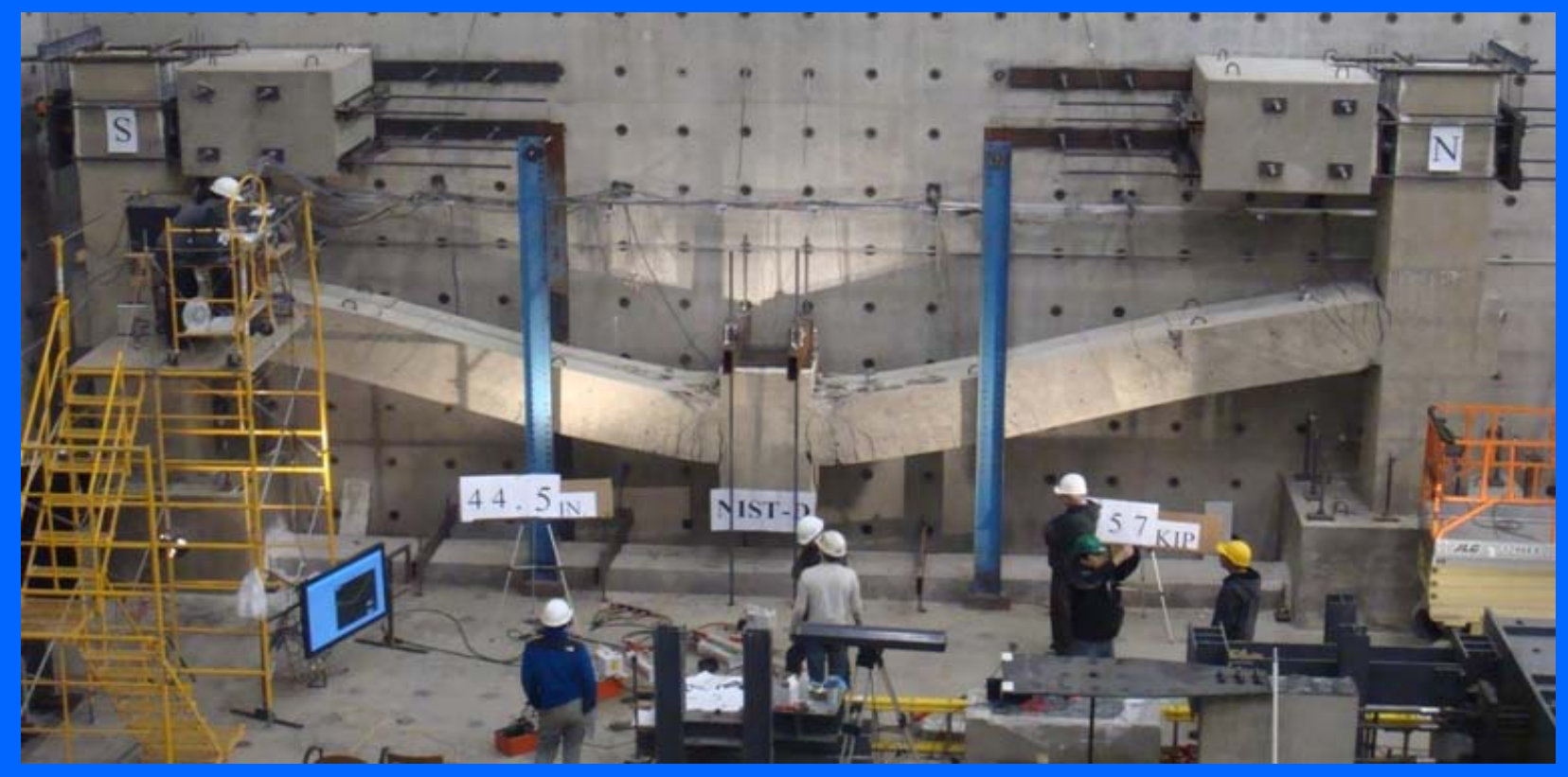



NIST Technical Note 1720

\section{An Experimental and Computational Study of Reinforced Concrete Assemblies under a Column Removal Scenario}

H. S. Lew, Yihai Bao, Fahim Sadek and Joseph A. Main

Engineering Laboratory

National Institute of Standards and Technology

Santiago Pujol and Mete A. Sozen Department of Civil and Environmental Engineering

Bowen Laboratory, Purdue University

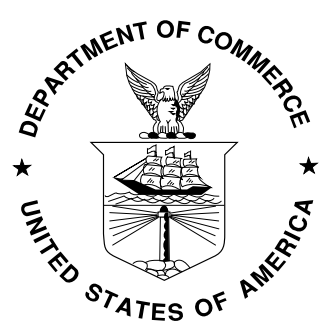

U.S. Department of Commerce John E. Bryson, Secretary 
Certain commercial entities, equipment, or materials may be identified in this document in order to describe an experimental procedure or concept adequately. Such identification is not intended to imply recommendation or endorsement by the National Institute of Standards and Technology, nor is it intended to imply that the entities, materials, or equipment are necessarily the best available for the purpose.

National Institute of Standards and Technology Technical Note 1720 Natl. Inst. Stand. Technol. Tech. Note 1720, 104 Pages (October 2011) CODEN: NTNOEF 


\section{ABSTRACT}

This report presents an experimental and computational study of two reinforced concrete beamcolumn assemblies, each comprising three columns and two beams. The two beam-column assemblies represent portions of the structural framing system of two ten-story reinforced concrete frame buildings, which were designed as part of the National Institute of Standards and Technology research program aimed at mitigating disproportionate structural collapse. One building was designed for Seismic Design Category C (SDC C) and the other for Seismic Design Category D (SDC D). The beam-column assemblies were taken from the exterior momentresisting frames of these buildings. The assembly from the SDC C building was part of an intermediate moment frame (IMF) and the assembly from the SDC D building was part of a special moment frame (SMF). The full-scale test assemblies were subjected to monotonically increasing vertical displacement of the center column to simulate a column removal scenario. The test was terminated when a collapse mechanism of each assembly was developed and the vertical load carrying capacity of the assembly was depleted. The primary test specimen response characteristics were measured. These included vertical and horizontal displacements at specific locations, rotations at beam ends, and strains in reinforcing bars at various locations. In addition, concrete surface strains were recorded by measuring the change in length between prepositioned targets at pre-selected critical zones of the beams. The failure of both the IMF and SMF assemblies was characterized by (1) crushing of concrete at the top of the beam near the center column, (2) development of major flexural cracks (deepening and widening), and (3) fracture of the bottom longitudinal beam reinforcing bars at a major crack opening near the center column.

Computational analyses of the beam-column assembly tests were carried out using two levels of modeling: (1) detailed models with a large number of elements: solid elements for concrete and beam elements for both longitudinal and transverse reinforcement, and (2) reduced models with a limited number of elements: beam elements for beams and columns and rigid links connected by nonlinear rotational springs for the beam-column joints. The analyses conducted using these models provided insight into the overall behavior and failure modes of the test assemblies. Good agreement was observed between the experimental and computational results. Both detailed and reduced models were capable of capturing the primary response characteristics. The reduced models developed in this study will be valuable in the analysis of complete structural systems for assessing the reserve capacity and robustness of building structures. The analyses confirm that the ultimate loads under the column removal scenario are primarily resisted through catenary action, wherein axial tension develops in the beams. The tensile force increase is limited by the fracture strength of the tensile reinforcement of the beams.

Keywords: buildings; computational model; computer simulation; design standards; disproportionate collapse; finite element analysis; progressive collapse; reinforced concrete structures; structural robustness; testing. 
This page intentionally left blank. 


\section{Preface}

The experimental and computational study reported herein is part of a comprehensive research program being carried out by the National Institute of Standard and Technology (NIST) on prevention of disproportionate collapse of building structures. To meet the critical need for experimental data, NIST developed a plan to test a series of full-scale structural assemblies of common building types.

This report presents the results from an experimental and computational study of two reinforced concrete beam-column assemblies. NIST developed the test plan and designed the specimens. The specimens represent portions of concrete moment frame buildings designed for Seismic Design Categories C and D, respectively. Detailed design of the buildings was carried out by S. K. Ghosh and Associates. The design was guided by a panel of experts who reviewed the design and provided valuable comments. The following experts served on the panel: David R. Bonneville (Degenkolb Engineers, San Francisco, CA), Donald O. Dusenberry (Simpson, Gumpertz \& Heger, Waltham, MA), Ramon Gilsanz (Gilsanz, Murray, Steficek, LLP, New York, NY), Thomas A. Sabol (Englekirk \& Sabol, Los Angeles, CA), and Andrew W. Taylor (KPFF Consulting Engineers, Seattle, WA).

The Applied Technology Council (ATC) and the Consortium of Universities for Research in Earthquake Engineering (CUREE) Joint Venture provided technical services under a contract to NIST. The Bowen Laboratory of Purdue University, under contract to the ATC/CUREE Joint Venture, fabricated and erected the test specimens, deployed the instruments, performed the test, and collected the test data.

The study reported herein was partially supported by the Department of Homeland Security. 
This page intentionally left blank. 


\section{TABLE OF CONTENTS}

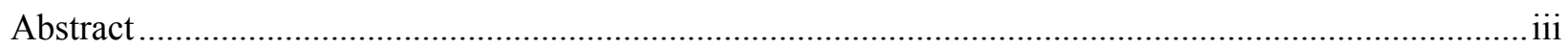

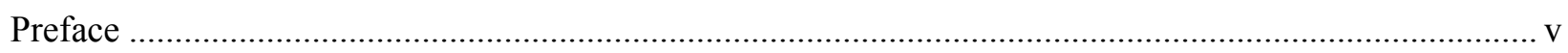

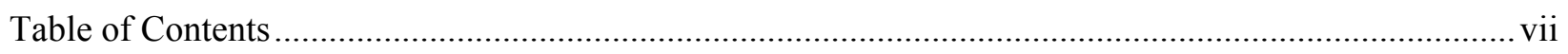

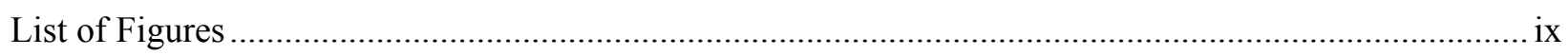

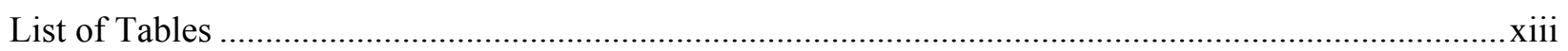

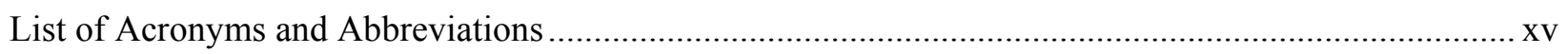

Executive Summary ........................................................................................................ Xvii

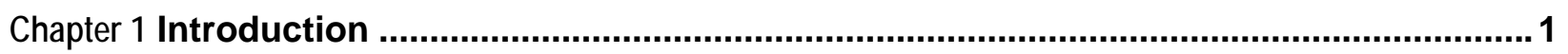

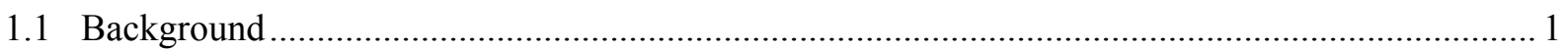

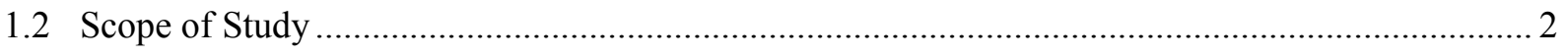

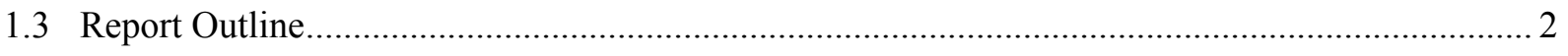

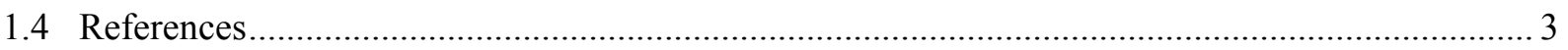

Chapter 2 Description of Prototype Building Designs ....................................................... 5

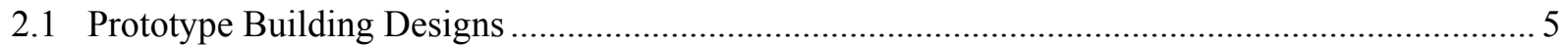

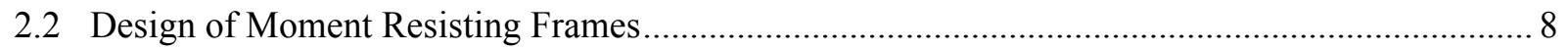

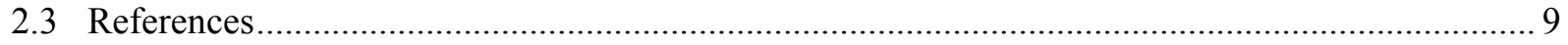

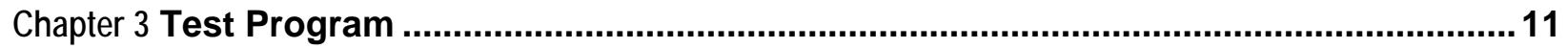

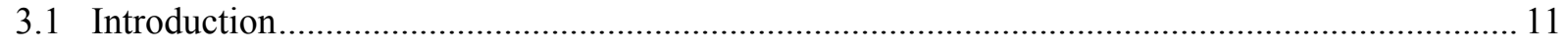

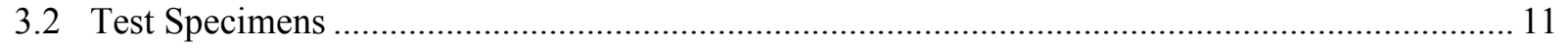

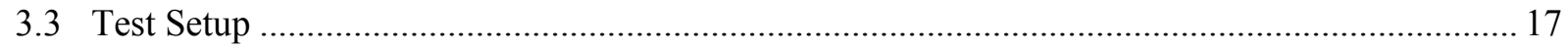

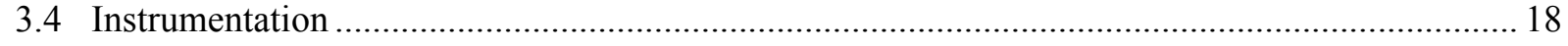

3.4.1 Displacement Transducers (Position transducers and LVDTs) ........................................ 22

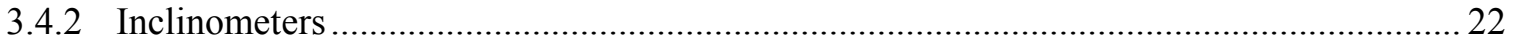

3.4.3 Surface Deformation Measurement Devices .................................................................. 23

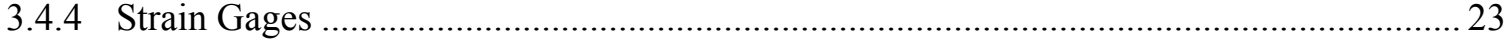

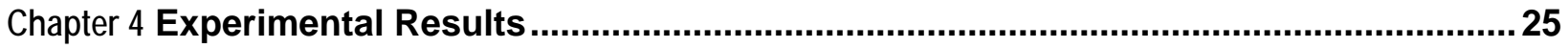

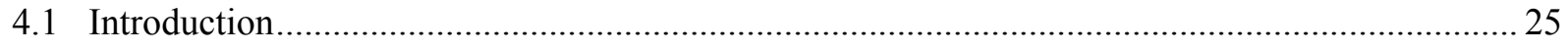

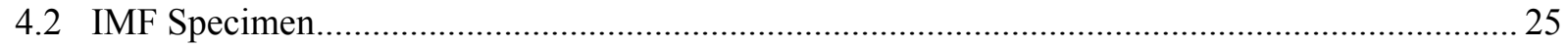




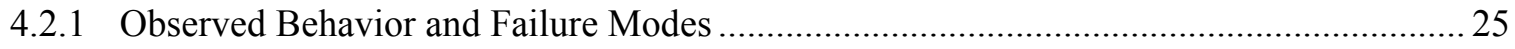

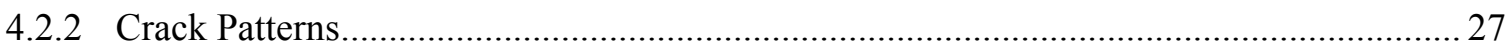

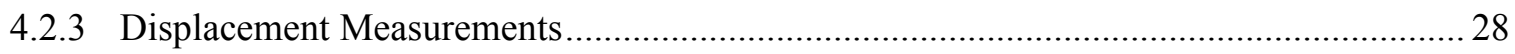

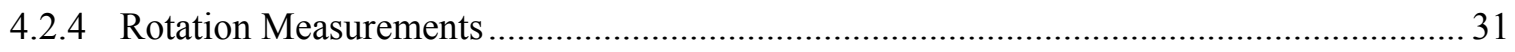

4.2.5 Strain Measurements .......................................................................................... 32

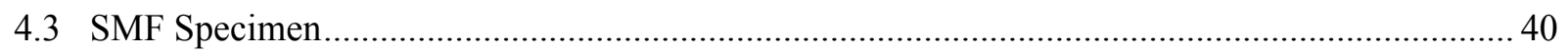

4.3.1 Observed Behavior and Failure Modes ..................................................................... 40

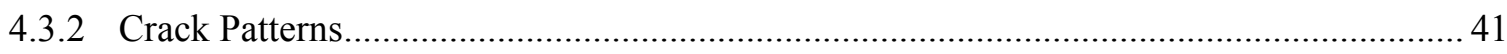

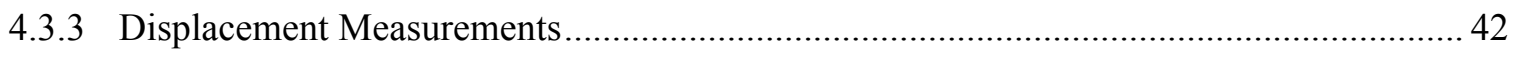

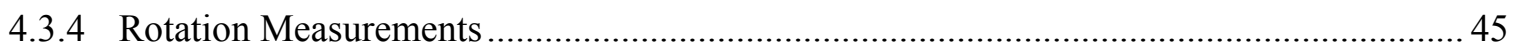

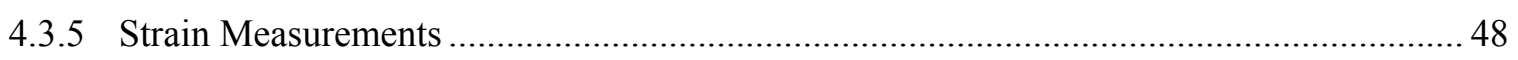

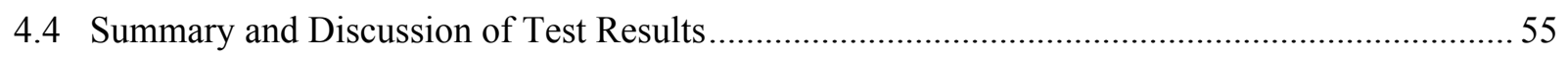

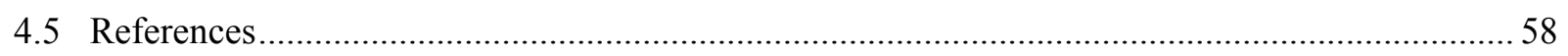

Chapter 5 Computational Modeling and Analysis of Test Specimens..................................59

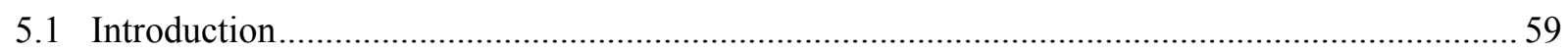

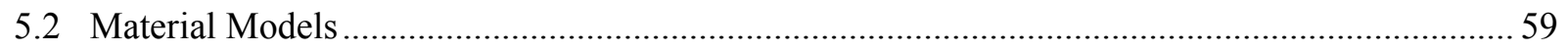

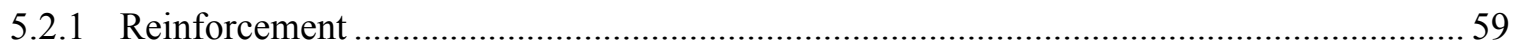

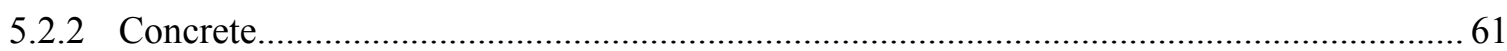

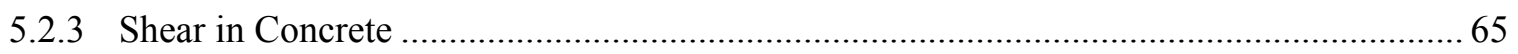

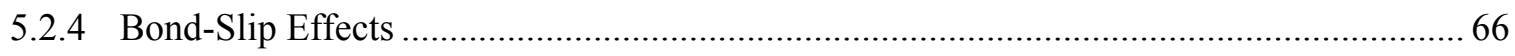

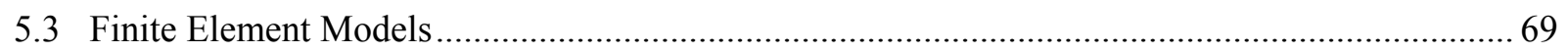

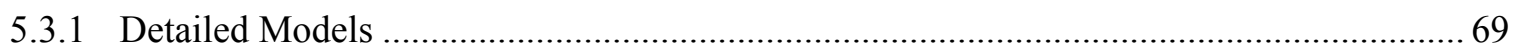

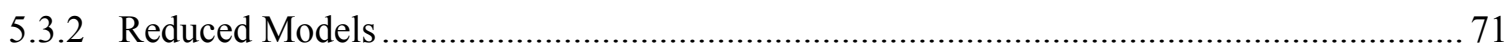

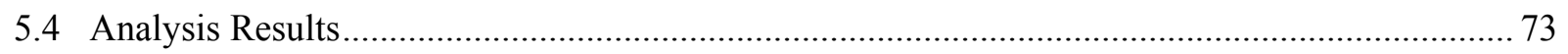

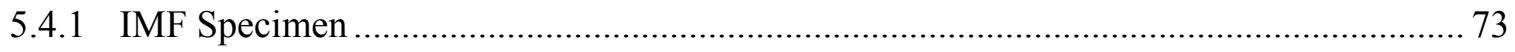

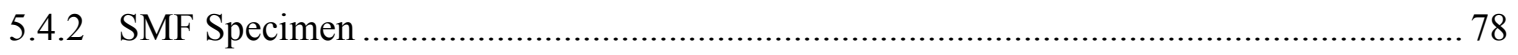

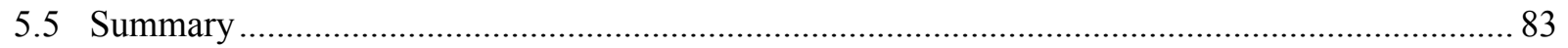

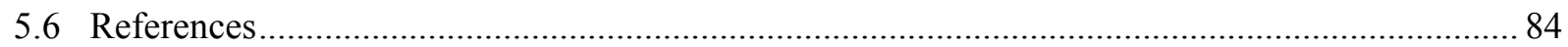

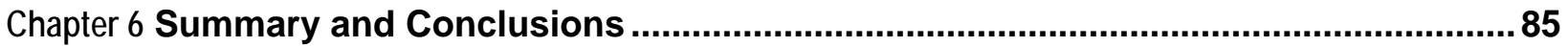




\section{LIST OF FIGURES}

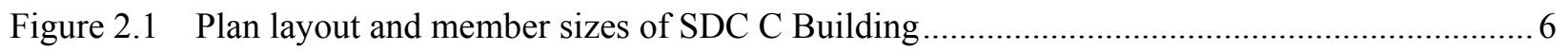

Figure 2.2 Plan layout and member sizes of SDC D Building............................................................. 6

Figure 2.3 Elevation of SDC C Building and SDC D Building ........................................................ 7

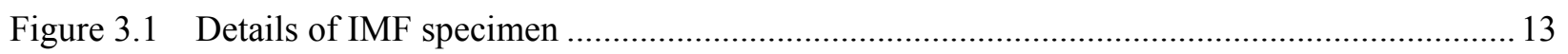

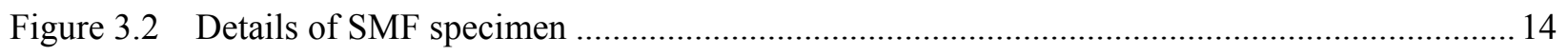

Figure 3.3 Threaded mechanical couplers for splicing longitudinal bars of beams .............................. 15

Figure 3.4 Anchorage of beam longitudinal reinforcement ............................................................ 15

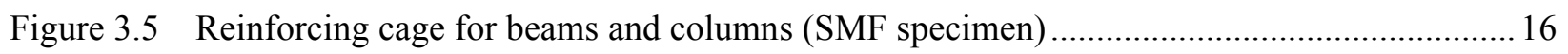

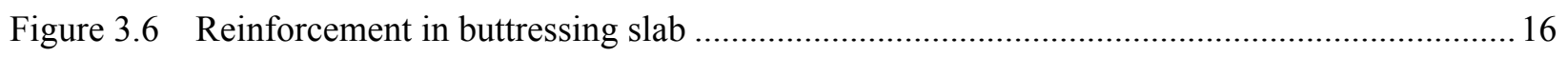

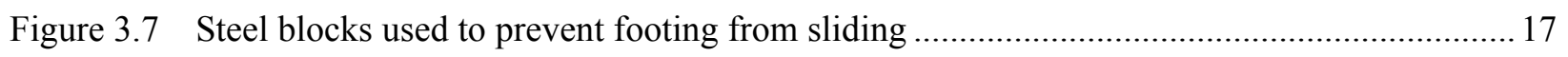

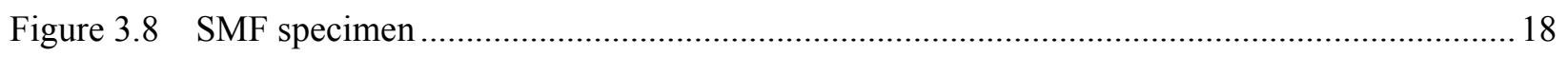

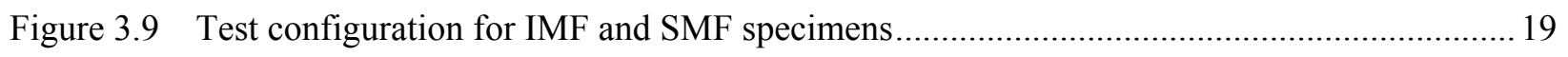

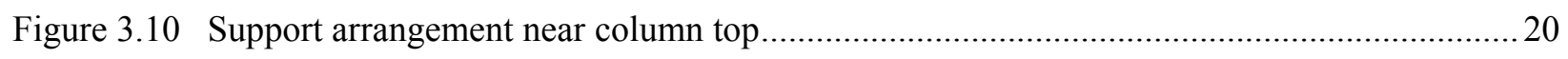

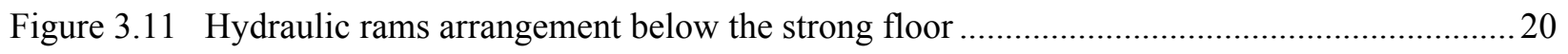

Figure 3.12 Instrument layouts (INC-inclinometer, ENC-position transducer, LC-load cell, other

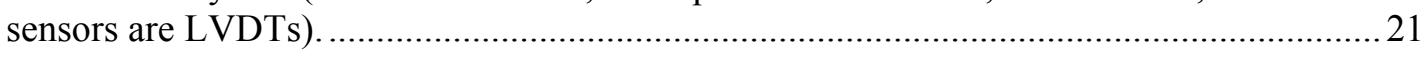

Figure 3.13 Optotrak target points for IMF specimen .................................................................. 23

Figure 4.1 IMF specimen subjected to large displacement...............................................................26

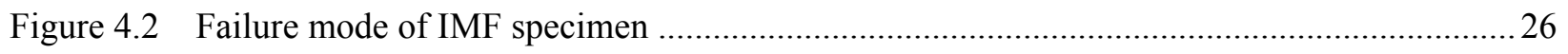

Figure 4.3 Crack patterns of IMF specimen at center column deflections of (a) 24 in (610 mm)

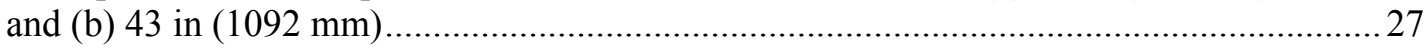

Figure 4.4 Vertical load versus vertical deflections of IMF specimen at (a) $1 / 4$ span of beams (ENC0 and ENC7), (b) mid-span of beams (ENC1 and ENC6), (c) 3/4 span of beams (ENC2 and ENC5), and (d) center column (ENC3 and ENC4)....

Figure 4.5 Vertical deflection profiles of beams corresponding to indicated vertical Loads for

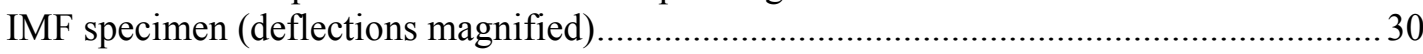

Figure 4.6 Horizontal displacement of end columns at (a) top (SCOL T, NCOL T), and (b) beam mid-height (SCOL M, NCOL M) versus vertical displacement of center

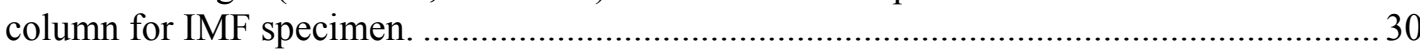

Figure 4.7 Applied vertical load versus beam end rotations for IMF specimen ..................................31

Figure 4.8 Beam end rotations versus vertical displacement of center column for IMF specimen ..........31

Figure 4.9 Strain measurements for IMF specimen: (a) Optotrak target locations and b) reinforcing bar strain gage locations .33 
Figure 4.10 Beam mid-span (Section B3 and B8) reinforcing bar strains versus vertical displacement of center column for IMF specimen: (a) top reinforcing bars and (b) bottom reinforcing bars

Figure 4.11 Column-bottom (Section S1 and N1) reinforcing bar strains versus vertical displacement of center column for IMF specimen: (a) interior reinforcing bars and (b) exterior reinforcing bars 35

Figure 4.12 Beam reinforcement strains at bar-cutoff sections versus vertical displacement of center column for IMF specimen: (a) top bars at sections B2 and B9, (b) top bars at sections B4 and B7, (c) bottom bars at sections B2 and B9, and (d) bottom bars at sections B4 and B7

Figure 4.13 Concrete surface strain distributions of IMF specimen at beam ends: (a) near north end column and (b) near south end column 38

Figure 4.14 Concrete surface strain distributions of IMF specimen at beam ends: (a) near north side of center column and (b) near south side of center column 39

Figure 4.15 View of SMF specimen subjected to large displacement ................................................... 40

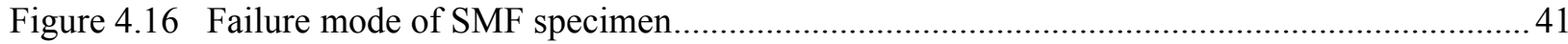

Figure 4.17 Crack patterns of SMF specimen at center column deflections of (a) 24.5 in $(622 \mathrm{~mm})$ and $(\mathrm{b}) 48$ in $(1219 \mathrm{~mm})$ 42

Figure 4.18 Vertical load versus vertical displacements of SMF specimen at (a) 1/4 span of beams (ENC 0 and ENC 7), (b) mid-span of beams (ENC 1 and ENC 6), (c) 3/4 span of beams (ENC 2 and ENC 5), and (d) center column (ENC 3 and ENC 4)

Figure 4.19 North footing displacement versus vertical displacement of center column 44

Figure 4.20 Vertical deflection profiles of beams corresponding to indicated vertical loads for SMF specimen 45

Figure 4.21 Horizontal displacement of end columns at (a) top (SCOL T, NCOL T), and (b) beam mid-height (SCOL M, NCOL M) versus vertical displacement of center column for SMF specimen 46

Figure 4.22 Vertical loads versus beam end rotations for SMF specimen: (a) near end columns and (b) near center column 47

Figure 4.23 Beam end rotation versus vertical displacement of center column for SMF specimen: (a) near end columns and (b) near center column .48

Figure 4.24 Stain measurements for SMF specimen: (a) Whittemore gage target locations and (b) reinforcing bar strain gage locations .50

Figure 4.25 Mid-span (Sections B3 and B8) strain gage measurements versus vertical displacement of center column for SMF specimen: (a) top reinforcing bars and (b) bottom reinforcing bars

Figure 4.26 Column reinforcement strains at sections S1 and N1 versus vertical displacement of center column for SMF specimen: (a) interior reinforcing bars and (b) exterior reinforcing bars...

Figure 4.27 Beam reinforcement strains at bar-cutoff sections versus vertical displacement of center column for SMF specimen: (a) top bars at sections B2 and B9, (b) top bars at sections B4 and B7, (c) bottom bars at sections B2 and B9, and (d) bottom bars at sections B4 and B7 
Figure 4.28 Concrete surface strain distributions of SMF specimen at beam ends: (a) near north end column and (b) near south end column.

Figure 4.29 Concrete surface strain distributions of SMF specimen at beam ends: (a) near north side of center column and (b) near south side of center column

Figure 4.30 Three stages of load transfer: (a) arching action, (b) plastic hinge formation, and (c) catenary action $\left(\mathrm{F}_{\mathrm{s}}\right.$ : force in steel, $\mathrm{F}_{\mathrm{c}}$ : force in concrete, $\mathrm{F}_{\mathrm{c}, \mathrm{s}}$ : force in concrete and steel)

Figure 5.1 Example finite element models of No. 9 reinforcing bar: (a) beam element with 8 in $(203 \mathrm{~mm})$ mesh size, (b) beam element with 4 in $(102 \mathrm{~mm})$ mesh size and (c) beam element with 2 in $(51 \mathrm{~mm})$ mesh size.

Figure 5.2 (a) Input stress-strain curve and (b) engineering stress-strain curves for a No. 9 reinforcing bar obtained from a standard tensile test and from finite element analyses using different sizes of beam elements

Figure 5.3 (a) Input stress-strain curves and (b) engineering stress-strain curves for a No. 9 reinforcing bar obtained from a standard tensile test and from finite element analyses using different sizes of beam elements

Figure 5.4 Compressive stress-strain curves of concrete with and without confinement ......................62

Figure 5.5 Compressive stress-strain relationship of unconfined concrete ........................................... 64

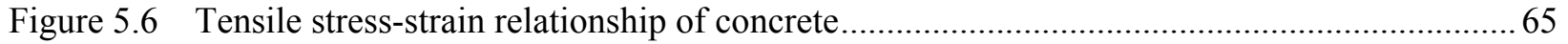

Figure 5.7 Comparison of calculated and observed response (Vecchio et al. 1986) ............................66

Figure 5.8 Bond stress distribution (a) with full anchorage and (b) without full anchorage .................. 68

Figure 5.9 Bond-slip effects of reinforcement fiber at critical beam elements .....................................68

Figure 5.10 Overview of detailed model of (a) IMF and (b) SMF specimen ....................................... 70

Figure 5.11 Enlarged views of portions of the detailed model .......................................................... 71

Figure 5.12 Overview of reduced model of (a) IMF and (b) SMF specimens...................................... 72

Figure 5.13 Detailed view of beam-column joint in reduced model of IMF specimen ..........................73

Figure 5.14 Deflected shape of IMF specimen: (a) detailed model at a center column vertical displacement of 42.2 in $(1072 \mathrm{~mm})$ and (b) reduced model at a center column vertical displacement of 42.8 in $(1087 \mathrm{~mm})$ (contours represent vertical displacements in inches)

Figure 5.15 Failure mode of IMF detailed model (contours represent plastic strains)

Figure 5.16 Concrete damage index contours compared with observed crack patterns at center column displacement of (a) 24 in $(610 \mathrm{~mm})$ and (b) 42 in $(1067 \mathrm{~mm})$ for IMF specimen (contours represent damage index: $0=$ no damage, $1=$ complete damage)

Figure 5.17 (a) Applied vertical load and (b) horizontal displacement of end column at beam mid-height versus vertical displacement of center column for IMF specimen .76

Figure 5.18 Axial stresses in reinforcing bars along a beam segment near mid-span at center column displacements of (a) 4.6 in $(117 \mathrm{~mm})$ and (b) 42 in $(1067 \mathrm{~mm})$ for IMF specimen (contours represent stress in psi) 77

Figure 5.19 Beam axial force versus vertical displacement of center column for IMF specimen . .77 
Figure 5.20 Minimum principal stress contours of concrete at a center column displacement of 4.6 in $(117 \mathrm{~mm})$ for IMF specimen (Contours represent stress in psi)

Figure 5.21 Deflected shape of SMF specimen: (a) detailed model at a center column vertical displacement of 48.2 in (1224 $\mathrm{mm})$ and (b) reduced model at a center column vertical displacement of 47.0 in (1194 $\mathrm{mm})$ (Contours represent vertical displacements in inches)

Figure 5.22 Failure mode of the SMF detailed model (Contours represent plastic strains).

Figure 5.23 Concrete damage index contours compared with observed crack patterns at center column displacement of (a) $24.5 \mathrm{in}(622 \mathrm{~mm})$ and (b) 48.2 in (1224 $\mathrm{mm}$ ) for SMF specimen (contours represent damage index: $0=$ no damage, $1=$ complete damage).........

Figure 5.24 (a) Vertical load, (b) horizontal displacement of south column at beam mid-height and (c) horizontal displacement of north column at beam mid-height versus center column displacement for SMF specimen

Figure 5.25 Axial stresses in reinforcing bars along a beam segment near mid-span beam at center column displacement of (a) 4.4 in $(112 \mathrm{~mm})$ and (b) 48 in $(1219 \mathrm{~mm})$ for SMF specimen (Contours represent stress in psi). 82

Figure 5.26 Beam axial force versus vertical displacement of center column for SMF specimen 82

Figure 5.27 Minimum principal stress contours of concrete at a center column displacement of 4.4 in $(112 \mathrm{~mm})$ for SMF specimen (Contours represent stress in psi) 83 


\section{LIST OF TABLES}

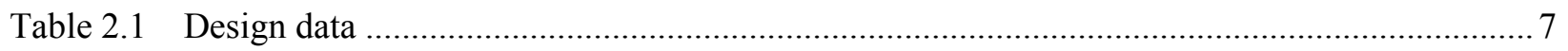

Table 2.2 Seismic design parameters for SDC C and D buildings .................................................... 8

Table 2.3 Summary of design seismic and wind forces .................................................................. 8

Table 3.1 Average compressive and tensile strengths of $6 \times 12$ concrete cylinders at the time of

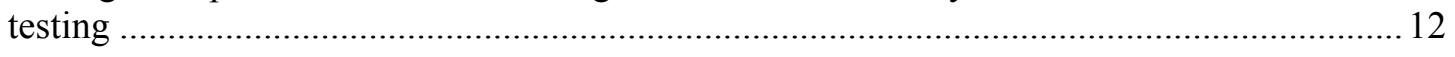

Table 3.2 Average mechanical properties of reinforcing bars .............................................................. 12

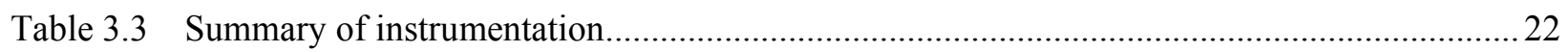

Table 4.1 Comparison of rotation capacities of IMF and SMF beam-column joints based on

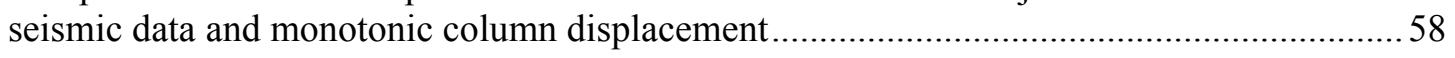

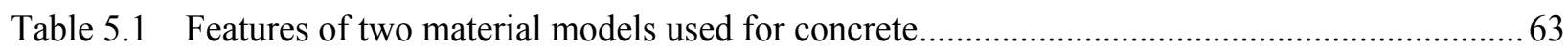

Table 5.2 Coefficient $n$ of concrete cutoff strain from CEB-FIP model code (CEB 1991) ....................63

Table 5.3 Tensile fracture energy from CEB-FIP model code (CEB 1991) .........................................65

Table 5.4 Average bond strengths as a function of steel stress (Lowes et al. 2003) ............................67 
This page intentionally left blank. 


\section{LIST OF ACRONYMS AND ABBREVIATIONS}

\section{Acronyms}

ACI American Concrete Institute

ASCE American Society of Civil Engineers

DoD U.S. Department of Defense

FEMA Federal Emergency Management Agency of the U.S. Department of Homeland Security

GSA U.S. General Services Administration

IBC International Building Code

ICC International Code Council

IMF Intermediate Moment Frame

SDC Seismic Design Category

SMF Special Moment Frame

UFC Unified Facilities Criteria

U.S. United States

\section{Unit Abbreviations}

$\begin{array}{ll}\mathrm{ft} & \text { foot } \\ \text { in } & \text { inch } \\ \text { kip } & 1000 \mathrm{lbf} \\ \mathrm{kN} & \text { kilonewton } \\ \mathrm{kPa} & \text { kilopascal } \\ \mathrm{ksi} & \text { kip per square inch } \\ \mathrm{lbf} & \text { pound-force } \\ \mathrm{m} & \text { meter } \\ \mathrm{mm} & \text { millimeter } \\ \mathrm{MPa} & \text { megapascal } \\ \mathrm{psf} & \text { pound-force per square foot } \\ \mathrm{psi} & \text { pound-force per square inch } \\ \mathrm{s} & \text { second }\end{array}$


This page intentionally left blank. 


\section{EXECUTIVE SUMMARY}

In recent years, the engineering community has paid greater attention to the vulnerability of multistory buildings to disproportionate collapse, which is a structural collapse that is disproportionate to the initiating event. Disproportionate collapse may be initiated by a variety of abnormal loading conditions, such as blast, uncontrolled fire, or vehicle impact. To enhance structural performance under such abnormal loading conditions, the 2009 version of the International Building Code introduced structural integrity requirements for design of multistory buildings. In addition, both the U.S. Department of Defense and the General Services Administration stipulate mandatory requirements for design of multistory buildings to resist disproportionate collapse. The American Society of Civil Engineers Standard 7 (ASCE 7) provides general guidelines to be considered for design of buildings to minimize the risk of disproportionate collapse. In general, these documents provide guidance to prevent spreading of an initial local failure progressively to cause total collapse or collapse of a disproportionately large part of a building. ASCE 7 recommends that resistance to disproportionate collapse be accomplished either implicitly, by providing minimum levels of strength, continuity, and ductility; or explicitly, by (1) providing sufficient strength to structural members that are critical to global stability or (2) providing alternate load paths so that local damage is absorbed and major collapse is averted. For concrete structures, the American Concrete Institute Building Code 318 (ACI 318) requires minimum continuity reinforcement to enhance overall structural integrity. At present these guidelines and code requirements are mainly based on engineering experience with limited experimental basis.

This report presents an experimental and computational study of two reinforced concrete beamcolumn assemblies, each comprising three columns and two beams. The two beam-column assemblies represent portions of the structural framing system of two ten-story concrete momentframe buildings. One building was designed for Seismic Design Category C (SDC C) and the other for Seismic Design Category D (SDC D). The beam-column assemblies were taken from the exterior moment resisting frames of these buildings, designed in accordance with the requirements in ACI 318. The moment resisting frames of the SDC C and SDC D buildings employed intermediate moment frames (IMFs) and special moment frames SMFs), respectively. The assemblies were subjected to monotonically increasing vertical displacement of the unsupported center column to observe their behavior under a simulated column removal scenario, including the development of catenary action in the beams. The vertical displacement of the center column was increased until the vertical load-carrying capacity of each assembly was depleted.

The overall behavior of each beam-column assembly was analyzed using two levels of modeling complexity: (1) detailed models with a large number of elements: solid elements to represent the concrete and beam elements to represent the reinforcement, and (2) reduced models with a limited number of elements: beam elements to represent the beams and columns, and rigid links connected by nonlinear rotational springs to represent the beam-column joints. The analyses 
conducted using these models provided insight into the behavior and failure modes of the joints and the development of catenary action in the beams.

Based on the study reported herein, the following conclusions are reached.

1. For both the IMF and SMF assemblies, the behavior of the assemblies was dominated by flexure in the early stages of the response. With increased vertical displacement of the center column, resistance was provided through the development of compressive diagonal axial forces, or "arching action," due to the restraint on axial elongation of the beams by the end columns. With further increase in the vertical displacement, tensile axial forces developed in the beams and the behavior was dominated by catenary action.

2. The failure of both the IMF and SMF assemblies was characterized by: (1) crushing of concrete at the top of the beam section near the center column, (2) development of major flexural cracks (deepening and widening), and (3) fracture of one of the bottom reinforcing bars at a major crack opening near the center column.

3. The test results show that the rotational capacities of both the IMF and SMF beam-tocolumn joints under monotonic column displacement are about seven to eight times as large as those based on seismic test data. The rotations at peak load in this study were about $0.185 \mathrm{rad}$ and $0.200 \mathrm{rad}$ for the IMF and SMF assemblies, respectively, whereas the rotational capacities of these connections based on seismic testing data are approximately $0.026 \mathrm{rad}$ and $0.025 \mathrm{rad}$, respectively.

4. This study indicates generally good agreement between the experimental and the computational results. Both the detailed and reduced models were capable of capturing the primary response characteristics and failure modes of the test specimens.

This study shows that analysis using reduced models consisting of beam and spring elements can accurately predict the response characteristics of both the IMF and SMF beam-column assemblies. Furthermore, the reduced models developed in this study will be valuable in the analysis of complete structural systems for assessing the reserve capacity and robustness of building structures. 


\section{Chapter 1 \\ INTRODUCTION}

\section{$1.1 \quad$ BACKGROUND}

In recent years, the engineering community has paid greater attention to the vulnerability of multistory buildings to disproportionate collapse, which could pose a substantial hazard to human life. Disproportionate collapse is a structural collapse in which the final extent of damage is disproportionate to the cause. Disproportionate collapse may be initiated by a variety of abnormal loading conditions, such as blast, vehicle impact, and uncontrolled fire. To enhance structural performance under such abnormal loading conditions, the 2009 version of the International Building Code (ICC 2009) introduced structural integrity requirements for design of multistory buildings assigned to specific occupancy categories, including buildings with occupancy of greater than 300, schools, hospitals, police stations and aviation control towers. In addition, both the U.S. Department of Defense (DoD 2009) and the General Services Administration (GSA 2003) stipulate mandatory requirements for design of multistory buildings to resist disproportionate collapse. The American Society of Civil Engineers Standard 7 (ASCE 2010) provides general guidelines for design of buildings to minimize the risk of disproportionate collapse. For concrete building structures, the American Concrete Institute Building Code 318 (ACI 2008) requires minimum continuity reinforcement to enhance overall structural integrity. Currently, these guidelines and code requirements are based mainly on engineering experience with limited experimental basis.

In general, these documents provide guidance to prevent progressive spreading of an initial local failure to cause total collapse or collapse of a disproportionately large part of a building. The ASCE 7 Standard recommends that resistance to disproportionate collapse be accomplished either implicitly, by providing minimum levels of strength, continuity, and ductility; or explicitly, by (1) providing sufficient strength to structural members that are critical to global stability or (2) providing alternate load paths so that local damage is absorbed and major collapse is averted through adequate connections and ties. In this latter approach, the structural integrity is assessed by analysis to ascertain whether alternate load paths exist around failed structural members. The analysis must demonstrate the adequacy of undamaged members to redistribute the loads previously carried by the damaged member(s). In this regard, physical tests are indispensible to validate the analytical models used to represent the nonlinear, large-deformation behavior associated with the transfer of forces through structural members and their connections.

The National Institute of Standards and Technology (NIST) is carrying out a comprehensive analytical and experimental research program to study the vulnerability of multistory building structures to disproportionate collapse and to develop guidance to reduce the risk of disproportionate collapse. As part of this research, prototype ten-story buildings have been designed with various structural systems, including steel frame, cast-in-place concrete frame, and precast concrete frame buildings. Beam-column assemblies representing portions of these structural systems have been tested at full scale under simulated column removal. In addition to 
providing insight into the behavior and failure modes of these structural systems under column removal scenarios, an important objective of these tests was to provide experimental data for validation of finite element-based modeling approaches for collapse analysis. Sadek et al. (2010) describe testing and analysis of steel beam-column assemblies with moment connections, while this report focuses on cast-in-place concrete beam-column assemblies. Reduced models developed as part of this research are being incorporated into three-dimensional models of the prototype ten-story buildings, which will be used to assess the vulnerability of different structural systems to disproportionate collapse.

\subsection{SCOPE OF STUDY}

The study presented herein includes full-scale testing and finite-element based analysis of two reinforced concrete beam-column assemblies. One is taken from a ten-story building designed for Seismic Design Category C (SDC C) and the other is taken from a ten-story building designed for Seismic Design Category D (SDC D). The design of these two prototype buildings was based on the ACI 318 building code (ACI 2002). The building designed for SDC C employed intermediate moment frames (IMFs) for the lateral force resisting system, and the building designed for SDC D employed special moment frames (SMFs). Each beam-column assembly consisted of three columns and two beam spans taken from the exterior lateral load resisting frames of the prototype buildings. The columns spanned from mid-height of the second story to mid-height of the third story, while the beams connected the three columns at the third floor level. Both assemblies were subjected to monotonically increasing downward displacement of the unsupported center column, simulating a column removal scenario. Each test was terminated upon reaching the collapse mechanism of the assembly. Both detailed and reduced finite element models of the test specimens were developed. The instrumentation plan and the testing were guided by pre-test predictions of the detailed model. The tests and associated computational models help fill the gap in defining the response characteristics of the momentresisting beam-column joints under collapse scenarios.

\subsection{REPORT OUTLINE}

This report describes the test program and the modeling approaches used in this study and presents and compares the experimental and computational results for the two beam-column assemblies. Chapter 2 describes the design of the two ten-story prototype reinforced-concrete buildings. The dimensions and reinforcing details of the test specimens were taken directly from the prototype buildings. Chapter 3 presents the test setup for both specimens, including the test configuration, the loading apparatus and sequence, and the instrumentation used. Chapter 4 summarizes the test results, including the observed behavior and failure modes of each specimen, and presents the measured responses, including displacements, rotations, strains, and loads. Chapter 5 describes both detailed and reduced finite element models used in the analysis of the test specimens and presents the results of these analyses, including validation of the models against experimental results. Chapter 6 presents a summary and conclusions of the report. 


\section{$1.4 \quad$ REFERENCES}

American Concrete Institute (ACI). (2002). "Building code requirements for structural concrete." ACI 318-02, Farmington Hills, MI.

American Concrete Institute (ACI). (2008). "Building code requirements for structural concrete." ACI 318-08, Farmington Hills, MI.

American Society of Civil Engineers (ASCE). (2010). "Minimum design loads for buildings and other structures." ASCE/SEI 7-10, Reston, VA

Department of Defense, (DOD). (2009). "Design of buildings to resist progressive collapse." Unified Facilities Criteria (UFC) 4-023-03, Washington, D.C.

General Services Administration (GSA). (2003). "Progressive collapse analysis design guidelines for new federal office buildings and major modernization projects." Washington, DC.

International Code Council (ICC). (2009). International Building Code, Falls Church, VA.

Sadek, F., Main, J.A., Lew, H.S., Robert, S.D., Chiarito, V.P., and El-Tawil, S. (2010). “An experimental and computational study of steel moment connections under a column removal scenario." NIST TN 1669, National Institute of Standards and Technology, Gaithersburg, MD 
This page intentionally left blank. 


\section{Chapter 2 \\ DESCRIPTION OF PROTOTYPE BUILDING DESIGNS}

\section{$2.1 \quad$ PROTOTYPE BUILDING DESIGNS}

The National Institute of Standards and Technology (NIST), working with a panel of practicing structural engineers, developed the overall configuration and dimensions of two ten-story prototype reinforced concrete buildings for office occupancy. A rectangular plan was chosen for the buildings with plan dimensions of $100 \mathrm{ft} \times 150 \mathrm{ft}(30.5 \mathrm{~m} \times 45.7 \mathrm{~m})$. To examine the effectiveness of seismic design and detailing in resisting disproportionate collapse, one building was designed for Seismic Design Category (SDC) C and the other for SDC D. The SDC C building was designed for Atlanta, Georgia and used intermediate moment frames (IMFs) for the lateral force resisting system, while the SDC D building was designed for Seattle, Washington and used special moment frames (SMFs) for the lateral force resisting system. Figures 2.1 and 2.2 show the plan layouts of the SDC C and SDC D buildings, respectively. The story heights of the buildings are shown in Figure 2.3. The detailed design of the buildings was carried out by a consulting engineering firm (Shen and Ghosh 2006).

The prototype buildings were designed in accordance with the following code and standards:

- International Code Council (ICC), 2003 International Building Code (ICC 2003)

- American Society of Civil Engineers (ASCE) Standard 7-02, Minimum Design Loads for Buildings and Other Structures (ASCE 2002)

- American Concrete Institute (ACI), Building Code Requirements for Structural Concrete (ACI 318-02) and Commentary (ACI 318R-02) (ACI 2002)

Superimposed dead loads, live loads, wind forces, and earthquake forces were determined in accordance with ASCE 7-02 (ASCE 2002). The reduction of live loads was based on Section 1607.9.1 of the IBC (ICC 2003). The following superimposed dead loads and live loads were used in the design of both buildings, assuming Category II occupancy (see ASCE 7-02 Table 1-1):

- $\quad$ Superimposed roof dead load: $\quad 10 \mathrm{psf}\left(0.48 \mathrm{kN} / \mathrm{m}^{2}\right)$

- $\quad$ Superimposed floor dead load: $\quad 30 \mathrm{psf}\left(1.44 \mathrm{kN} / \mathrm{m}^{2}\right)$

- Roof live load: $25 \mathrm{psf}\left(1.20 \mathrm{kN} / \mathrm{m}^{2}\right)$

- Floor live load: $100 \operatorname{psf}\left(4.79 \mathrm{kN} / \mathrm{m}^{2}\right)$

Normal weight concrete with a specific weight of $150 \mathrm{lbf} / \mathrm{ft}^{3},\left(23.6 \mathrm{kN} / \mathrm{m}^{3}\right)$ and a nominal compressive strength of 4000 psi $(27.6 \mathrm{MPa})$ and ASTM 615-Grade 60 reinforcing bars with a minimum specified yield strength of $\mathrm{f}_{\mathrm{y}}=60 \mathrm{ksi}(414 \mathrm{MPa})$ were used for all structural members. A 10 in $(254 \mathrm{~mm})$ thick normal-weight concrete slab was used at all floor levels in both 
buildings. The slab thickness was selected on the basis of Table 9.5(c) in ACI 318-02 (ACI 2002) for a two-way slab with edge beams.

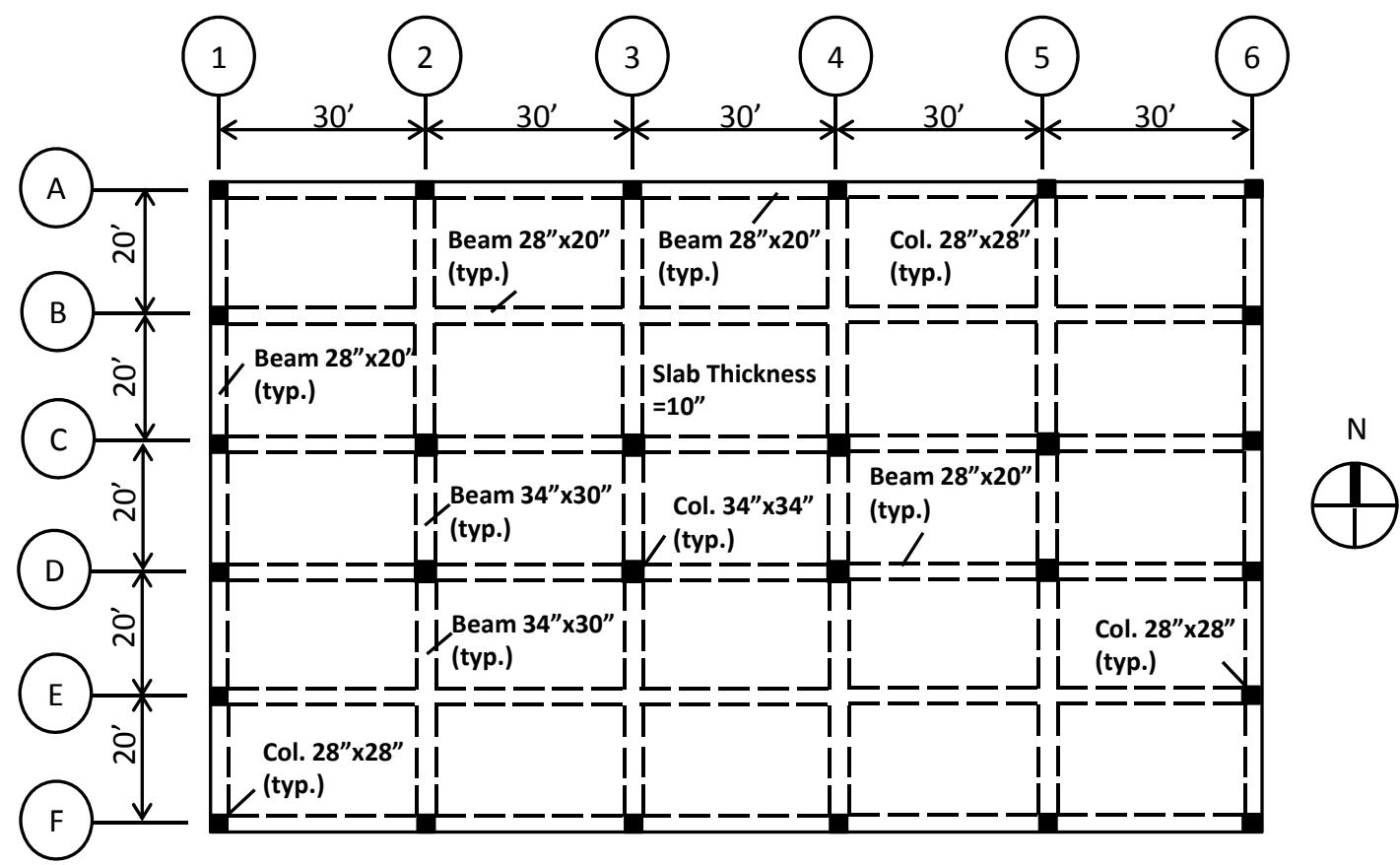

Figure 2.1 Plan layout and member sizes of SDC C Building

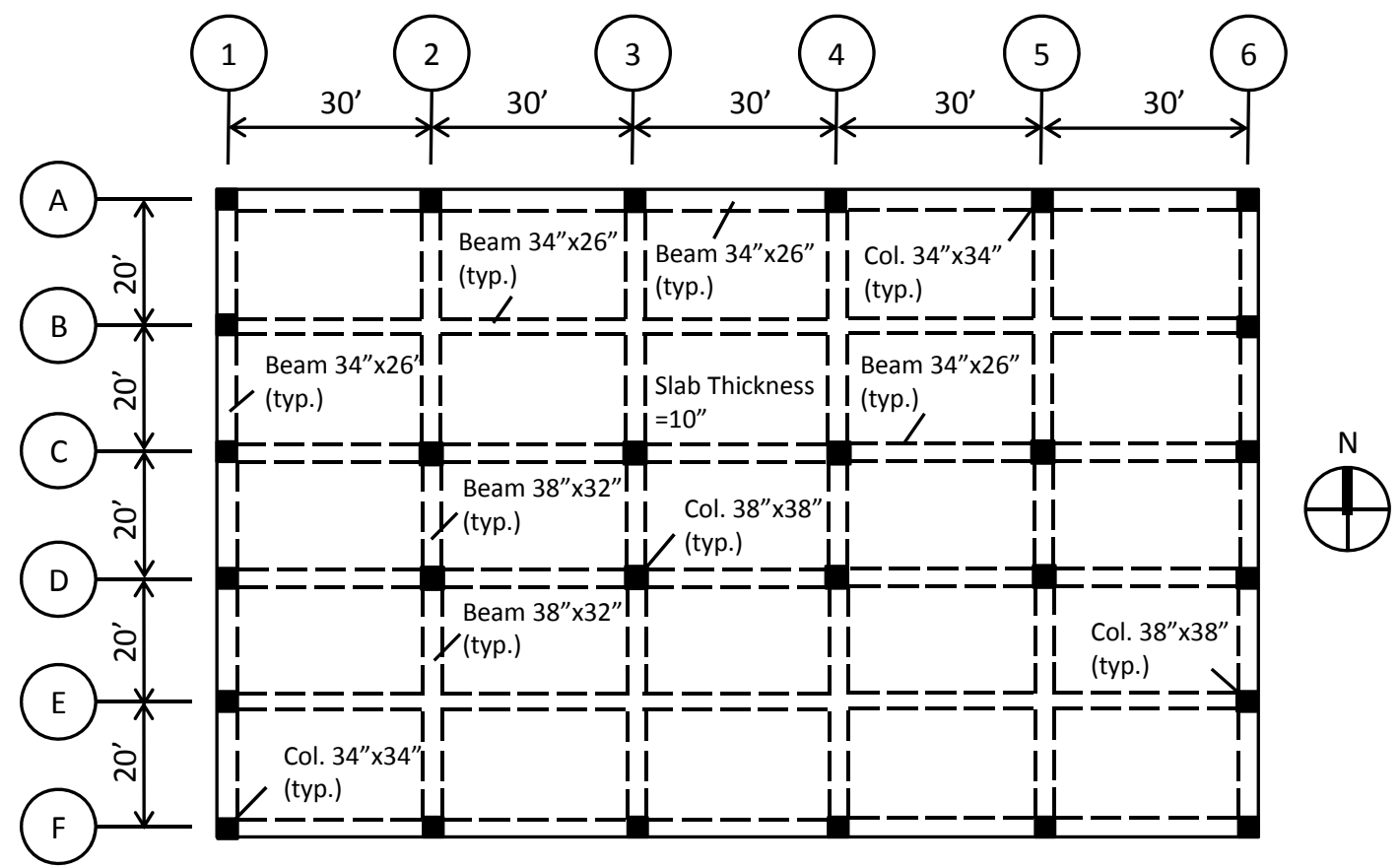

Figure 2.2 Plan layout and member sizes of SDC D Building 


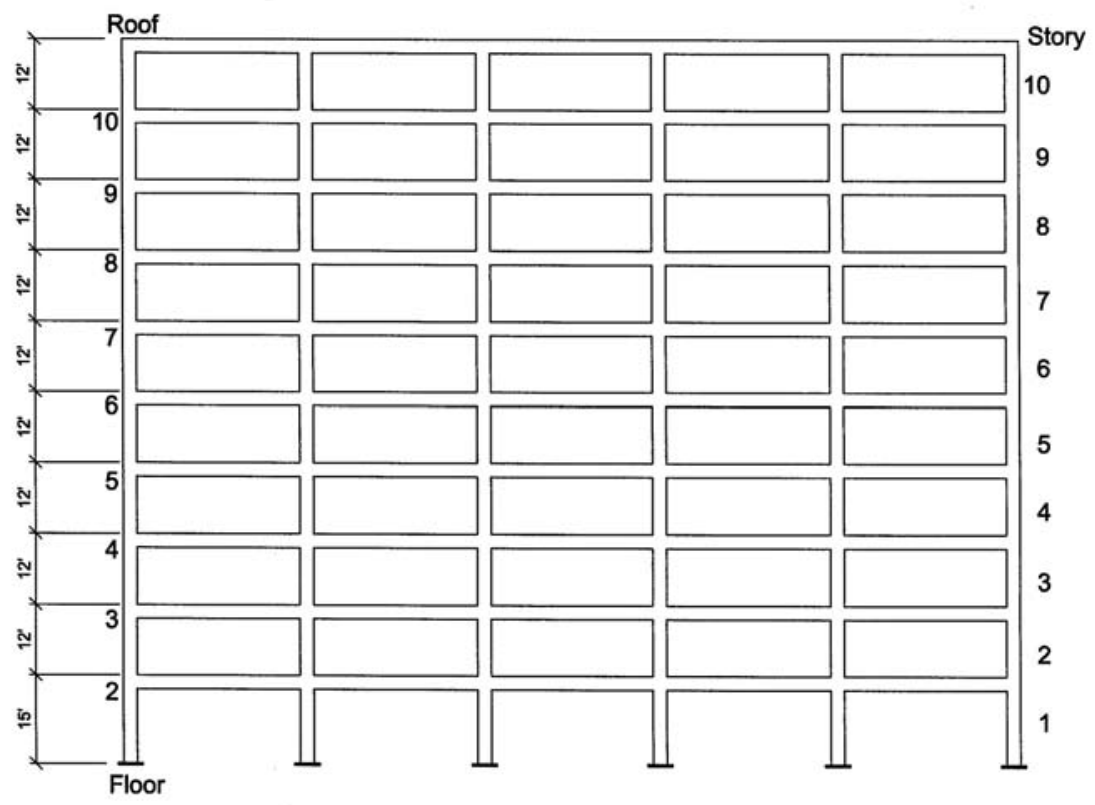

Figure 2.3 Elevation of SDC C Building and SDC D Building

The design was carried out for the combined effects of gravity and lateral loads according to ASCE 7-02 (ASCE 2002). The equivalent lateral force procedure of ASCE 7-02, Section 9.5.5 was used to compute the seismic base shear, and the design procedure outlined in Section 6.5.3 was used to determine the wind forces on the building in both principal directions. The prototype buildings are classified as Seismic Use Group I based on the Occupancy Category of II. The design assumed a wind importance factor $\mathrm{I}_{\mathrm{w}}=1.0$, a wind exposure category $\mathrm{B}$ (suburban terrain), an earthquake importance factor $\mathrm{I}_{\mathrm{E}}=1.0$, and Site Class $\mathrm{D}$ soil (stiff soil). The design data used for analysis of the two prototype buildings are listed in Table 2.1, in which $\mathrm{S}_{\mathrm{s}}$ and $\mathrm{S}_{1}$ are the mapped maximum considered earthquake spectral acceleration at short period and at a period of $1 \mathrm{~s}$, respectively, $\mathrm{R}$ is the response modification coefficient, and $\mathrm{C}_{\mathrm{d}}$ is the deflection amplification factor.

A summary of seismic design parameters for the two buildings is shown in Table 2.2, in which $\mathrm{S}_{\mathrm{DS}}$ and $\mathrm{S}_{\mathrm{D} 1}$ are the design spectral response accelerations at short periods and at a period of $1 \mathrm{~s}$, respectively, and $\mathrm{C}_{\mathrm{S}}$ is the seismic response coefficient. A summary of the design seismic and wind forces is shown in Table 2.3. For both the SDC C (Atlanta, GA) and SDC D (Seattle, WA) buildings, the design was controlled by the load combination of gravity and seismic loads.

Table 2.1 Design data

\begin{tabular}{|c|c|c|c|c|c|c|c|c|c|}
\hline \multirow{2}{*}{ Location } & \multicolumn{4}{|c|}{ Wind } & \multicolumn{5}{c|}{ Seismic } \\
\cline { 2 - 10 } & Speed, $\mathrm{mph}(\mathrm{m} / \mathrm{s})$ & Exposure & $\mathbf{I}_{\mathbf{w}}$ & $\mathbf{S}_{\mathbf{S}}, \mathbf{g}$ & $\mathbf{S}_{1}, \mathbf{g}$ & Site Class & $\mathbf{I}_{\mathbf{E}}$ & $\mathbf{R}$ & $\mathbf{C}_{\mathbf{d}}$ \\
\hline Atlanta, GA & $90(40)$ & $\mathrm{B}$ & 1.0 & 0.276 & 0.117 & $\mathrm{D}$ & 1.0 & 5 & 4.5 \\
\hline Seattle, WA & $85(38)$ & $\mathrm{B}$ & 1.0 & 1.580 & 0.549 & $\mathrm{D}$ & 1.0 & 8 & 5.5 \\
\hline
\end{tabular}


Table 2.2 Seismic design parameters for SDC C and D buildings

\begin{tabular}{|c|c|c|c|c|c|c|}
\hline Building & $\begin{array}{c}\text { Approx. Period, } \\
\mathrm{T}_{\mathrm{a}} \mathrm{S} \\
\end{array}$ & $\begin{array}{c}S_{D S} \\
g\end{array}$ & $\begin{array}{c}S_{D 1} \\
g\end{array}$ & $\mathrm{C}_{\mathrm{s}}$ & $\begin{array}{c}\text { Seismic Weight, W } \\
\text { kip (kN) }\end{array}$ & $\begin{array}{c}\text { Design Base Shear, V } \\
\text { kip (kN) }\end{array}$ \\
\hline $\mathrm{SDC} C$ & 1.216 & 0.291 & 0.182 & 0.0299 & 32690 (145 400) & $-\quad 978(4350)$ \\
\hline SDC D & 1.216 & 1.053 & 0.549 & 0.0564 & $36600(162800)$ & 2065 (9186) \\
\hline
\end{tabular}

Table 2.3 Summary of design seismic and wind forces

\begin{tabular}{|c|c|c|c|c|c|}
\hline \multirow{2}{*}{ Building } & \multirow{2}{*}{ Location } & \multirow{2}{*}{ Story } & \multirow{2}{*}{$\begin{array}{l}\text { Seismic Force at Each Floor Level } \\
\qquad \operatorname{kip}(k N)\end{array}$} & \multicolumn{2}{|c|}{$\begin{array}{l}\text { Wind Force at Each Floor Level } \\
\qquad \operatorname{kip}(k N)\end{array}$} \\
\hline & & & & $E-W$ & N-S \\
\hline \multirow{11}{*}{ SDC C } & \multirow{11}{*}{ Atlanta, GA } & 10 & $179(796)$ & $11(50)$ & $18(80)$ \\
\hline & & 9 & $180(801)$ & $22(100)$ & $36(160)$ \\
\hline & & 8 & $154(685)$ & $22(100)$ & $36(160)$ \\
\hline & & 7 & $130(578)$ & $22(100)$ & 35 (155) \\
\hline & & 6 & $106(472)$ & $21(95)$ & 34 (150) \\
\hline & & 5 & 84 (374) & $20(90)$ & 33 (145) \\
\hline & & 4 & $63(280)$ & $20(90)$ & $31(140)$ \\
\hline & & 3 & 44 (196) & $19(85)$ & 30 (135) \\
\hline & & 2 & $26(116)$ & $18(80)$ & $28(125)$ \\
\hline & & 1 & $12(53)$ & $17(75)$ & 27 (120) \\
\hline & & $\Sigma$ & $978(4350)$ & $194(863)$ & 307 (1366) \\
\hline \multirow{11}{*}{ SDC D } & \multirow{11}{*}{ Seattle, WA } & 10 & 377 (1677) & $10(44)$ & $16(71)$ \\
\hline & & 9 & 381 (1695) & $20(89)$ & 32 (142) \\
\hline & & 8 & $326(1450)$ & $20(89)$ & 32 (142) \\
\hline & & 7 & 274 (1219) & $20(89)$ & 31 (138) \\
\hline & & 6 & $224(996)$ & $19(85)$ & $30(133)$ \\
\hline & & 5 & $177(787)$ & $18(80)$ & $29(129)$ \\
\hline & & 4 & $133(592)$ & $18(80)$ & $28(125)$ \\
\hline & & 3 & $92(409)$ & $17(76)$ & 27 (120) \\
\hline & & 2 & $56(249)$ & $16(71)$ & $25(111)$ \\
\hline & & 1 & $26(116)$ & $15(67)$ & $24(107)$ \\
\hline & & $\Sigma$ & 2066 (9190) & $173(770)$ & 274 (1219) \\
\hline
\end{tabular}

\subsection{DESIGN OF MOMENT RESISTING FRAMES}

Design of the moment-resisting frames for the buildings was based on three-dimensional analyses of the buildings using a commercially available computer program for linear elastic analysis. Fixed-base connections were assumed at the structure-foundation interface. The 
designs of both IMFs and SMFs followed the requirements of the ACI 318-02 code (ACI 2002). Specifically, the flexural members of IMFs met the requirements of Sections 21.2 and 21.12, whereas the flexural members of SMFs satisfied the requirements of Sections 21.2 through 21.5.

The flexural reinforcement satisfied the limits prescribed in Section 10.3.5 of ACI 318-02 for maximum reinforcement and Section 10.5.1 for minimum reinforcement, as well as Sections 3.3.2 and 7.6.1 (minimum spacing for concrete placement), Section 7.7.1 (minimum cover for protection of reinforcement), and Section 10.6.4 (maximum spacing for control of flexural cracking).

The columns in the IMFs satisfied the requirements of Section 21.12.3 and the columns in SMFs satisfied Section 21.4.5 of ACI 318-02. Transverse reinforcement consisted of rectangular hoops, ties, and crossties.

\section{$2.3 \quad$ REFERENCES}

American Concrete Institute (ACI). (2002). "Building code requirements for structural concrete and commentary." ACI 318-02 and ACI 318R-02, Farmington Hills, MI.

American Society of Civil Engineers (ASCE). (2002). "Minimum design loads for buildings and other structures." SEI/ASCE 7-02, Reston, VA.

International Code Council (ICC). (2003). International Building Code, Falls Church, VA.

Shen, Q., and Ghosh, S. K. (2006). Assessing ability of seismic structural systems to withstand progressive collapse: Design of reinforced concrete frame buildings. Report submitted to the Building and Fire Research Laboratory, National Institute of Standards and Technology, Gaithersburg, MD. 
This page intentionally left blank 


\section{Chapter 3 \\ Test PRogram}

\section{$3.1 \quad$ INTRODUCTION}

This chapter describes the overall test program, which includes the design of full-scale test specimens, the test setup including test apparatus and instrumentation, and the test procedure. The primary objectives of these tests are to (1) characterize the response of the beam-column assemblies under a column removal scenario, including the capacity of the beams and the beamto-column joints to carry loads through catenary action, and (2) provide experimental data for validation of computational models to be used in assessing the robustness of structural systems. The test specimens were beam-column assemblies from the third-floor framing system of the ten-story buildings described in Chapter 2. Thus, the specimen from the SDC C building was part of an intermediate moment frame (IMF), while the specimen from the SDC D building was part of a special moment frame (SMF). Throughout the remainder of this report, these two specimens will be referred to as the IMF specimen and the SMF specimen, respectively.

Section 3.2 presents in detail the description of the test specimens, while Section 3.3 describes the test setup for both specimens including boundary conditions, test apparatus, and loading sequence. Section 3.4 presents the instrumentation plan for each of the two tests.

\subsection{TEST SPECIMENS}

Figures 3.1 and 3.2 show member cross section and beam-to-column joint details of the IMF specimen and the SMF specimen, respectively. All beams and columns were designed with concrete having a nominal compressive strength of $4000 \mathrm{psi}(27.6 \mathrm{MPa})$ with ASTM A706Grade 60 reinforcing bars with a minimum specified yield strength of $\mathrm{f}_{\mathrm{y}}=60 \mathrm{ksi}(413.7 \mathrm{MPa})$. Table 3.1 shows the average compressive and tensile strengths of the concrete measured at the time of testing using $6 \times 12$ cylinders, and Table 3.2 shows mean values of the measured mechanical properties of the reinforcing bars used to fabricate the specimens. As indicated in Figures 3.1 and 3.2, top and bottom longitudinal reinforcing bars in the beams were spliced with threaded couplers located at mid-span to avoid premature lap splice failure (see Figure 3.3). All beam longitudinal bars were anchored at the exterior beam-column joints by means of threaded mechanical anchorage devices to simulate continuity of the longitudinal bars. These anchorage devices were supplemented with $3 / 4$ in $(19 \mathrm{~mm}$ ) thick steel plates (see Figure 3.4$)$. The concrete adjacent to the devices was confined with spirals made with Grade 40 plain wire.

The footings for the end columns were cast prior to casting of the beams and columns (see Figure 3.5). The footings for both specimens were 88 in $(2235 \mathrm{~mm})$ long in the direction of the beam, 64 in $(1626 \mathrm{~mm})$ wide and 42 in $(1067 \mathrm{~mm})$ high. The longitudinal bars in the columns were fully embedded in the footings with 24 in $(610 \mathrm{~mm})$ long $90^{\circ}$ hooks placed near the bottom of the footings (see Figures 3.1 and 3.2). Each footing was clamped down to the strong floor using ten $1 \frac{1}{4}$ in $(32 \mathrm{~mm})$ post tensioning bars. Each bar was post tensioned to $150 \mathrm{kip}(667 \mathrm{kN})$, 
for a total clamping force of $1500 \mathrm{kip}(6670 \mathrm{kN})$ on each footing. To restrain the inward movement of the end columns, a concrete slab with a 28 in $\times 10$ in $(711 \mathrm{~mm} \times 254 \mathrm{~mm})$ cross section was cast between the two footings as a buttress. It was reinforced with six Grade 60 \#8 bars in the longitudinal direction and hoops made with Grade 60 \#4 bars in the transverse direction spaced at 6 in $(152 \mathrm{~mm})$ on center. Additional confinement was provided by spirals at the ends of the slab in contact with the footings (see Figure 3.6).

Since the SMF specimen was tested first and experienced some slippage at the north footing (see Section 4.3.3), the footings for the IMF specimen were cast against the reaction walls to minimize their movement during testing. The north footing was further restrained with two steel reaction blocks that were butted against the footing using threaded spacers (see Figure 3.7). The possible movement between the anchor bolts used to attach these blocks to the strong floor and the holes in the strong floor was eliminated by shimming before post-tensioning the anchor bolts.

Table 3.1 Average compressive and tensile strengths of 6x12 concrete cylinders at the time of testing

\begin{tabular}{|c|c|c|c|}
\hline \multirow{2}{*}{ Specimen } & \multicolumn{2}{|c|}{$\begin{array}{c}\text { Compressive Strength } \\
\text { psi (MPa) }\end{array}$} & $\begin{array}{c}\text { Split-Cylinder Tensile Strength } \\
\text { psi (MPa) }\end{array}$ \\
\cline { 2 - 4 } & Footings & Beams and Columns & Beams and Columns \\
\hline IMF & $5700(39)$ & $4700(32)$ & $450(3.1)$ \\
\hline SMF & $5300(37)$ & $5200(36)$ & $420(2.9)$ \\
\hline
\end{tabular}

Table 3.2 Average mechanical properties of reinforcing bars

\begin{tabular}{|c|c|c|c|c|}
\hline Heat & Bar Size & $\begin{array}{c}\text { Yield Strength, } \mathbf{f}_{\mathrm{y}} \\
\text { ksi (MPa) }\end{array}$ & $\begin{array}{c}\text { Ultimate Strength, } \mathbf{f}_{\mathrm{u}} \\
\text { ksi (MPa) }\end{array}$ & Rupture Strain $^{\dagger}$ \\
\hline $\mathrm{A}^{1}$ & 8 & $69(476)$ & $94(648)$ & $21 \%$ \\
\hline $\mathrm{B}^{2}$ & 9 & $67(462)$ & $93(641)$ & $18 \%$ \\
\hline $\mathrm{C}^{3}$ & 9 & $70(483)$ & $100(690)$ & $17 \%$ \\
\hline $\mathrm{D}^{4}$ & 10 & $73(503)$ & $106(731)$ & $16 \%$ \\
\hline $\mathrm{E}^{5}$ & 4 & $76(524)^{*}$ & $103(710)$ & $14 \%$ \\
\hline $\mathrm{F}^{6}$ & 4 & $79(545)^{\star}$ & $98(676)$ & $15 \%$ \\
\hline
\end{tabular}

* $0.2 \%$ offset yield strength

${ }^{\dagger}$ Gage length: 8 in (203 mm)

${ }^{1}$ Top bars in beam of IMF specimen and all beam reinforcement in SMF specimen

${ }^{2}$ Bottom bars in beam of IMF specimen

${ }^{3}$ Vertical bars in columns of IMF specimen

${ }^{4}$ Vertical bars in columns of SMF specimen

${ }^{5}$ Ties and stirrups in IMF specimen

${ }^{6}$ Ties and stirrups in SMF specimen 


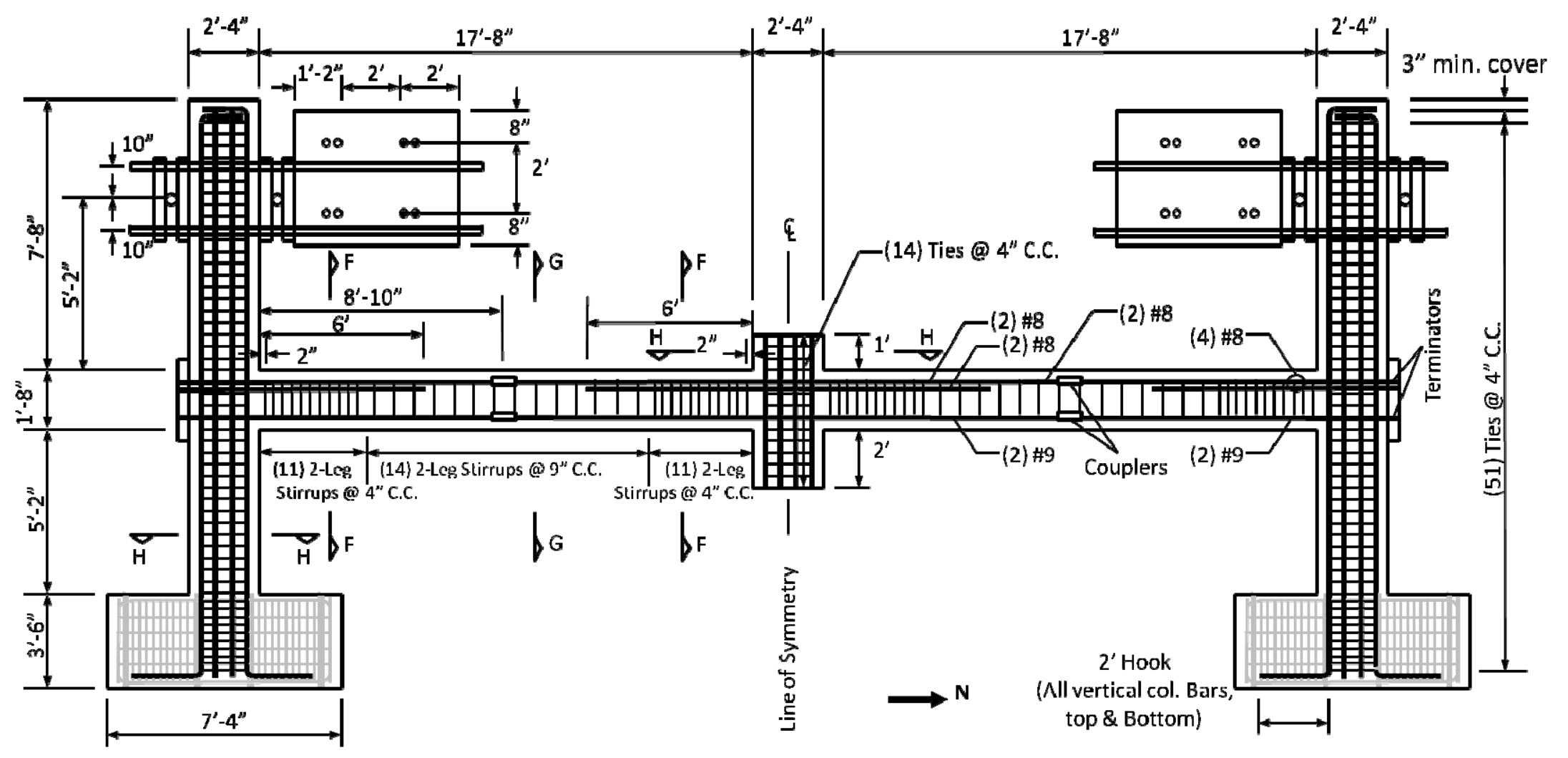

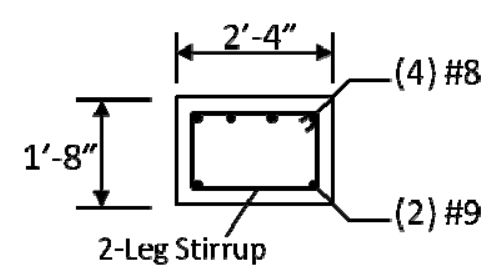

F-F

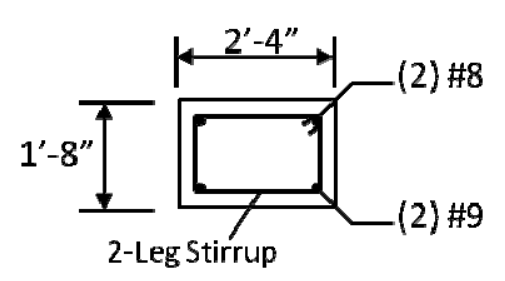

G-G

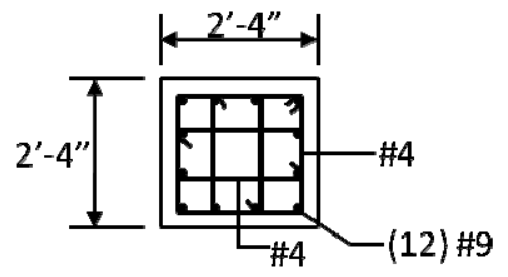

$\mathrm{H}-\mathrm{H}$

Figure 3.1 Details of IMF specimen 


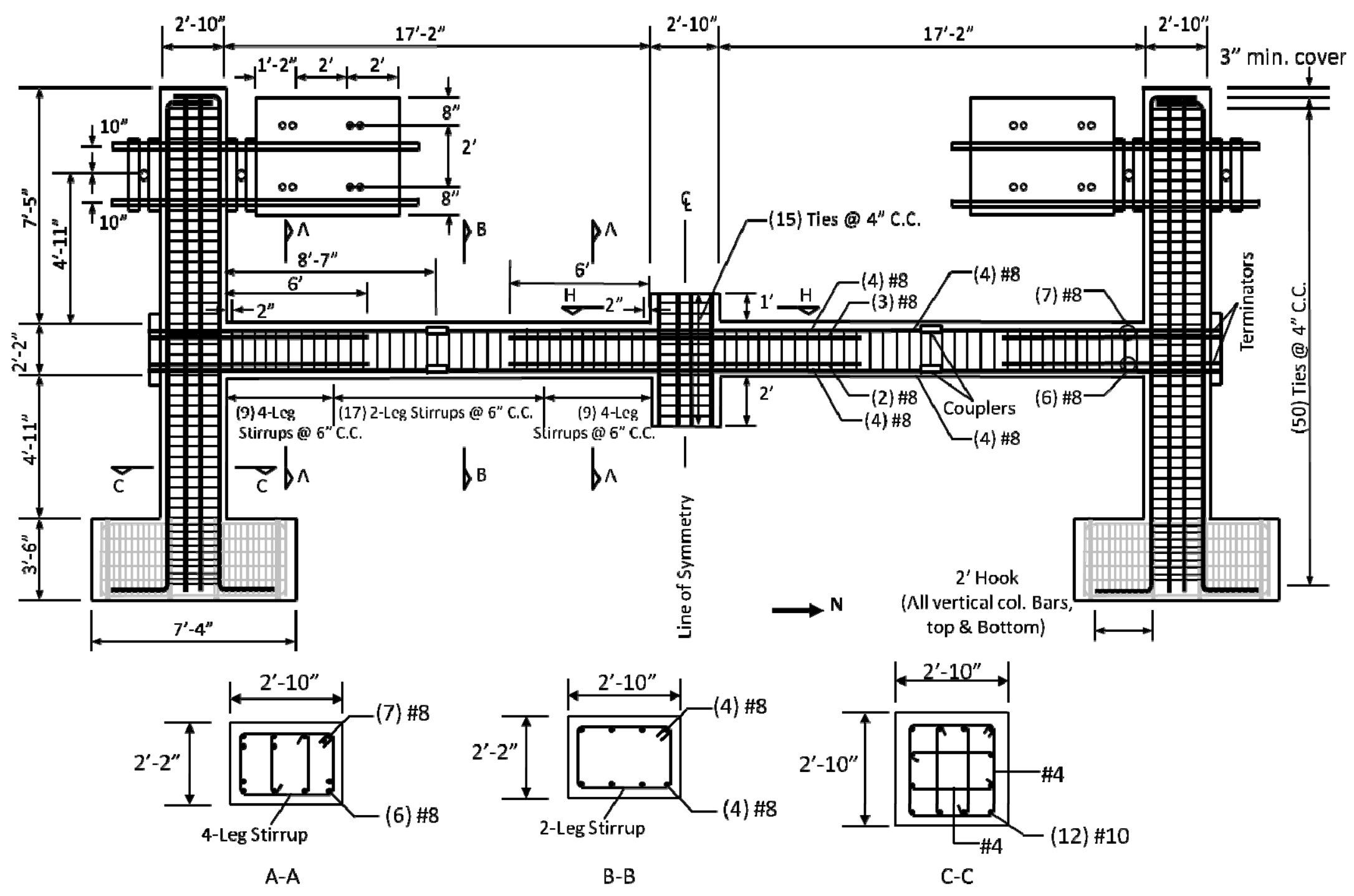

Figure 3.2 Details of SMF specimen 


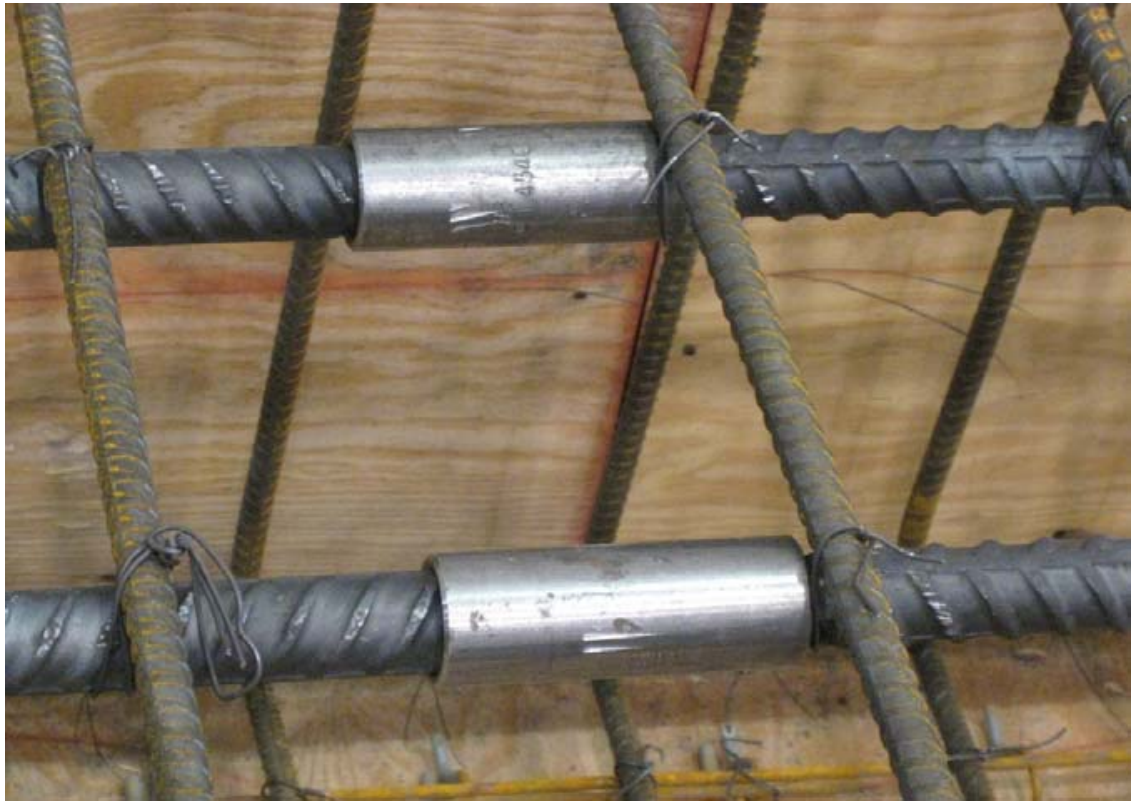

Figure 3.3 Threaded mechanical couplers for splicing longitudinal bars of beams

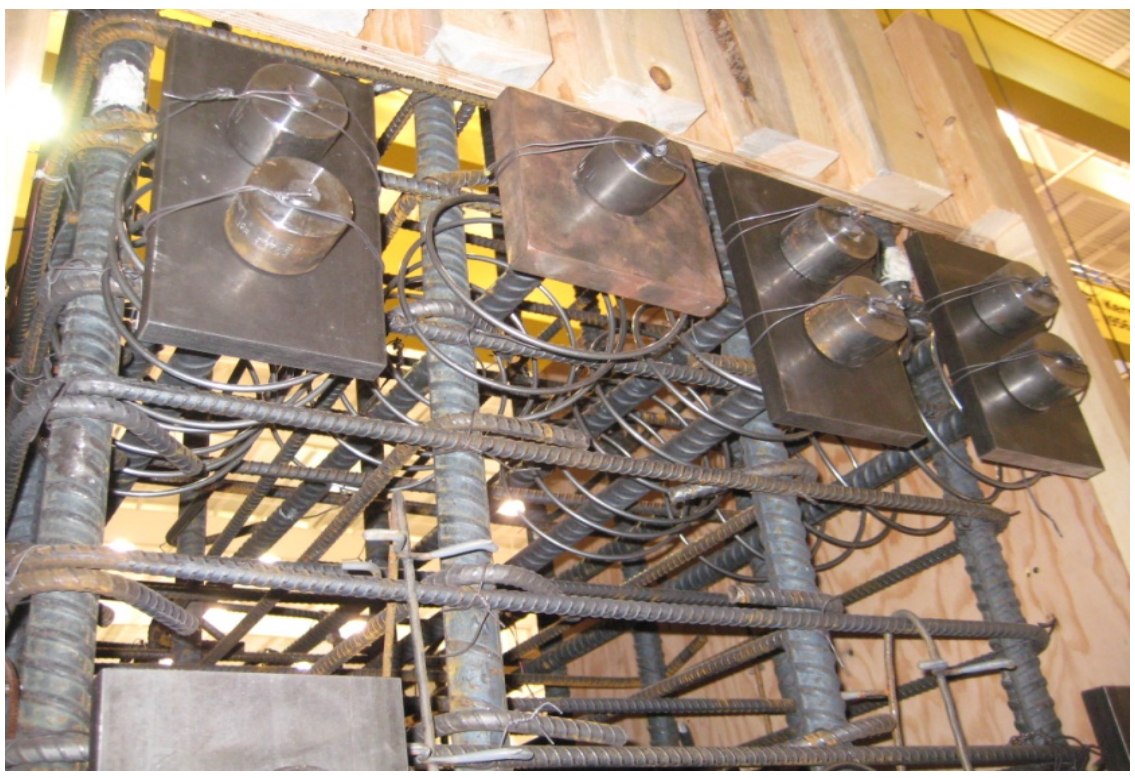

Figure 3.4 Anchorage of beam longitudinal reinforcement 


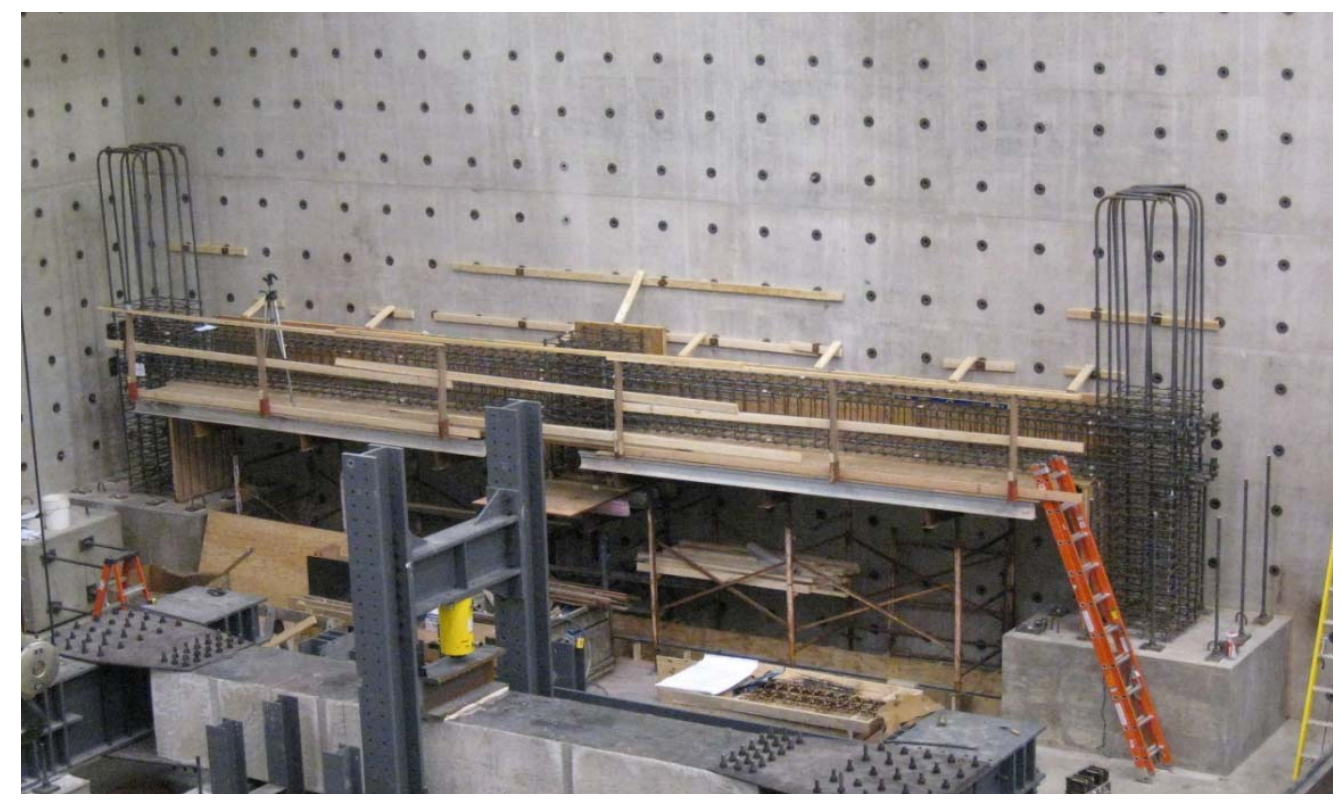

Figure 3.5 Reinforcing cage for beams and columns (SMF specimen)

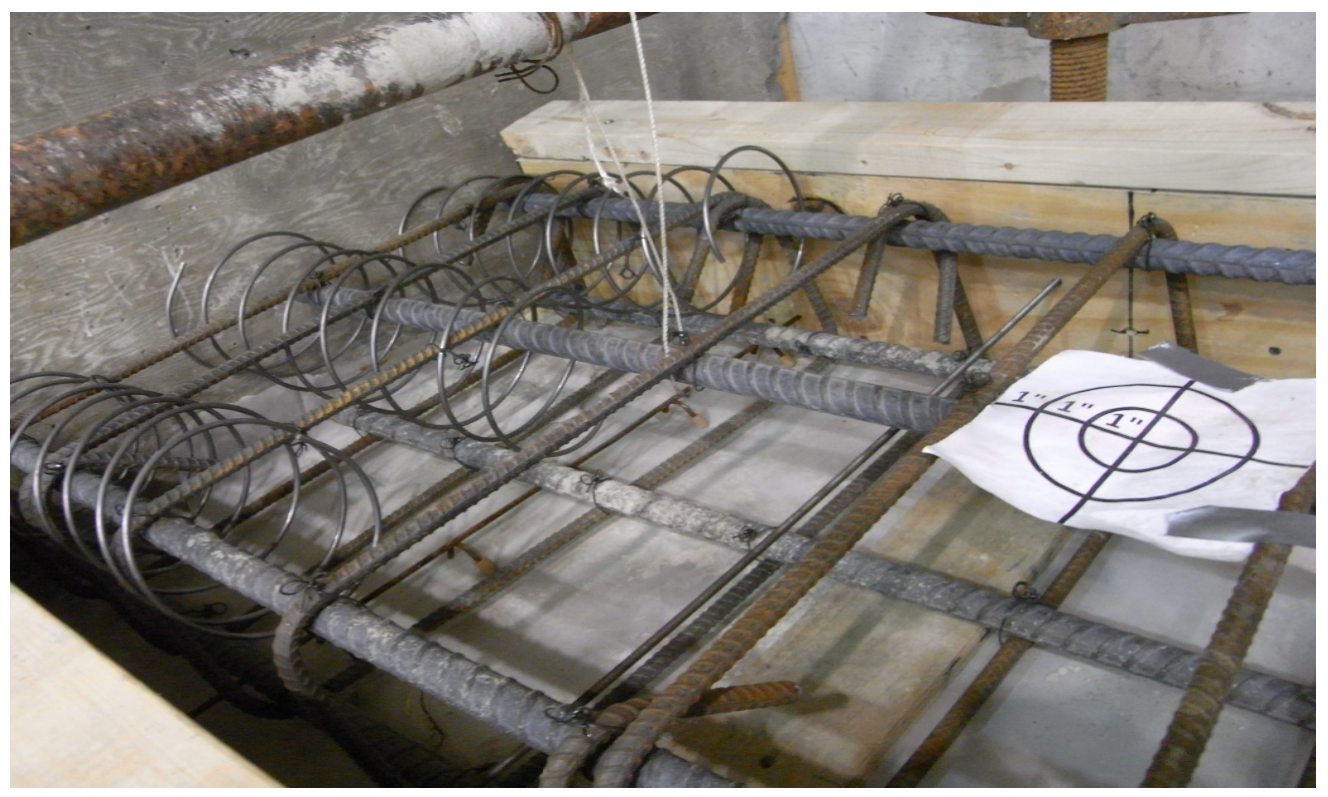

Figure 3.6 Reinforcement in buttressing slab 


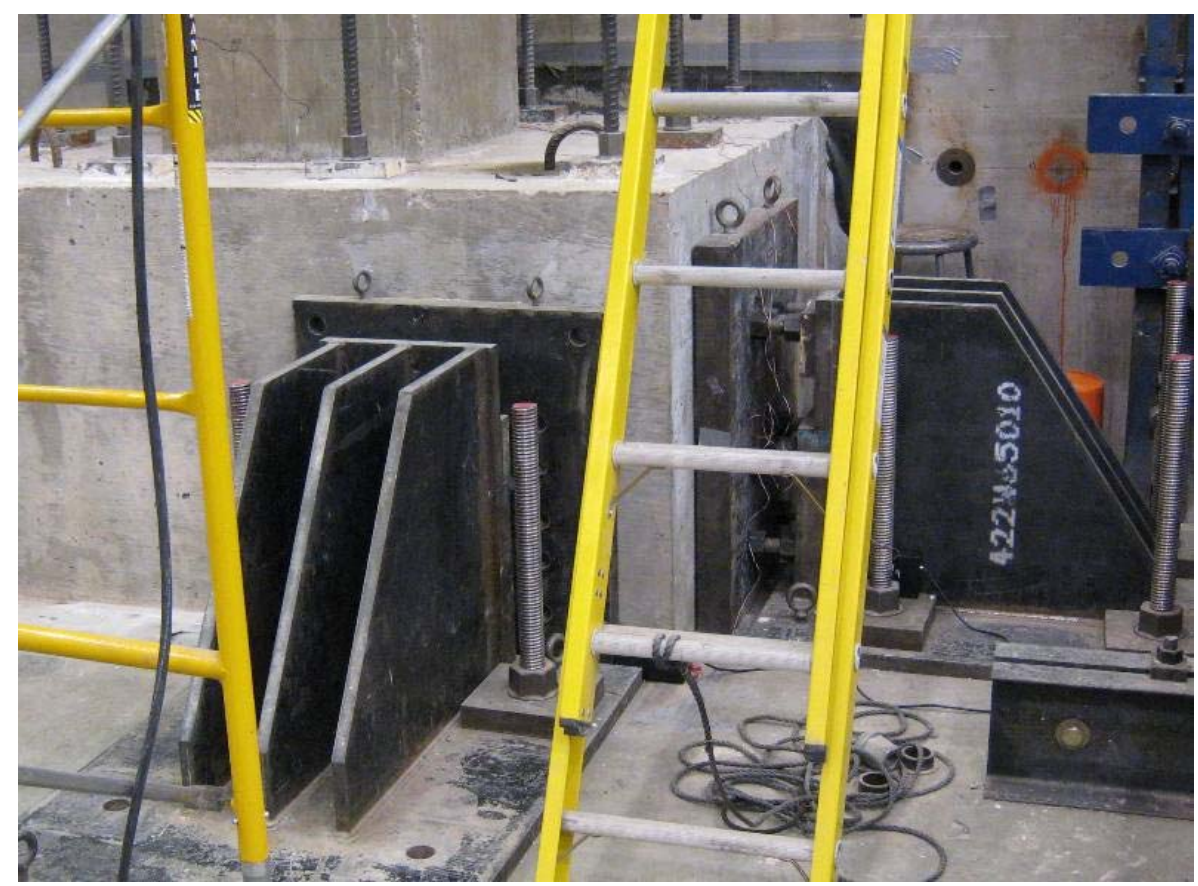

Figure 3.7 Steel blocks used to prevent footing from sliding

\section{$3.3 \quad$ TEST SETUP}

Figure 3.8 shows a photograph of the SMF specimen. The test setup for the IMF specimen was essentially the same as that of the SMF specimen. A schematic view of the test setup for both the IMF specimen and the SMF specimen is shown in Figure 3.9. For each specimen, the tops of the two end columns were restrained from horizontal movement by a two-roller fixture. One roller was placed on the interior (beam side) face of the column and the other on the exterior face (see Figure 3.10). These rollers reacted against 2 in $(51 \mathrm{~mm})$ thick steel plates which were cemented with hydrostone to the interior and exterior faces of the column. Recesses with a depth of $1 / 2$ in $(13 \mathrm{~mm})$ were formed on the column faces to accommodate these plates and improve their connection to the concrete. The plates that fitted in these recesses transferred forces from the rollers to the columns. The rollers were suspended by $1 / 2$ in $(13 \mathrm{~mm})$ steel rods from the tops of the columns. Horizontal movement of the steel plates on the exterior face of each column was restrained by four $1 \frac{1}{4}$ in $(32 \mathrm{~mm})$ post-tensioning bars which were anchored to a reinforced concrete block that was clamped to the reaction wall by post-tensioning bars with a total clamping force of $600 \mathrm{kip}(2669 \mathrm{kN})$. The tops of the columns were allowed to move in the vertical direction.

As shown in Figure 3.9, four 120 kip (534 kN) hydraulic rams with a 20 in $(508 \mathrm{~mm})$ stroke were placed below the strong floor of the laboratory to apply load at the top of the center column. Figure 3.11 shows a photograph of the ram arrangement below the strong floor. The load was transferred to the specimen using four $22 \mathrm{ft}(6.6 \mathrm{~m})$ long, 11/4 in $(31.6 \mathrm{~mm})$ diameter 
post-tensioning rods. These rods were connected to two $6 \mathrm{ft}(1.8 \mathrm{~m})$ long 10 in $\times 4$ in $\times 1 / 2$ in $(254 \mathrm{~mm} \times 102 \mathrm{~mm} \times 12.7 \mathrm{~mm})$ hollow structural section (HSS) rectangular tubes resting on a 34 in $\times 34$ in $\times 2$ in $(864 \mathrm{~mm} \times 864 \mathrm{~mm} \times 51 \mathrm{~mm})$ steel plate that transferred the load to the top of the center column. The weight of the rams, rods, tubes, and plates used to load to the specimens was approximately $2500 \mathrm{lbf}\left(\begin{array}{lll}11 & 120 \mathrm{~N}\end{array}\right)$. The load was applied under displacement control at a rate of approximately $1 \mathrm{in} / \mathrm{min}(25 \mathrm{~mm} / \mathrm{min})$.

Use of the four hydraulic rams to apply the load enabled control of any possible in-plane rotation of the center column in the advanced stages of loading. Pulling down the beam with the rams below the strong floor, rather than pushing it from a support above, minimized the tendency for lateral movement of the beam. Out-of-plane movement of the specimen was also restrained by four steel channels fixed to the reaction wall as seen in Figure 3.8.

Vertical downward displacement of the center column was applied in small increments of 2.5 in to 3 in $(64 \mathrm{~mm}$ to $76 \mathrm{~mm})$. After each increment in displacement, the specimen and the instrumentation were inspected, cracks were marked, and photographs were taken. The rams were reset when the stroke of the rams reached about 18 in to $20 \mathrm{in}(457 \mathrm{~mm}$ to $508 \mathrm{~mm})$. The displacement of the center column was increased until one or more of the longitudinal reinforcing bars in the beams fractured.

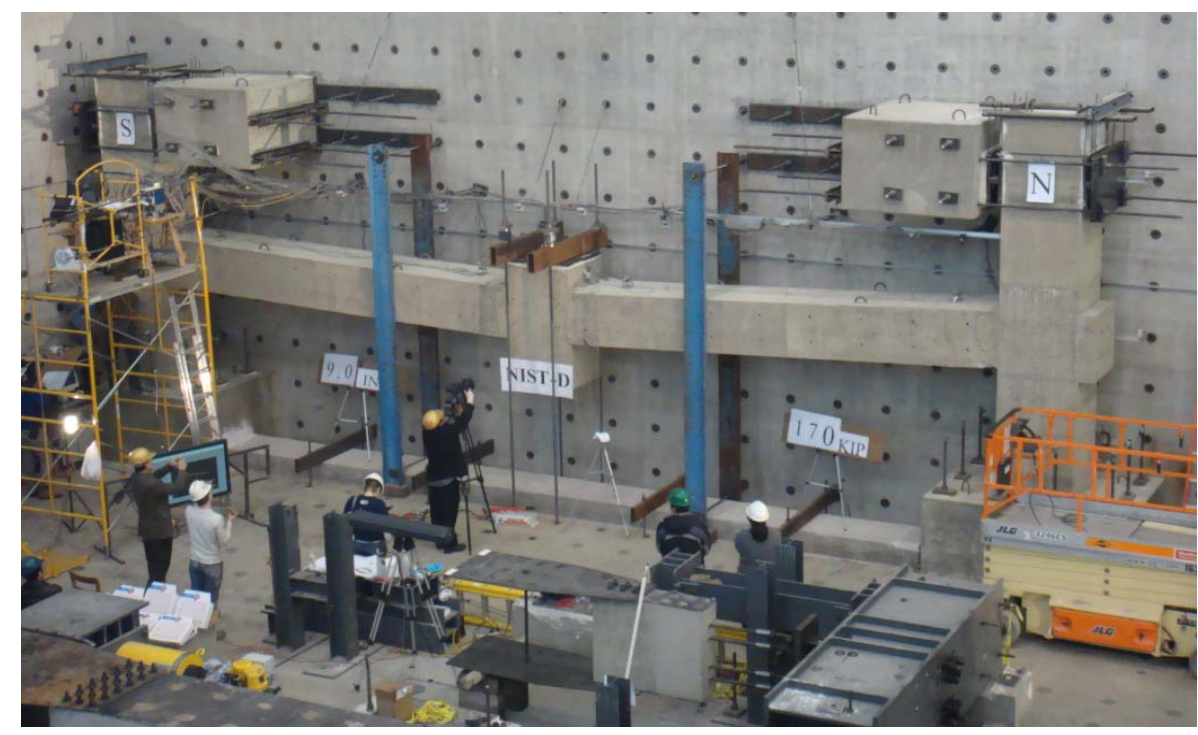

Figure 3.8 SMF specimen

\section{$3.4 \quad$ INSTRUMENTATION}

Seven types of measurements were taken for each specimen. The types of instruments used are summarized in Table 3.3. Figure 3.12 shows the layout of the linear variable differential transformers (LVDTs), load cells, position transducers, and inclinometers. The locations of the Whittemore gage targets, Optotrak targets, and strain gages are presented in Chapter 4 together with the test results. 


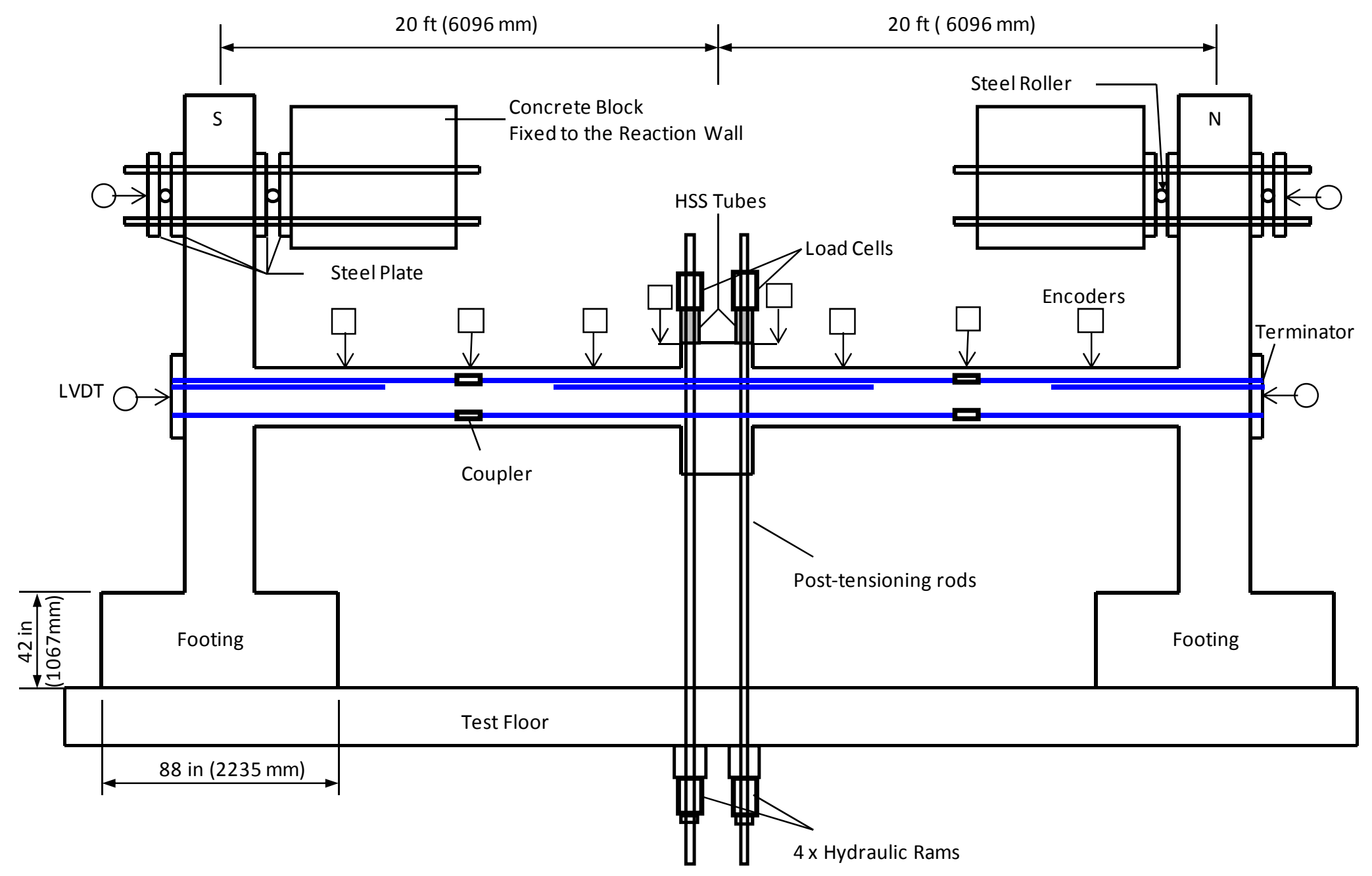

Figure 3.9 Test configuration for IMF and SMF specimens 


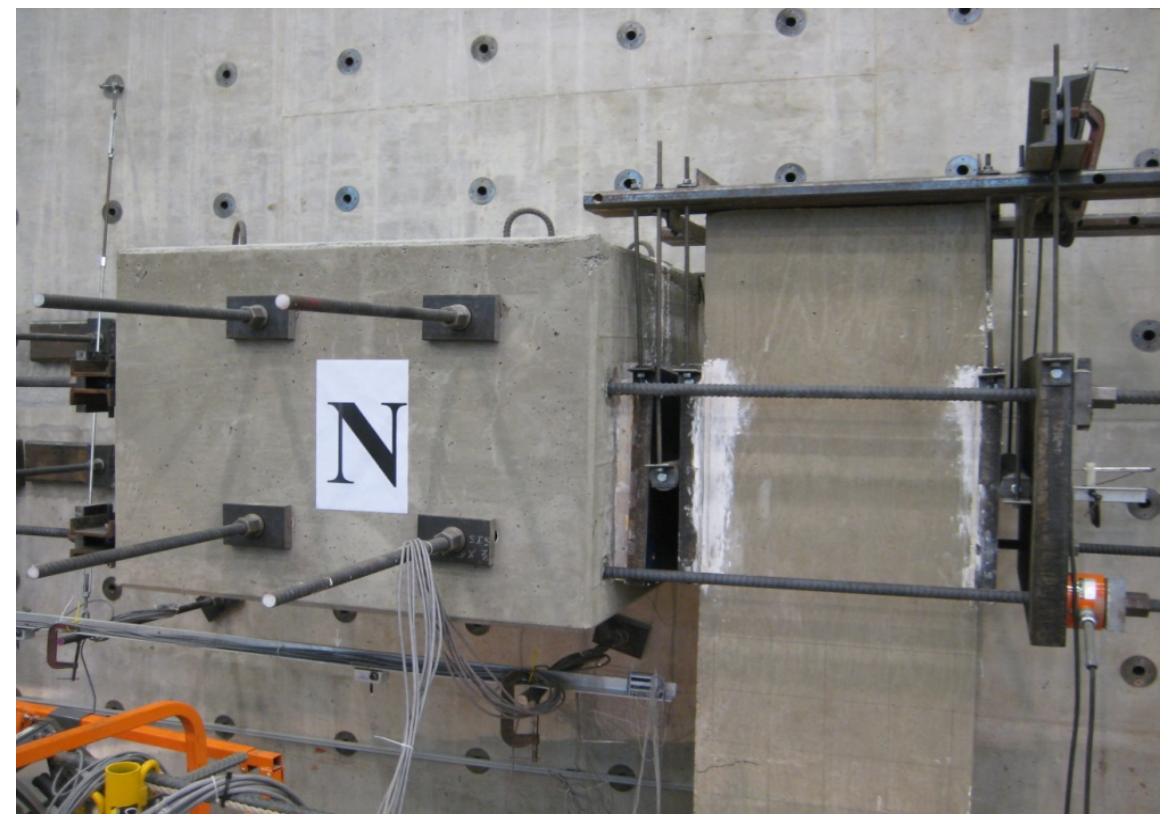

Figure 3.10 Support arrangement near column top

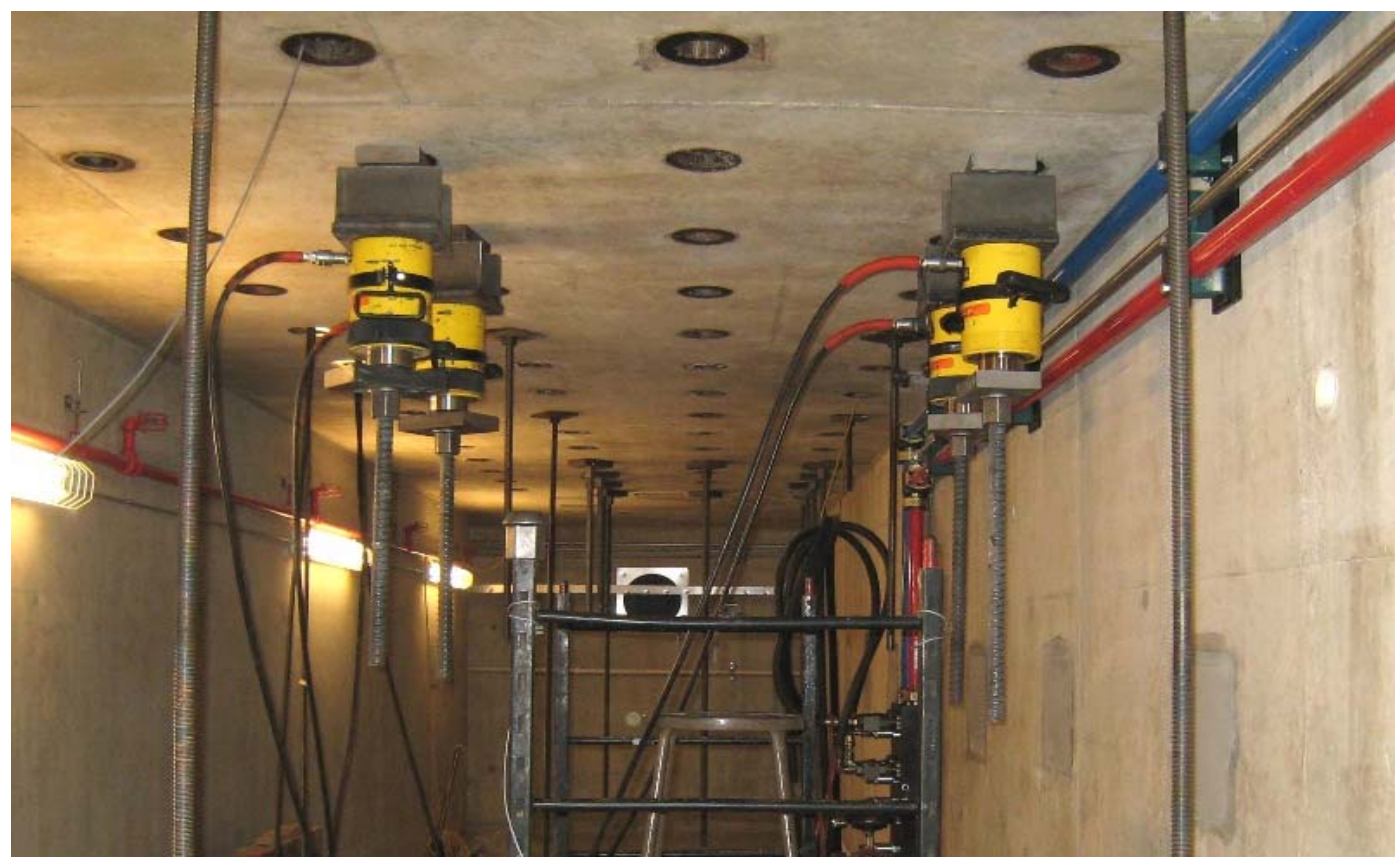

Figure 3.11 Hydraulic rams arrangement below the strong floor 


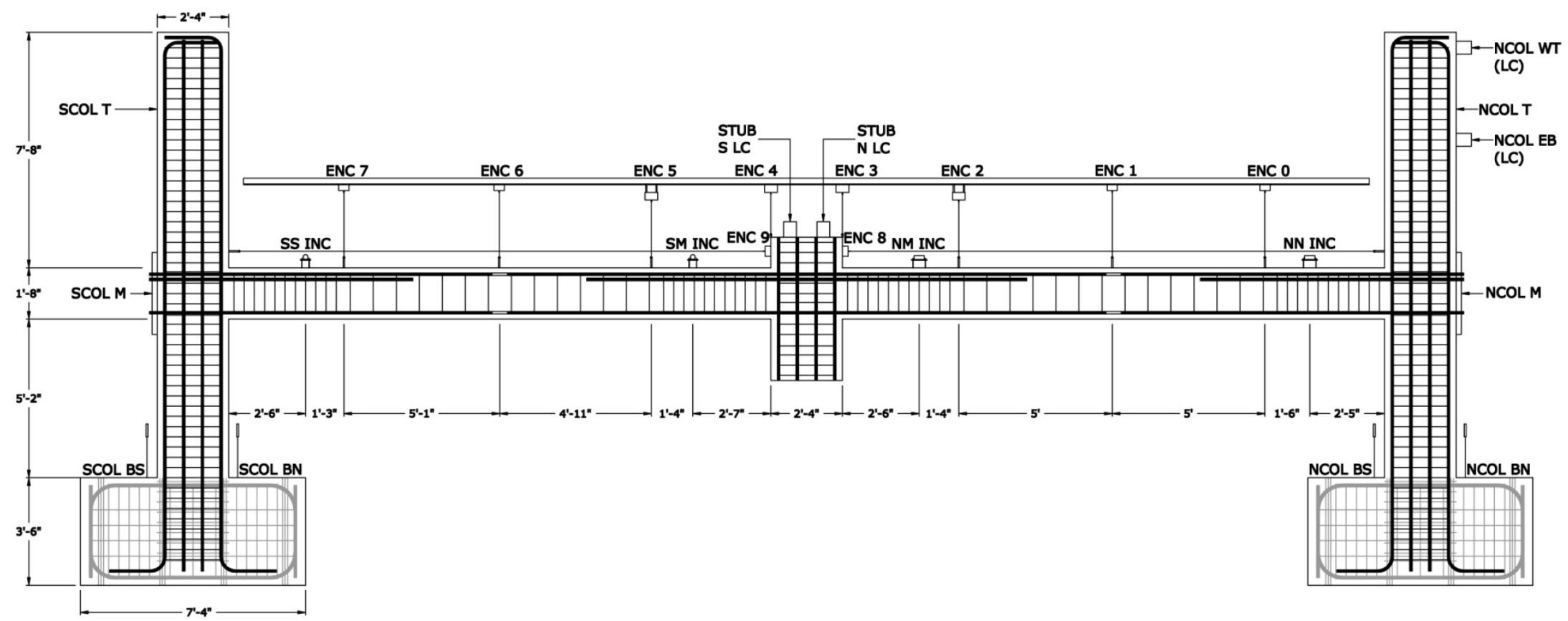

Figure 3.12 Instrument layouts (INC-inclinometer, ENC-position transducer, LC-load cell, other sensors are LVDTs). 
Table 3.3 Summary of instrumentation

\begin{tabular}{|c|c|c|}
\hline Instrument Type & Location & Measurement \\
\hline LVDT & North \& south columns & $\begin{array}{l}\text { Horizontal displacement } \\
\text { (column top and beam mid-height) }\end{array}$ \\
\hline LVDT & North \& south footings & $\begin{array}{l}\text { Vertical displacement } \\
\text { (movement of footing) }\end{array}$ \\
\hline Load cell & North \& south columns & Horizontal load (reaction at top) \\
\hline Load cell & Center column & Vertical load (applied load) \\
\hline Position transducer & Beams \& center column & $\begin{array}{l}\text { Vertical displacement } \\
\text { (beam deflections) }\end{array}$ \\
\hline Position transducer & Beams & $\begin{array}{l}\text { Horizontal displacement } \\
\text { (length change) }\end{array}$ \\
\hline Inclinometers & Beam ends & Rotation \\
\hline Whittemore gages* & Beam-column joints & Horizontal strain \\
\hline Optotrak $^{* *}$ & Beam-column joints & Horizontal strain \\
\hline Strain gages & Beam \& column reinforcing bars & Axial strain of reinforcement \\
\hline Dial gages & Base of footing & Horizontal displacement \\
\hline
\end{tabular}

${ }^{*}$ Used only for the SMF specimen

${ }^{* *}$ Electronic coordinate measurement device, used only for the IMF specimen

The uncertainty in the measured values of load, deflection, surface deformation, rotation, and strain was within $\pm 1 \%$. In addition to these digital measurements, digital cameras were used to capture the deformed shape of the specimens, surface cracks of concrete, and failure of components.

\subsubsection{Displacement Transducers (Position transducers and LVDTs)}

Based on pre-test analysis of the test specimen, the center column was expected to undergo large displacements of over 40 in $(1000 \mathrm{~mm})$ prior to final failure. To accommodate such large displacements, two spring-loaded string-type position transducers having a $6 \mathrm{ft}(1.8 \mathrm{~m})$ range and a 0.004 in $(0.1 \mathrm{~mm})$ accuracy were used to measure the vertical displacement of the center column. An additional six position transducers were used to measure the vertical displacement at different locations along the beam spans, and two position transducers were used to measure the change in length of the beam spans. Eight LVDTs having an accuracy of 0.005 in $(0.127 \mathrm{~mm})$ were used to measure horizontal displacements of the end columns and vertical displacements of the footings.

\subsubsection{Inclinometers}

To measure the rotation of the beam ends, four digital inclinometers were attached to the tops of the beams, about 30 in $(760 \mathrm{~mm})$ away from the column faces. The locations of the four inclinometers are shown in Figure 3.12, designated as SS INC, SM INC, NM INC, and NN INC. 


\subsubsection{Surface Deformation Measurement Devices}

To document the formation of concrete cracks, surface deformations were measured in the beamcolumn joint region using an electronic coordinate measurement device (Optotrak) for the IMF specimen and an electronic Whittemore gage device for the SMF specimen. The locations of the Optotrak target points are shown in Figure 4.9(a) and the locations of the Whittemore gage targets are shown in Figure 4.23(a). A photograph of the Optotrak target points in the beamcolumn joint region of the IMF specimen is shown in Figure 3.13. A change in the distance between any two target points is determined by measuring the coordinates of the targets.

\subsubsection{Strain Gages}

Uniaxial strain gauges were attached to the surface of reinforcing bars in beams and columns. The locations of strain gages are shown in Figures 4.9 and 4.23 for the IMF specimen and the SMF specimen, respectively. The primary purpose of the strain measurements was to observe experimentally the development of axial forces and bending moments in the beams and columns, including the onset of catenary action in the beams.

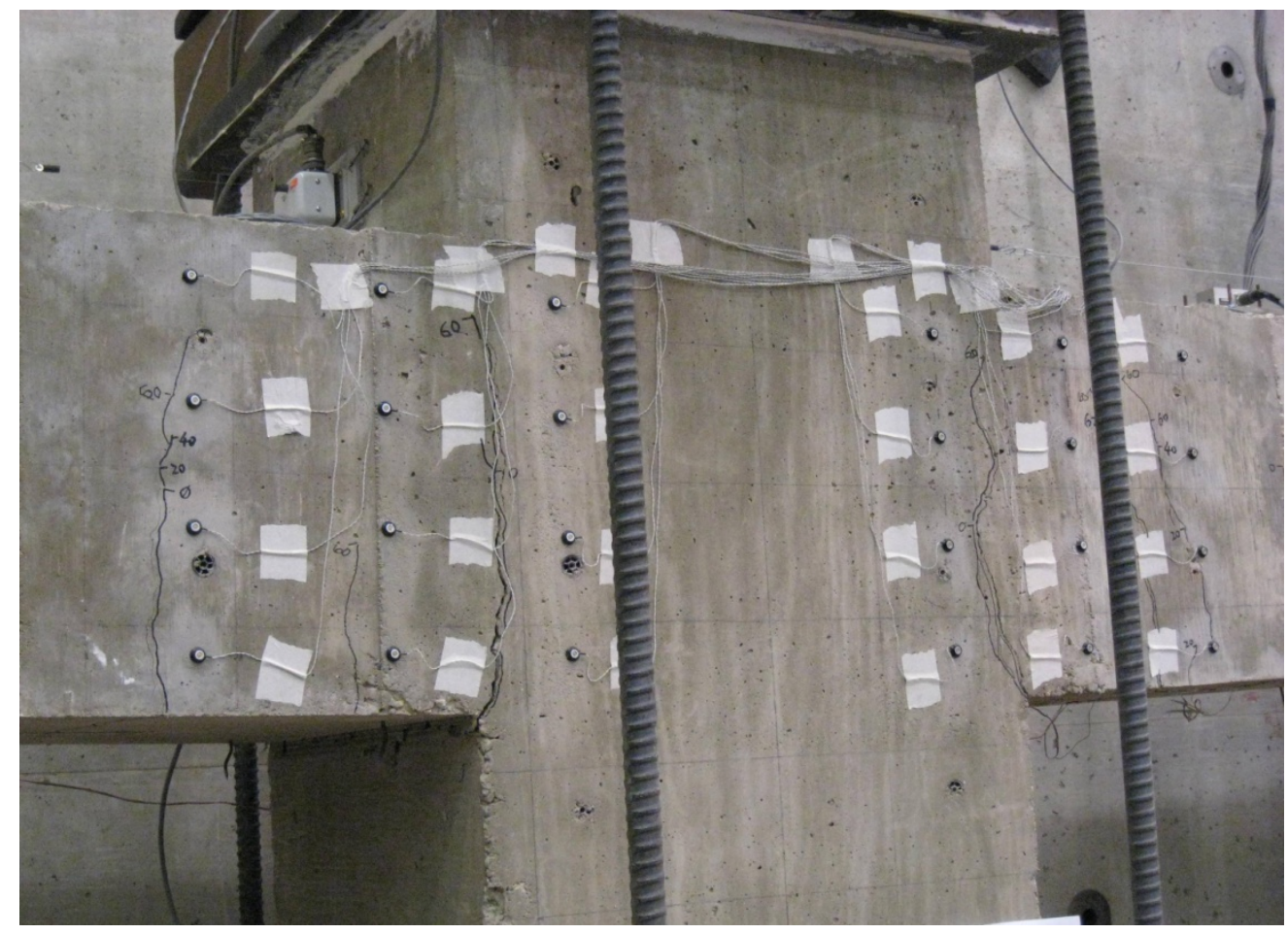

Figure 3.13 Optotrak target points for IMF specimen 
This page intentionally left blank 


\section{Chapter 4 \\ EXPERIMENTAL RESULTS}

\subsection{INTRODUCTION}

This chapter presents the test results of both the IMF and SMF specimens, described in Chapter 3. The test results include the observed behavior and failure modes of each specimen, along with the primary response parameters of the test specimens measured during the experiment. Such measurements include vertical and horizontal deflections of beams and columns, rotations at beam ends, and strains (reinforcing bars and concrete). The response parameters also include the vertical load applied by the hydraulic rams to pull down the center column, measured using load cells. Both the observed behavior and the measured response provide insights into the behavior of the specimens prior to and during the failure process. Sections 4.2 and 4.3 provide experimental results obtained from the IMF and SMF specimens, respectively, while Section 4.4 presents a summary and discussion of the test results.

\subsection{IMF SPECIMEN}

\subsubsection{Observed Behavior and Failure Modes}

Under monotonic vertical displacement of the center column, the IMF specimen experienced large deflections and rotations at the ends of the beams prior to failure (Figure 4.1). The failure was characterized by the following sequence (see Figure 4.2): (1) crushing and spalling of concrete at the top of the beams near the center column, (2) development of major flexural cracks (deepening and widening), and (3) fracture of one of the bottom reinforcing bars at a major crack opening near the center column. A south beam-bottom reinforcing bar near the center column first fractured at a vertical displacement of the center column of about 43.0 in $(1092 \mathrm{~mm})$, with a corresponding beam chord rotation of about $0.179 \mathrm{rad}\left(10.3^{\circ}\right)$, obtained by dividing the center column displacement by the centerline-to-centerline beam span of 240.0 in $(6096 \mathrm{~mm})$. At that displacement, the applied vertical load was approximately $123 \mathrm{kip}(547 \mathrm{kN})$. A second bar fractured when the center column deflection reached 44.5 in $(1130 \mathrm{~mm})$ at which point the test was terminated. 


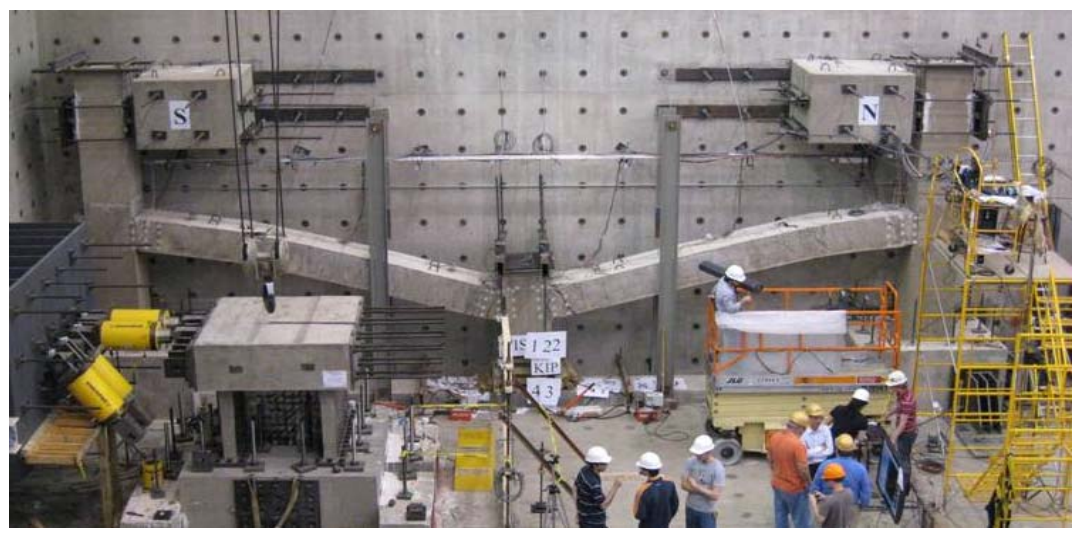

Figure 4.1 IMF specimen subjected to large displacement
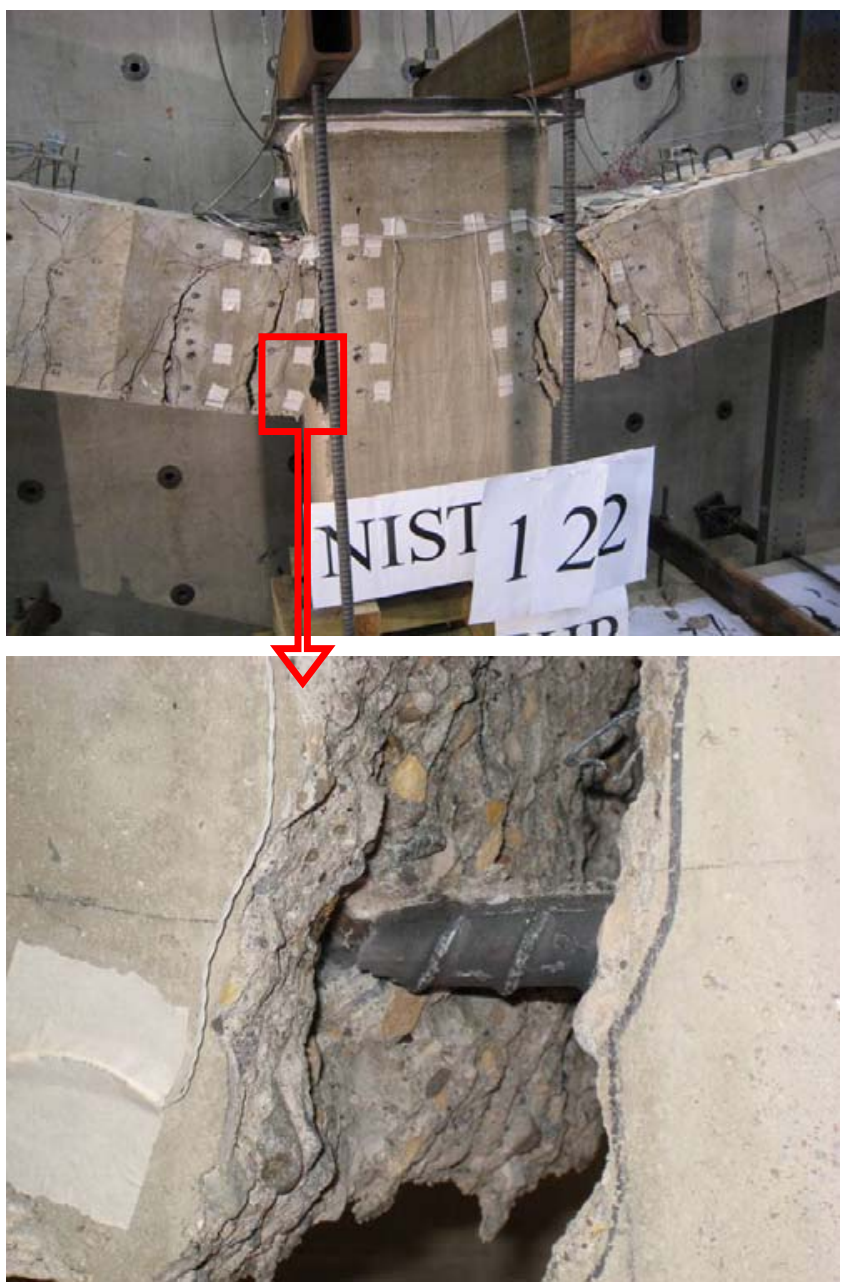

Figure 4.2 Failure mode of IMF specimen 


\subsubsection{Crack Patterns}

When shores were removed prior to testing, small vertical flexural cracks developed at the ends of both the south and north beams. The maximum width of the cracks measured was 0.008 in $(0.2 \mathrm{~mm})$. When testing commenced with downward displacement of the center column, more flexural cracks developed along the beams, as well as along the lower halves of the end columns (below the beams). As the vertical displacement of the center column approached 3.5 in (90 mm), with a vertical load approaching $60 \mathrm{kip}(267 \mathrm{kN})$, shear cracks started to develop in the bottom halves of the columns, and inclined cracks developed at the beam-column joints at the end columns. At a center column displacement of about 4.3 in $(110 \mathrm{~mm})$, with a load of about $63 \mathrm{kip}(280 \mathrm{kN})$, splitting cracks were noted at the top of the beams near the end columns. When the center column was displaced about 6.8 in $(173 \mathrm{~mm})$, corresponding to a vertical load of about $61 \mathrm{kip}(271 \mathrm{kN})$, splitting cracks also appeared at the top of the beam next to the north face of the center column. As the center column displaced further, concrete began to crush at the beam ends. It was noted that the crushing was more intense in the north beam than the south beam. Figure 4.3(a) shows a map of cracks at a center column displacement of about 24 in $(610 \mathrm{~mm})$. At this displacement, the maximum crack width of the north beam near the center column was about 1.3 in $(33 \mathrm{~mm})$. As the center column displacement was increased further, full-depth cracks appeared in the beams near both sides of the center column. After the fracture of the second longitudinal bar of the south beam, wide gaps were visible in the beams near the center column and also at the reinforcement cutoff points. Full-depth cracks were visible at the middle segments of the beams. Figure 4.3(b) shows a map of the final crack pattern.

(a)

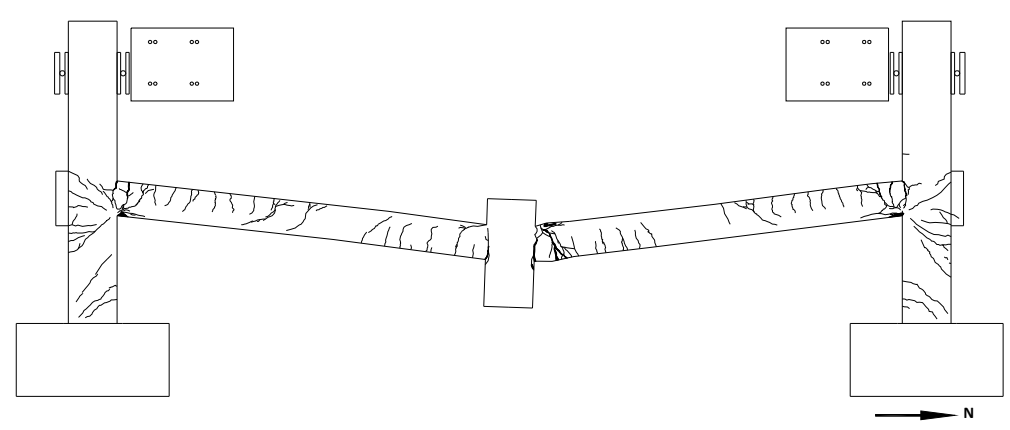

(b)

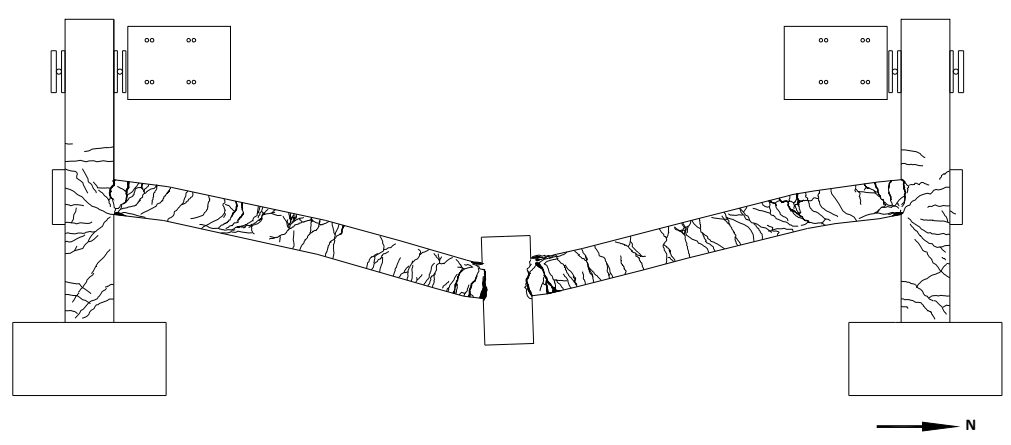

Figure 4.3 Crack patterns of IMF specimen at center column deflections of (a) 24 in (610 mm) and (b) 43 in (1092 mm) 


\subsubsection{Displacement Measurements}

Figure 4.4 shows the vertical load versus vertical deflections at (a) $1 / 4$ span of the beams (ENC0 and ENC7), (b) mid-span of the beams (ENC1 and ENC6), (c) 3/4 span of the beams (ENC2 and ENC5), and (d) the center column (ENC3 and ENC4). The locations of the position transducers were shown previously in Figure 3.12. As the plots indicate, the specimen was slightly unloaded when the hydraulic rams were halted every 2.5 in to 3.0 in $(64 \mathrm{~mm}$ to $76 \mathrm{~mm})$ to take instrument measurements and photographs. Figure 4.4(d) shows that the load reached an initial peak of $66.5 \mathrm{kip}(296 \mathrm{kN})$ at a center column displacement of about 5 in $(127 \mathrm{~mm})$ and started to decrease with increasing displacement. At a displacement of about 16 in $(406 \mathrm{~mm})$, the load had leveled off at $44 \mathrm{kip}(196 \mathrm{kN})$. With further increase in the center column displacement, the load started to increase again until it reached a maximum value of approximate $123 \mathrm{kip}(547 \mathrm{kN})$ at a displacement of 43 in $(1092 \mathrm{~mm})$. At that displacement, the first longitudinal bar of the south beam fractured at the face of the center column, which was followed by a second bar fracture at the same crack location when the displacement reached $44.5 \mathrm{in}(1130 \mathrm{~mm})$. Each of the four pairs of load-displacement curves plotted in Figure 4.4 shows good agreement between the measurements of symmetrically placed position transducers, which indicates that symmetry was largely maintained during the experiment. In subsequent plots, the average of ENC3 and ENC4 is used to represent the vertical displacement of the center column.

Figure 4.5 depicts the deflection profile of the beams (ENC0 through ENC7) at different load values. In the figure, dotted lines are used to connect the measured deflections. Note that the straight lines do not accurately represent the deflected shape of the beams. The small differences between the displacement measurements on each side of the center column indicate a slight rotation of the center column during the experiment.

The plots in Figure 4.6 show the horizontal displacements at the tops of the end columns (SCOL T and NCOL T), where the rollers were placed to restrain the movement, and the horizontal displacement at the beam mid-height (SCOL M and NCOL M) versus the vertical displacement of the center column. In the plots, positive values represent inward movement. Figure 4.6(a) shows that a small deflection was observed at the top of the columns. This is mainly due to slack in the support system at the top of the columns. A maximum outward deflection (average of SCOL T and NCOL T) of about 0.1 in $(2.5 \mathrm{~mm}$ ) was recorded at a vertical displacement of the center column of about 10 in $(254 \mathrm{~mm})$. As the vertical displacement was increased, the columns started to move inward and reached a maximum average deflection of about 0.04 in $(1 \mathrm{~mm})$ at the top. Figure 4.6(b) shows similar movement of the columns at beam mid-height with a peak outward deflection (average of SCOL M and NCOL M) of about 0.24 in $(6.1 \mathrm{~mm})$ at a vertical displacement of about 9 in $(230 \mathrm{~mm})$ and a maximum inward deflection of about $0.17 \mathrm{in}(4.3 \mathrm{~mm})$ at the end of the test. 

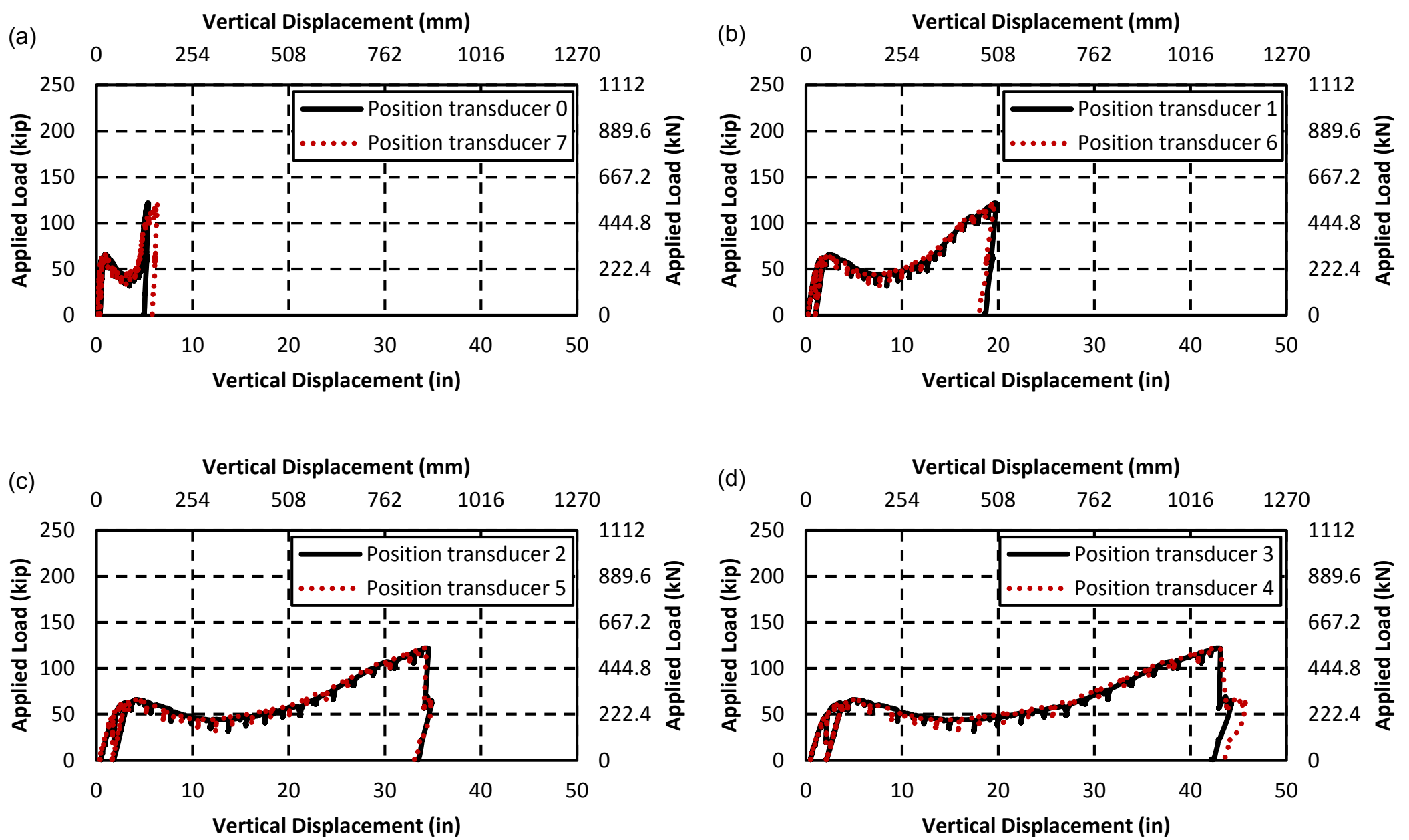

Figure 4.4 Vertical load versus vertical deflections of IMF specimen at (a) $1 / 4$ span of beams (ENC0 and ENC7), (b) mid-span of beams (ENC1 and ENC6), (c) 3/4 span of beams (ENC2 and ENC5), and (d) center column (ENC3 and ENC4) 


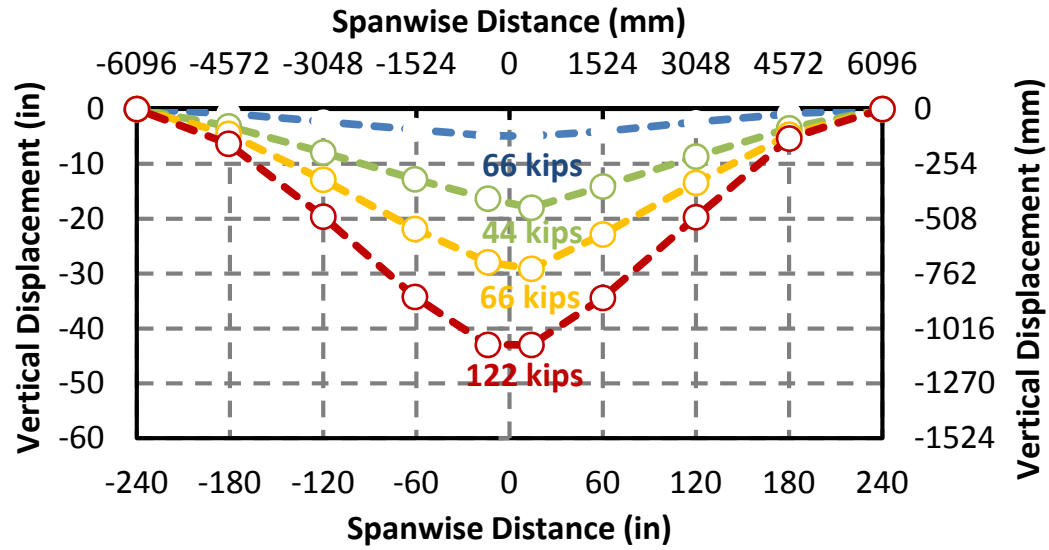

Figure 4.5 Vertical deflection profiles of beams corresponding to indicated vertical Loads for IMF specimen (deflections magnified)

(a) Vertical Displacement of Center Column ( $\mathrm{mm}$ )

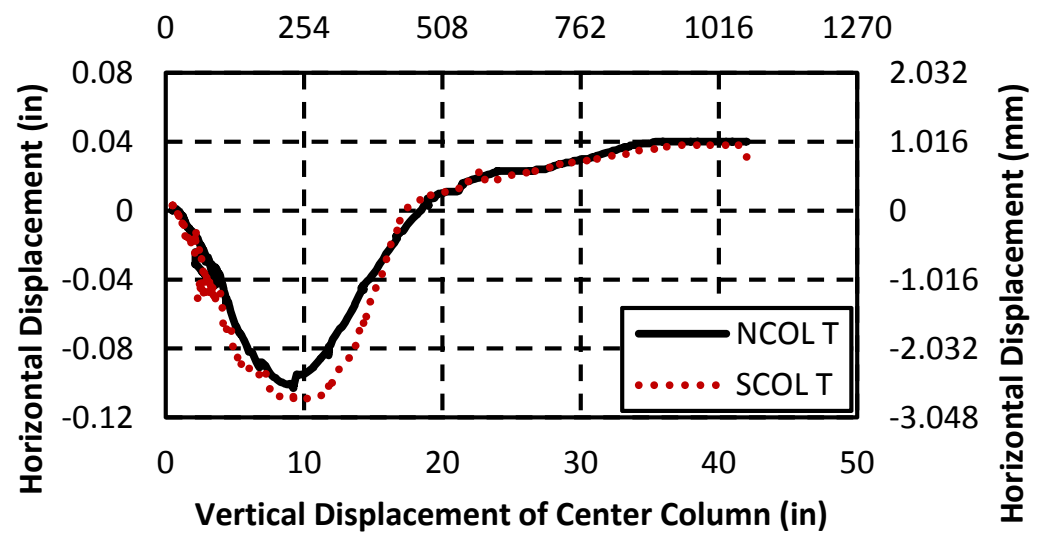

(b)

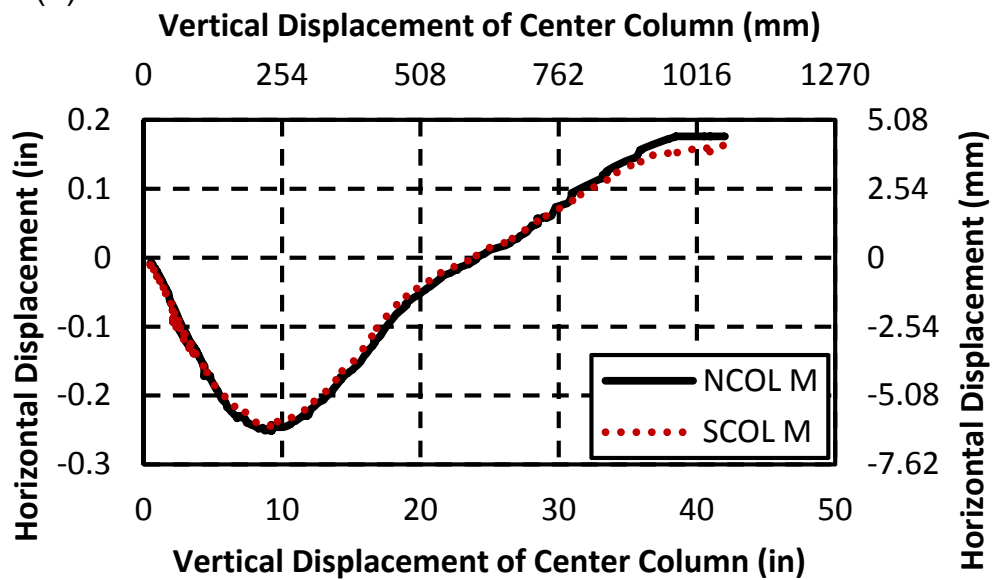

Figure 4.6 Horizontal displacement of end columns at (a) top (SCOL T, NCOL T), and (b) beam mid-height (SCOL M, NCOL M) versus vertical displacement of center column for IMF specimen. 


\subsubsection{Rotation Measurements}

Figure 4.7 shows the vertical load plotted against the rotations measured at the beam ends near the north and south end columns (inclinometers NN INC and SS INC, respectively, see Figure 3.12). Figure 4.8 presents the same rotation measurements plotted against the vertical displacement of the center column. Rotations of the north and south beams agreed closely until a vertical displacement of about 20 in $(508 \mathrm{~mm})$. As the displacement increased, the bottom of the south beam near the south end column exhibited significant crushing of concrete which caused a reduction of the effective cross section of the south beam near the end column. This condition led the south beam to undergo a larger rotation than the north beam. This disparity in beam-end rotation is evident in Figures 4.7 and 4.8. The average of the two measured beam-end rotations near the end columns (NN INC and SS INC) was calculated and plotted in Figures 4.7 and 4.8. These figures show that the maximum average rotation before failure was about $0.159 \mathrm{rad}\left(9.1^{\circ}\right)$. The other two inclinometers, which were near the center column (NM INC and SM INC, see Figure 3.12), did not provide meaningful data.

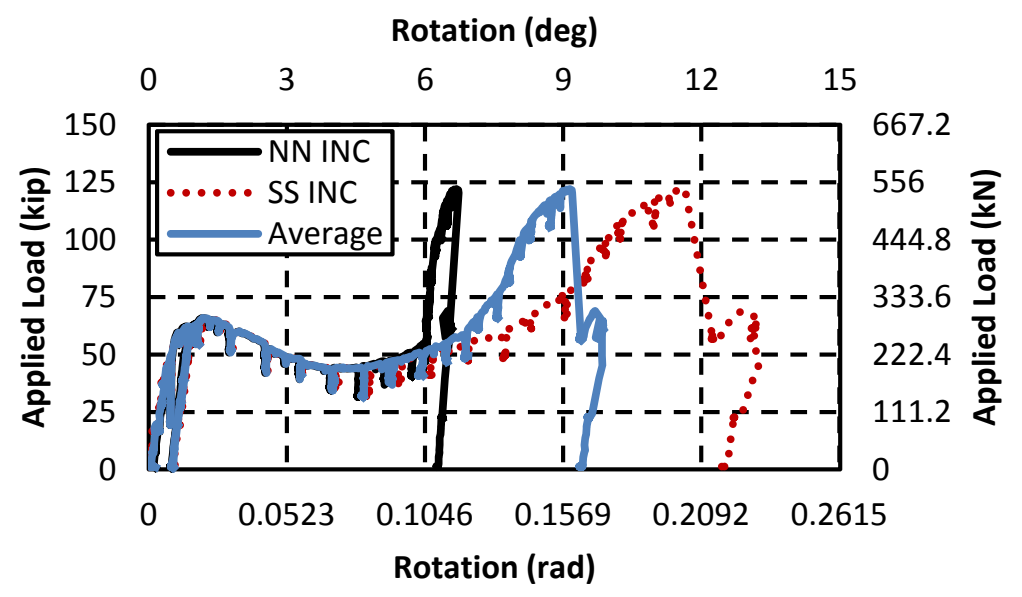

Figure 4.7 Applied vertical load versus beam end rotations for IMF specimen

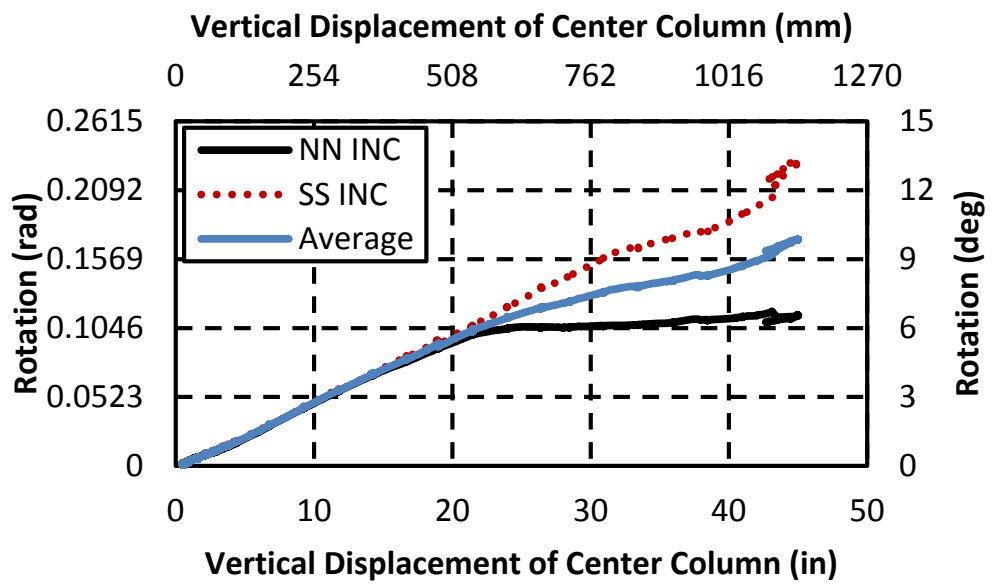

Figure 4.8 Beam end rotations versus vertical displacement of center column for IMF specimen 


\subsubsection{Strain Measurements}

Concrete surface strains were calculated using position transducer (Optotrak) readings which recorded a relative displacement between two targets cemented on the concrete surface as shown in Figure 4.9(a). The horizontal gage length between Optotrak targets was 8 in $(203 \mathrm{~mm})$, and the vertical spacing was 5 in $(127 \mathrm{~mm})$. Reinforcing bar strains were measured by electrical resistance strain gages attached to reinforcing bars embedded into concrete. The strain gage locations are shown in Figure 4.9(b). In the figure, the cross sections where strain gages were installed are labeled as S1 through S3 in the south column, N1 through N3 in the north column, and $\mathrm{B} 1$ through $\mathrm{B} 10$ in the beams.

Gages at sections B3 and B8 provide information about the reinforcement strains at mid-span of the beams. Figure 4.10 shows negative (compressive) strain in both top and bottom reinforcing bars of the beams before the vertical displacement exceeded about 20 in $(508 \mathrm{~mm})$, which indicates that a compressive axial force developed in the beams during this stage of loading. It was observed that although the applied load started to decrease, the compressive strain of the top and bottom bars continued to increase until the vertical displacement of the center column reached about 10 in $(254 \mathrm{~mm})$. Transition of beam axial forces from compression to tension occurred as the vertical displacement of the center column increased from 20 in $(508 \mathrm{~mm})$ to 30 in $(762 \mathrm{~mm})$. As the vertical displacement increased beyond $30 \mathrm{in}(762 \mathrm{~mm})$, all longitudinal reinforcement at the mid-span sections (B3 and B8) of the beams exhibited positive (tensile) strain, which clearly indicates the development of catenary action in the beams. Enlargements of the strain development in the early stages of loading are shown on the right hand side of the plots.

Gages at sections S1 and N1 provide information about strain in the longitudinal reinforcement at the base of the end columns. Figure 4.11(a) shows strains in the longitudinal bars located near the interior face at these sections, indicating that these bars were in tension initially and gradually changed to compression after reaching a peak tensile strain. On the other hand, Figure 4.11(b) shows that the reinforcing bars near the outer face were in compression initially and gradually changed to tension. These sign changes in the measured strains indicate a reversal of the in-plane curvature of the end columns, which was associated with the development of tensile axial forces in the beams due to catenary action.

At sections B1 and B10, near the end column interfaces, the measured strain in the top reinforcing bars of the beams exceeded the nominal yield strain (0.002) in tension at a vertical displacement of about 2 in $(51 \mathrm{~mm})$. Soon after the vertical displacement exceeded about 5 in $(127 \mathrm{~mm})$, these gages failed. The measured strain in the bottom reinforcing bars at sections B1 and B10 exceeded the nominal yield strain in compression at a vertical displacement of about 15 in $(381 \mathrm{~mm})$. Strain readings in these bars gradually changed from compression to tension beyond a vertical displacement of 30 in $(762 \mathrm{~mm})$. The bottom longitudinal reinforcing bars at sections B5 and B6 exceeded the nominal yield strain in tension at a vertical displacement of the center column of about 1.5 in $(38 \mathrm{~mm})$. 
(a)

(b)
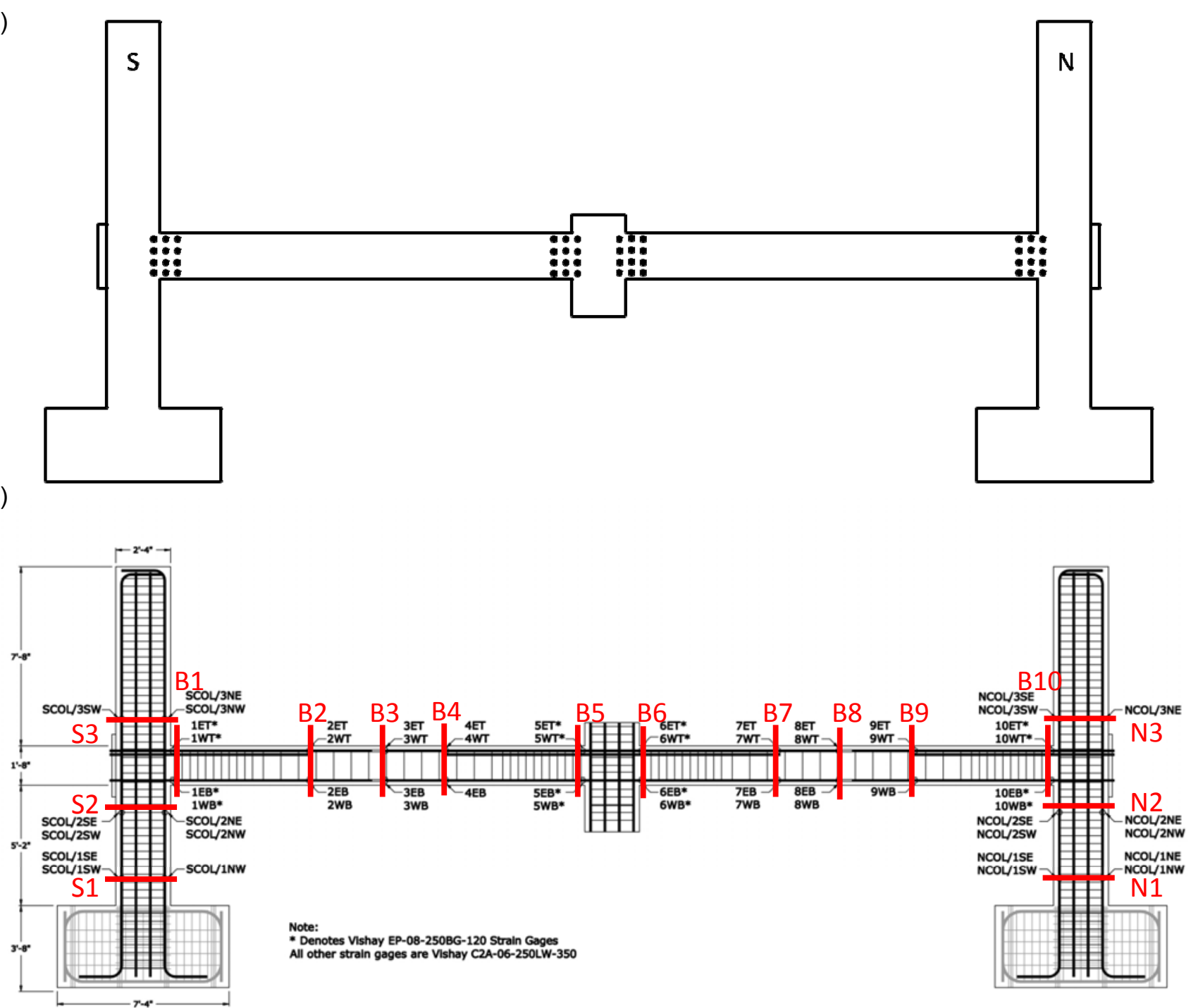

Figure 4.9 Strain measurements for IMF specimen: (a) Optotrak target locations and b) reinforcing bar strain gage locations 

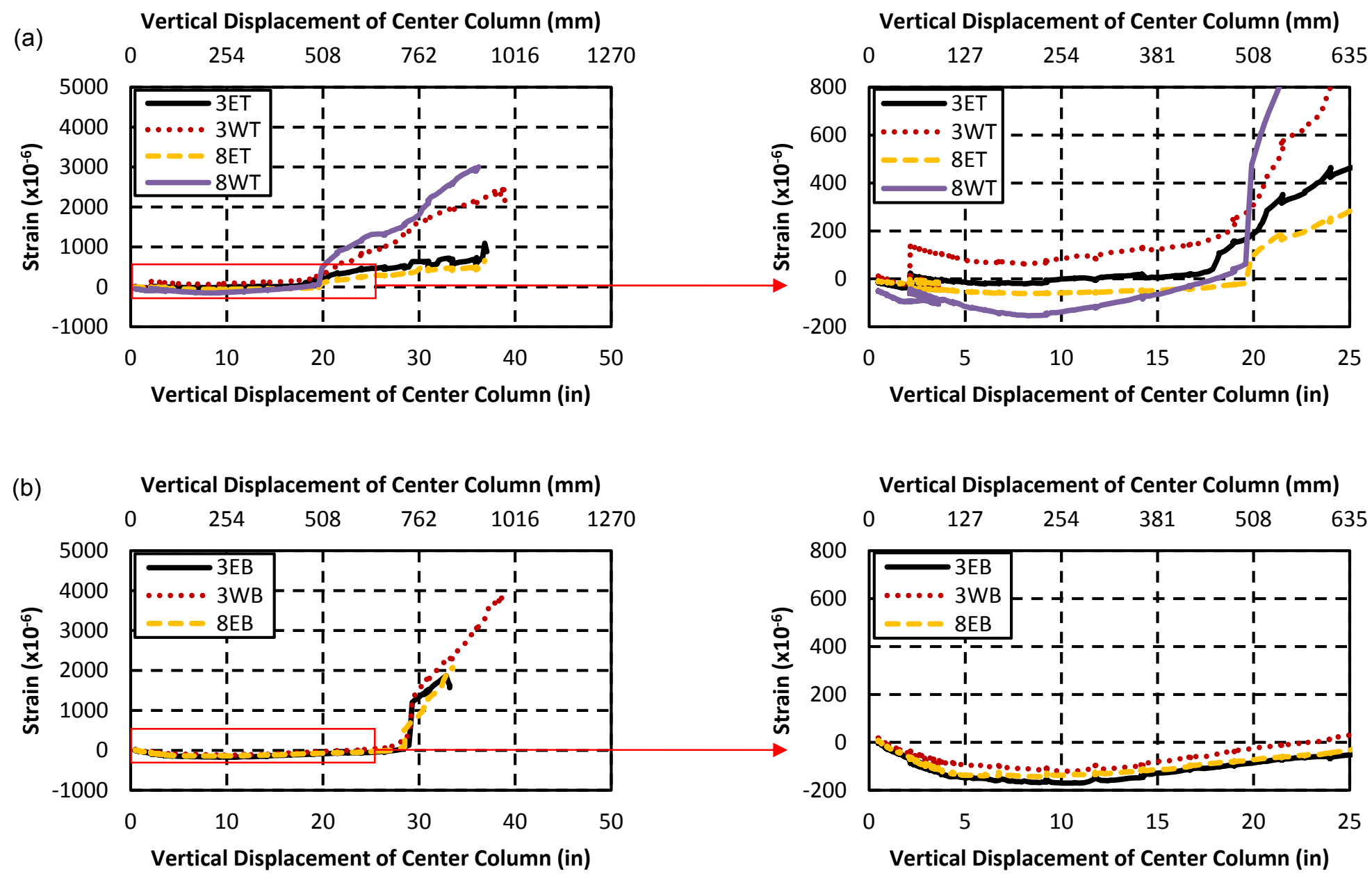

Figure 4.10 Beam mid-span (Section B3 and B8) reinforcing bar strains versus vertical displacement of center column for IMF specimen: (a) top reinforcing bars and (b) bottom reinforcing bars 
(a) Vertical Displacement of Center Column ( $\mathrm{mm}$ )

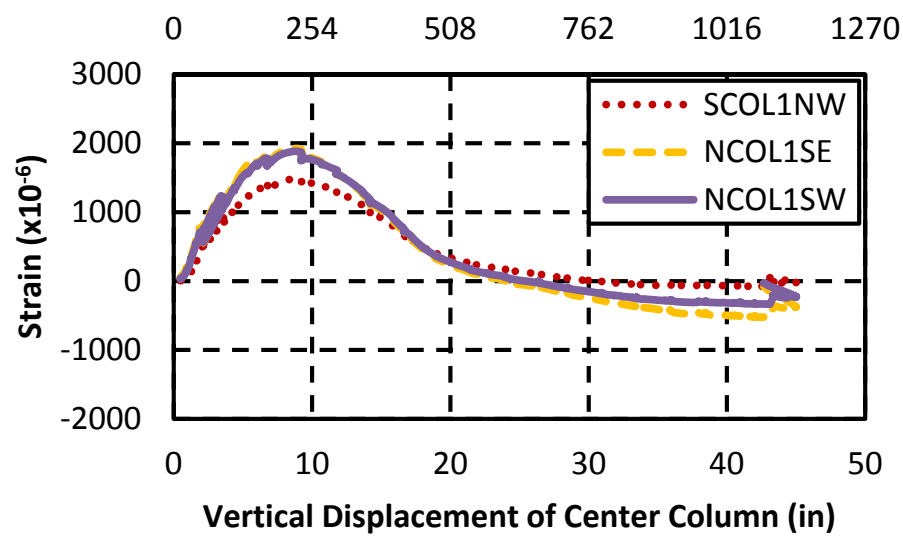

(b)

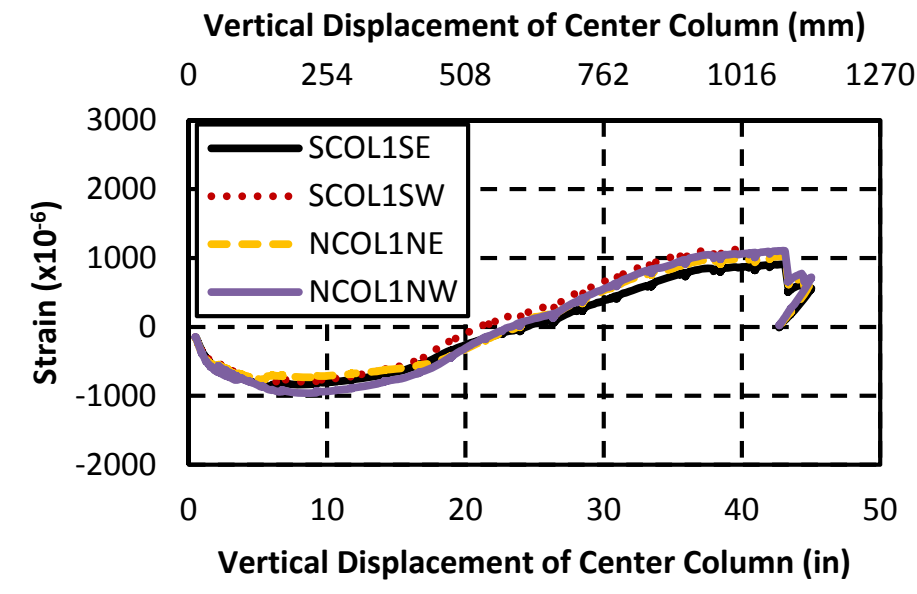

Figure 4.11 Column-bottom (Section S1 and N1) reinforcing bar strains versus vertical displacement of center column for IMF specimen: (a) interior reinforcing bars and (b) exterior reinforcing bars 
A number of strain gages malfunctioned from the early stage of loading. These include gages $5 \mathrm{~EB}$ and $5 \mathrm{WB}$, which failed when the vertical displacement exceeded 2.0 in $(51 \mathrm{~mm})$, and gages $6 \mathrm{~EB}$ and $6 \mathrm{WB}$, which failed at vertical displacements of about 9 in $(229 \mathrm{~mm})$ and 14 in $(356 \mathrm{~mm})$ with maximum tensile strains of about 0.04 and 0.06 , respectively. Gages 5ET and $5 \mathrm{WT}$ malfunctioned and did not provide data. Gages $6 \mathrm{ET}$ and $6 \mathrm{WT}$ failed at a vertical displacement of 12 in $(305 \mathrm{~mm})$, with maximum compressive strains of about 0.005 and 0.01 , respectively. See Figure 4.9 for the locations of these gages.

Strain gage measurements at bar-cutoff sections, where the shorter top reinforcing bars in the beams terminate (B2, B4, B7, and B9 in Figure 4.9), are presented in Figure 4.12. Strain readings at bar-cutoff sections B2 and B9 show that the top bars yielded in tension when the bottom bars were still in compression. This spreading of yielding in the longitudinal bars is the reason that the displacement profile in Figure 4.5 exhibits curvature along the beam spans, rather than consisting simply of straight line segments between plastic hinges at the beam ends.

Plots of average computed concrete surface strain based on Optotrak readings at beam-end sections near the end columns are presented in Figure 4.13. Strain distributions correspond to applied vertical loads of 49 kip, 63 kip, 59 kip, 44 kip, and 108 kip $(218$ kN, 280 kN, 262 kN, $196 \mathrm{kN}$, and $480 \mathrm{kN}$ ). These loads correspond to center column vertical displacements of $2.2 \mathrm{in}$, $4.3 \mathrm{in}, 6.8 \mathrm{in}, 14.2 \mathrm{in}$, and $38.5 \mathrm{in}(56 \mathrm{~mm}, 109 \mathrm{~mm}, 173 \mathrm{~mm}, 361 \mathrm{~mm}$, and $978 \mathrm{~mm})$. Similar plots are shown in Figure 4.14 for the beam-end sections near the center column. Enlargements of the cross-sectional strain distributions during the early stage of loading are shown on the righthand side of these figures. Figure 4.13 shows that the neutral axis moved upward during the initial stage of loading, for center column displacements less than 5 in $(127 \mathrm{~mm})$. Then the neutral axis moved downward as the center column displacement increased. This suggests that compressive axial force developed in the beams during the initial stages of loading, which later changed to tensile axial force as the center column displacement increased. The cross-sectional strain profiles shown in Figure 4.14(a) and (b) indicate that the north beam rotated more than the south beam at the center beam-column joint until the onset of catenary action. Subsequently, a large crack developed at the beam-column interface on the south side of the joint (see Figure 4.2). As a result, the rotation of the south beam increased rapidly and the difference in the end rotations of the north and the south beams diminished. With further increases in the center column displacement, considerable localized reduction in the cross-sectional area of the bottom reinforcing bars developed and these bars eventually fractured. 
(a) Vertical Displacement of Center Column ( $\mathrm{mm})$

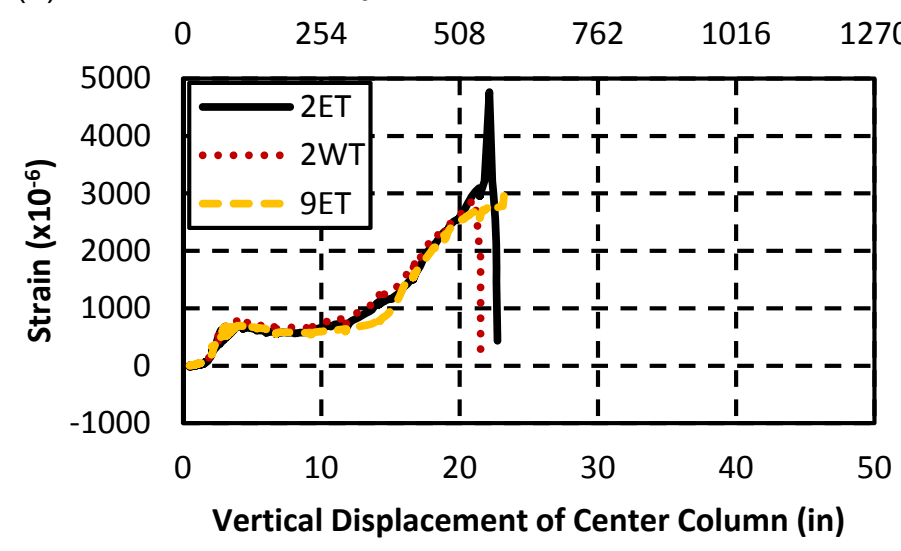

(c) Vertical Displacement of Center Column ( $\mathrm{mm}$ )

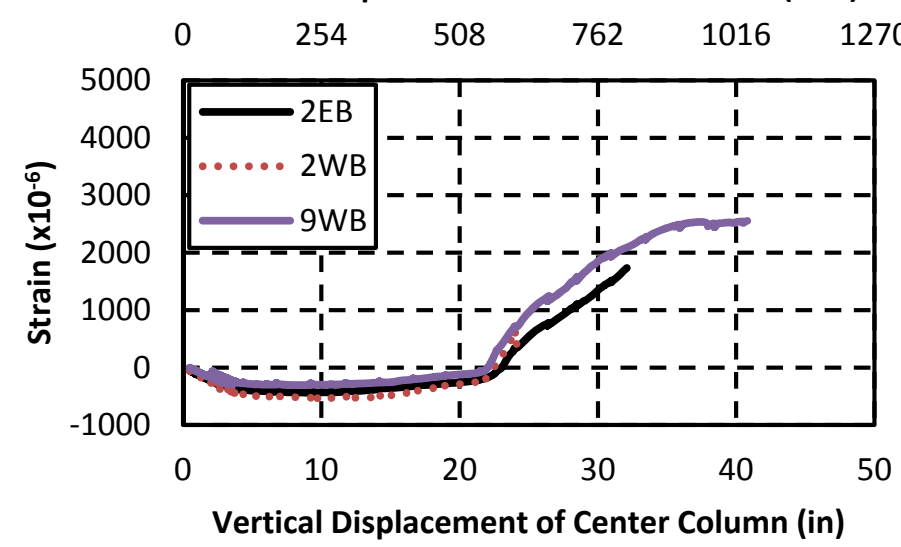

(b) Vertical Displacement of Center Column (mm)

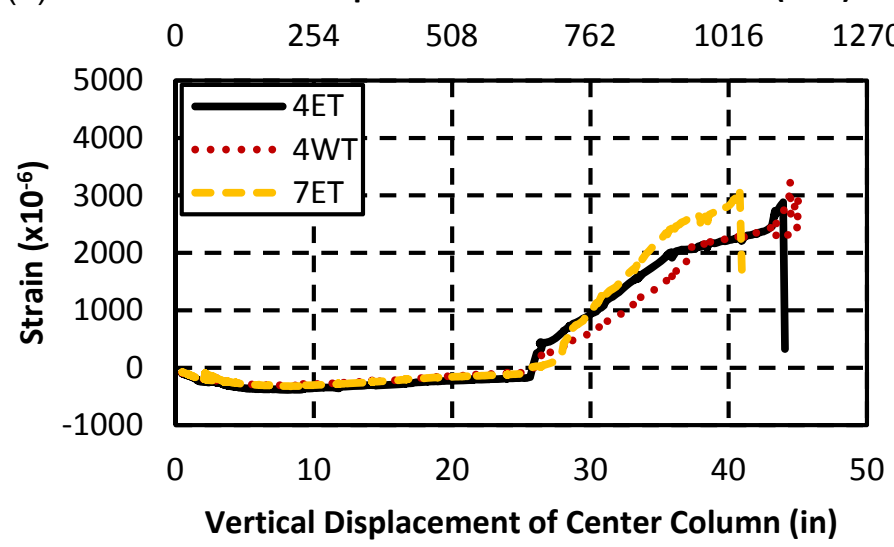

(d) Vertical Displacement of Center Column (mm)

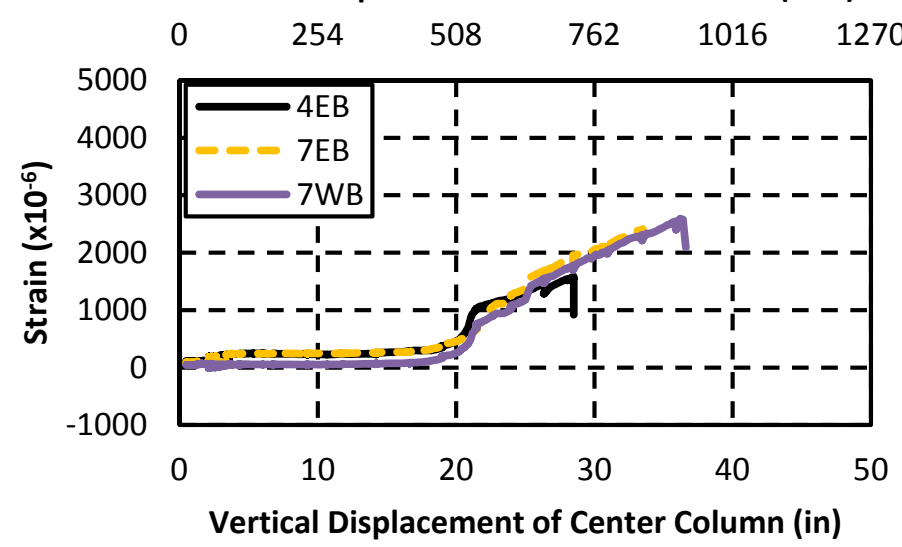

Figure 4.12 Beam reinforcement strains at bar-cutoff sections versus vertical displacement of center column for IMF specimen: (a) top bars at sections B2 and B9, (b) top bars at sections B4 and B7, (c) bottom bars at sections B2 and B9, and (d) bottom bars at sections B4 and B7 

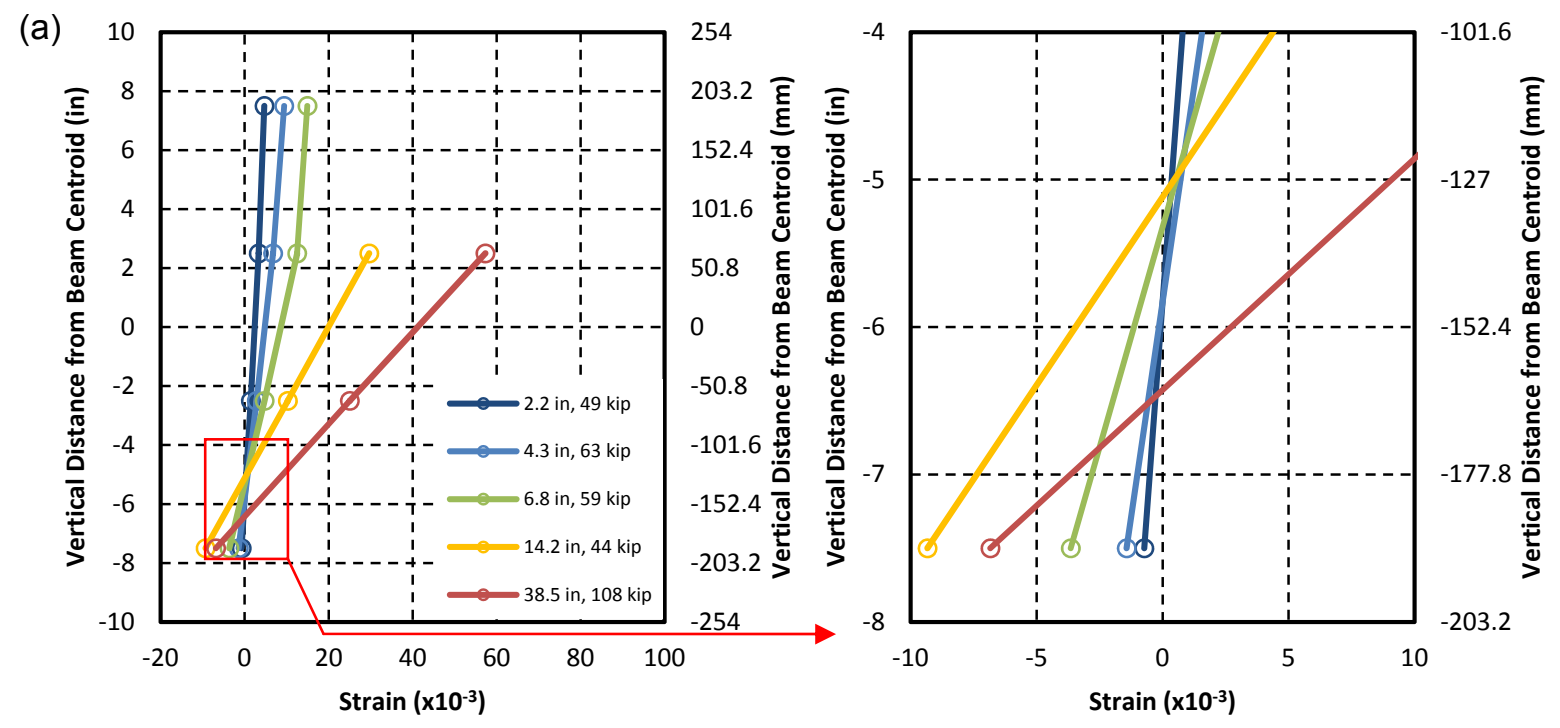

(b)
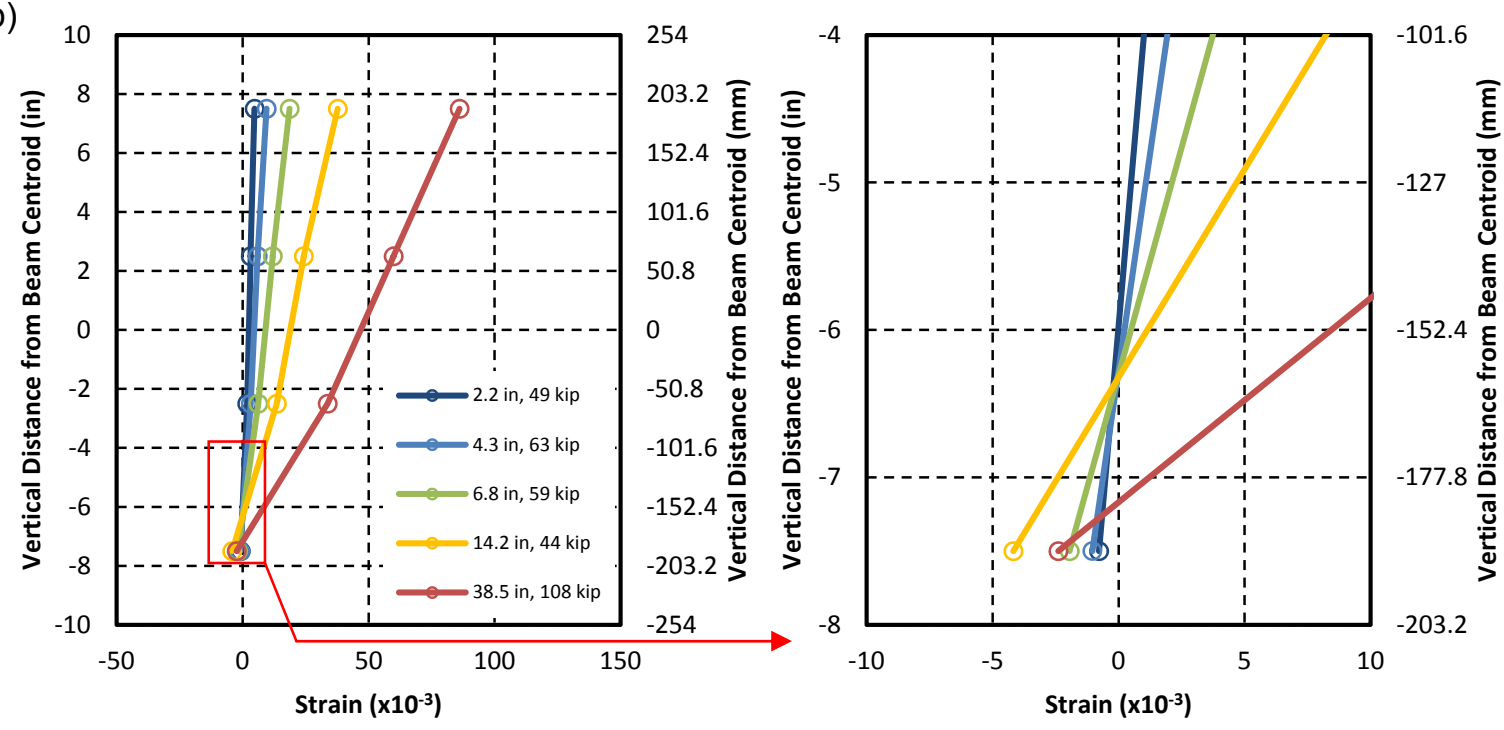

Figure 4.13 Concrete surface strain distributions of IMF specimen at beam ends: (a) near north end column and (b) near south end column 

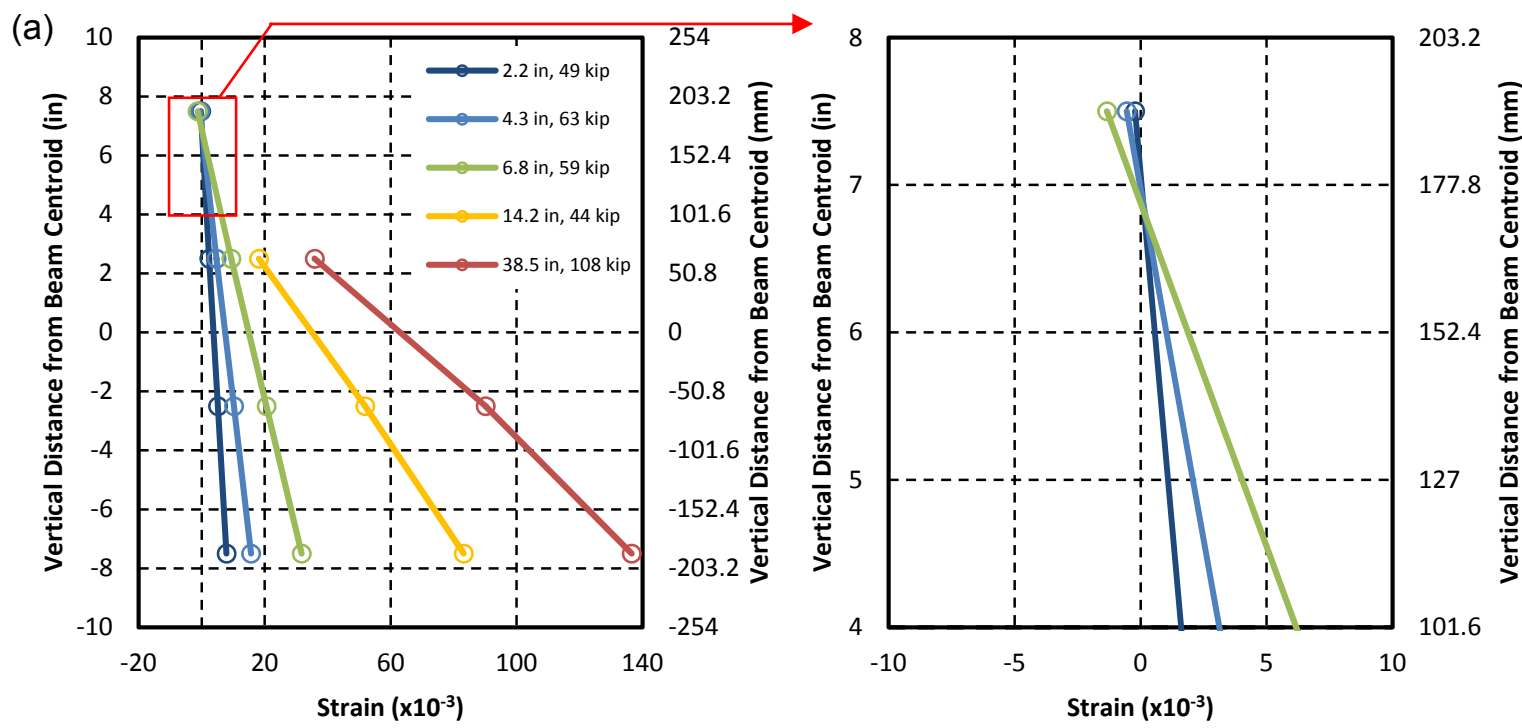

(b)
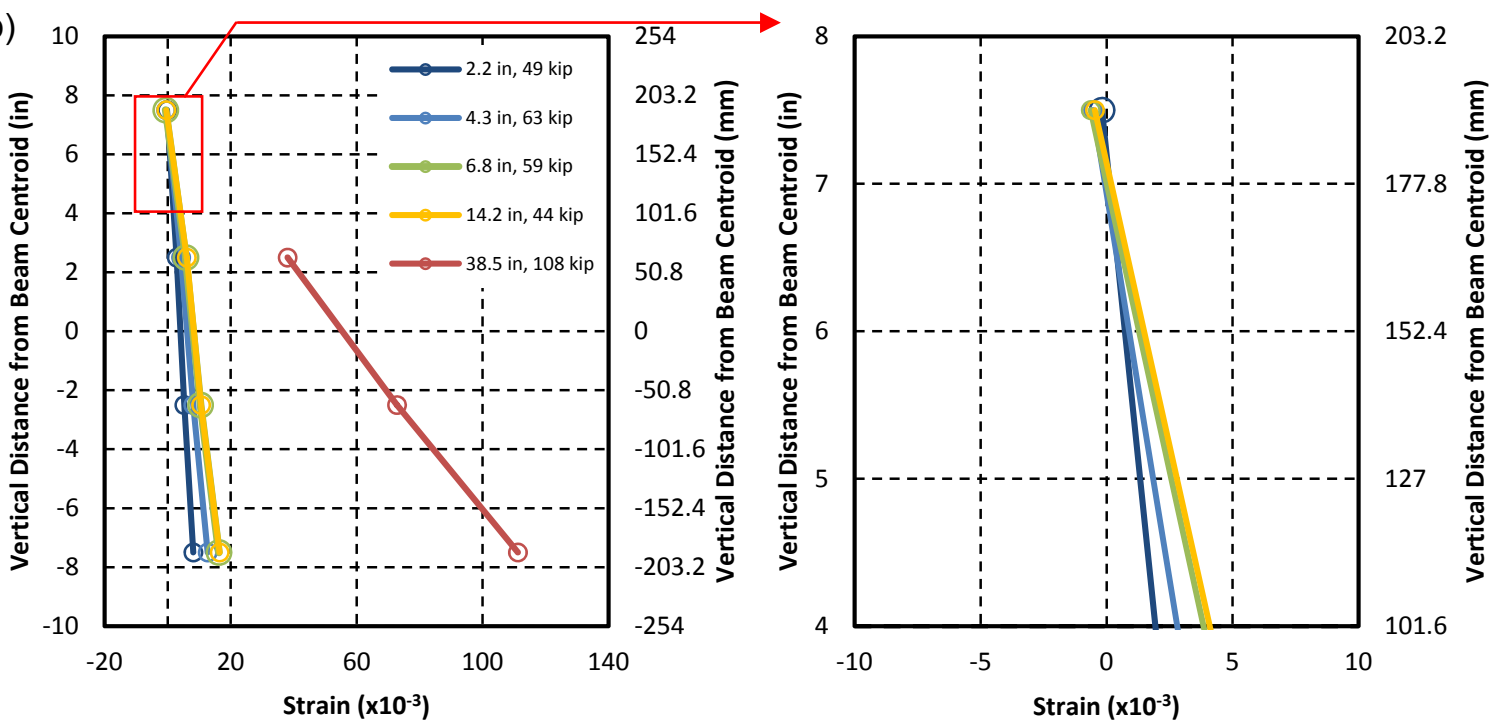

Figure 4.14 Concrete surface strain distributions of IMF specimen at beam ends: (a) near north side of center column and (b) near south side of center column 


\subsection{SMF SPECIMEN}

\subsubsection{Observed Behavior and Failure Modes}

Under monotonic vertical displacement of the center column, the SMF specimen (see Figure 4.15) experienced larger deflections and rotations than the IMF specimen before failure. The SMF specimen failed at a vertical displacement of the center column of about 48 in $(1219 \mathrm{~mm})$, with a corresponding beam chord rotation of about $0.20 \mathrm{rad}\left(11.5^{\circ}\right)$, obtained by dividing the center column displacement at failure by the centerline-to-centerline beam span of 240.0 in $(6096 \mathrm{~mm})$. The applied vertical load corresponding to that displacement was approximately $277 \mathrm{kip}(1232 \mathrm{kN})$. The failure was initiated by fracture of one of the beam-bottom reinforcing bars in tension near the north face of the center column (see Fig. 4.16). As loading continued, all of the reinforcing bars in the bottom layer fractured. Compared with the IMF specimen, the larger rupture strain of the longitudinal reinforcement (21\% versus $18 \%$ for SMF and IMF, respectively, see Table 3.2) at the bottom of the beams of the SMF specimen may have contributed to the larger deflections and rotations that were achieved.

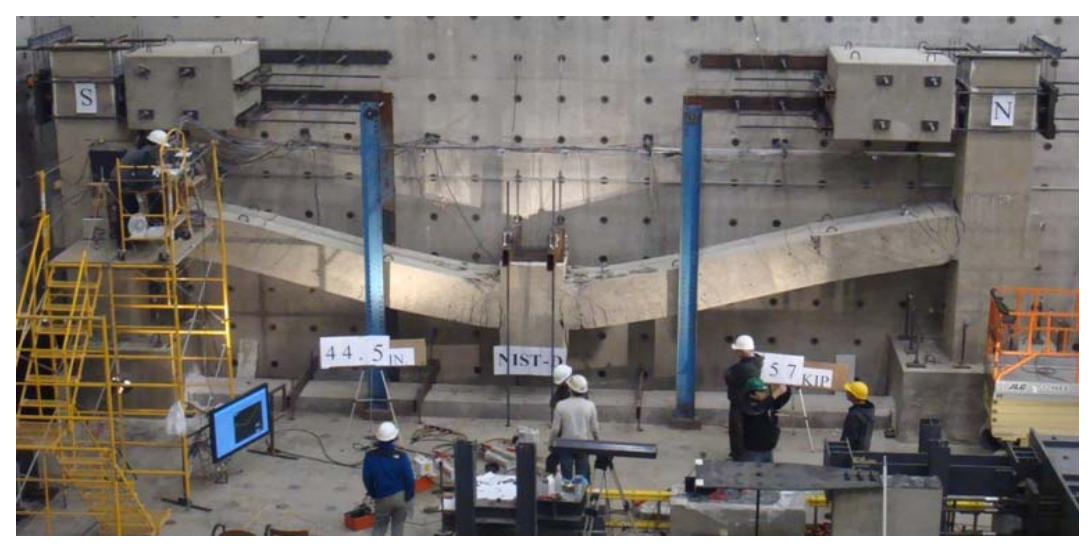

Figure 4.15 View of SMF specimen subjected to large displacement 

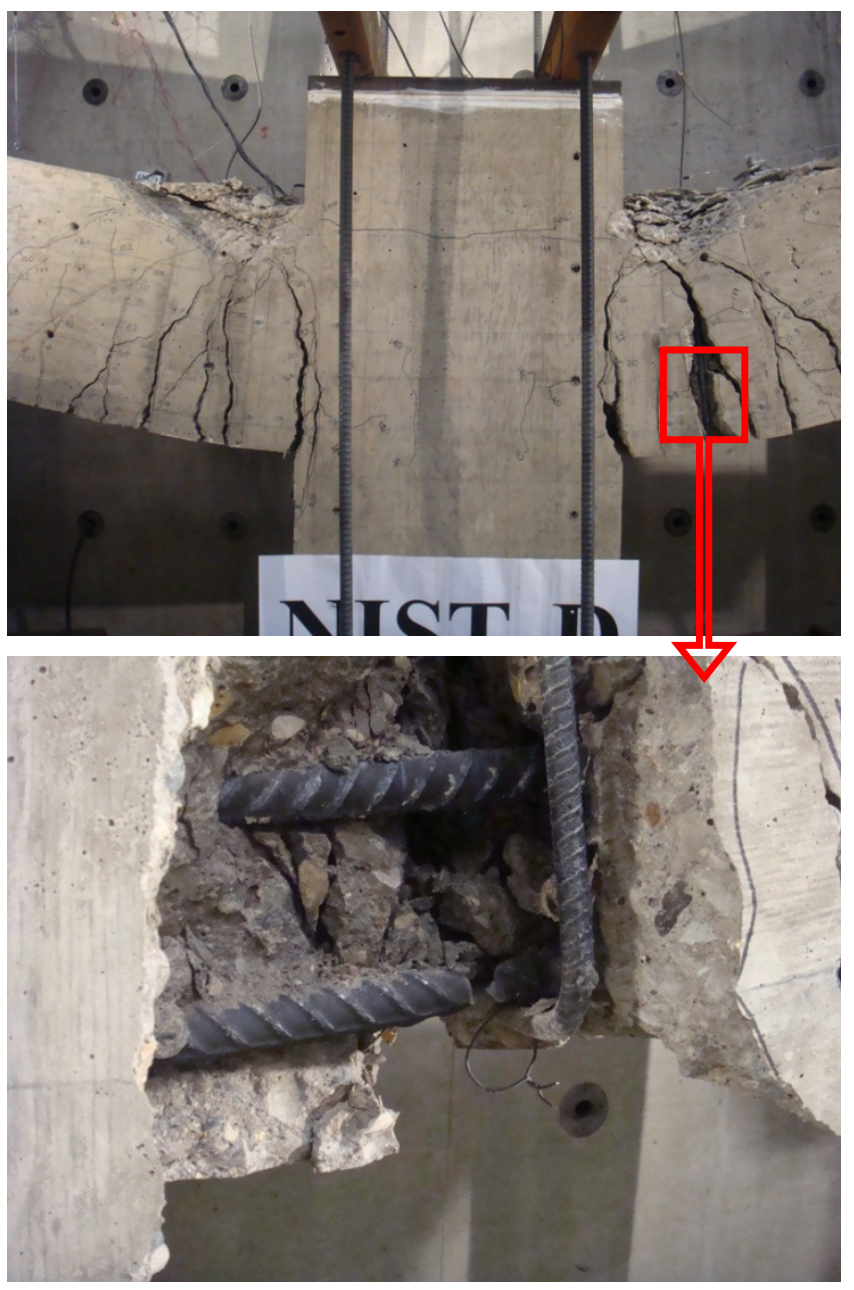

Figure 4.16 Failure mode of SMF specimen

\subsubsection{Crack Patterns}

During shore removal before testing, small cracks were noted at the beam ends close to the end columns and the center column. When testing commenced with downward displacement of the center column, flexural cracks developed along the beam and along the lower halves of the columns (below the beams). When the vertical displacement of the center column approached 1.4 in $(36 \mathrm{~mm})$, with a vertical load approaching $105 \mathrm{kip}(467 \mathrm{kN})$, flexural-shear cracks started to develop in the beams and the lower halves of the columns. Inclined cracks developed in the beam-column joints, and horizontal cracks developed in the center column when the center column displacement approached 1.7 in $(44 \mathrm{~mm})$, with the load approaching $150 \mathrm{kip}(667 \mathrm{kN})$. Splitting cracks due to compression were observed in the beam near the center column at a center column displacement of about 3.1 in $(80 \mathrm{~mm})$, with a load of nearly $192 \mathrm{kip}(854 \mathrm{kN})$. Splitting cracks were also observed in the beam near the end columns at a center column displacement of about 3.8 in $(96 \mathrm{~mm})$, with a vertical load of about $200 \mathrm{kip}(890 \mathrm{kN})$. At that load, the maximum width of flexural beam cracks near the center column was 0.25 in $(6.35 \mathrm{~mm})$. Figure 4.17 (a) shows a map of the cracks that had formed at a center column displacement of $24.5 \mathrm{in}(622 \mathrm{~mm})$. 
In the beams, cracks concentrated in the beam-end zones, while some cracks developed near the reinforcement cutoff points where half of the top reinforcing bars working in tension were discontinued. In the columns, cracks were concentrated in the lower halves. The maximum crack width was approximately 0.7 in $(18 \mathrm{~mm})$. As the center column displacement was increased further, full-depth cracks appeared in the beams near the center column. After fracture of the bottom layer reinforcement, wide gaps were visible in the beams near the center column and at the reinforcement cutoff points. Full-depth cracks were also visible at the middle segments of the beams. Figure 4.17(b) shows a map of the final crack pattern.

(a)

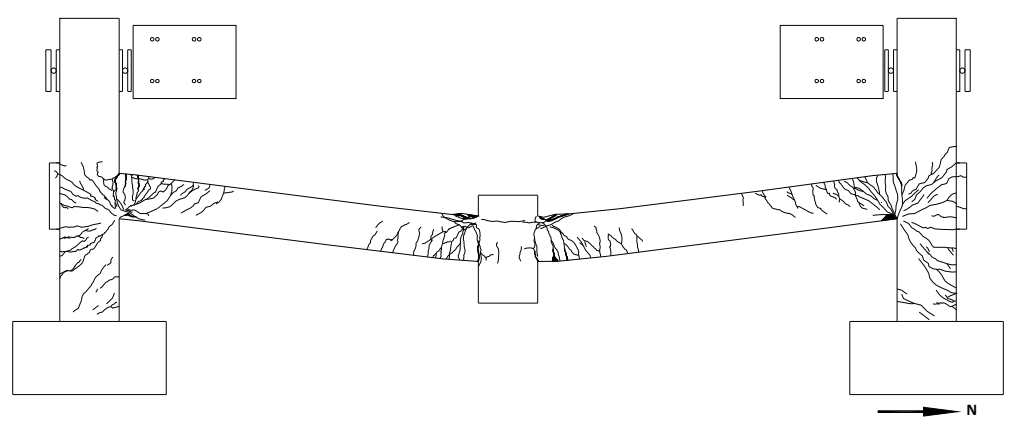

(b)

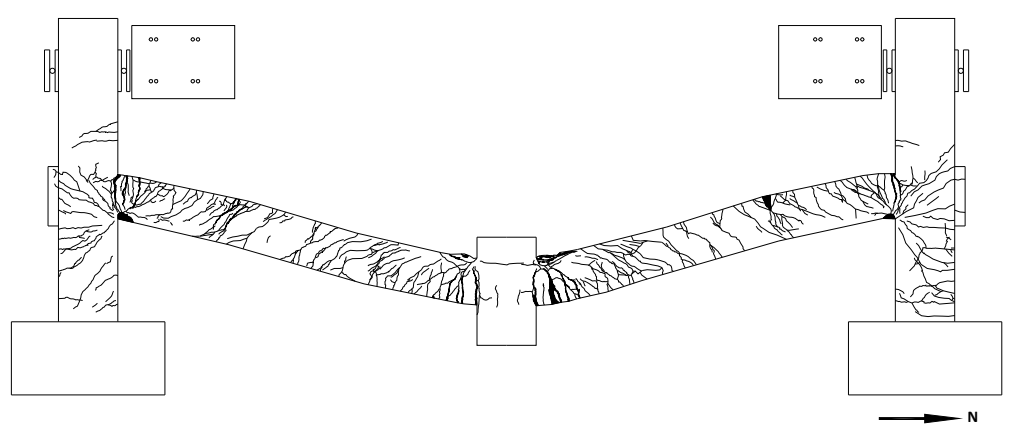

Figure 4.17 Crack patterns of SMF specimen at center column deflections of (a) 24.5 in (622 mm) and (b) 48 in $(1219 \mathrm{~mm})$.

\subsubsection{Displacement Measurements}

The plots in Figure 4.18 show the vertical load versus vertical displacements at (a) $1 / 4$ span of the beams (ENC0 and ENC7), (b) mid-span of the beams (ENC1 and ENC6), (c) $3 / 4$ span of the beams (ENC2 and ENC5), and (d) the center column (ENC3 and ENC4). The locations of the position transducers were shown in Figure 3.12. As the plots indicate, the specimen was slightly unloaded when the hydraulic rams were halted every 2.5 in to $3.0 \mathrm{in}(64 \mathrm{~mm}$ to $76 \mathrm{~mm})$ to take measurements and photographs. The pairs of load-displacement curves are nearly the same in each of the four plots in Figure 4.18, which indicates that symmetry was largely maintained during the experiment. In subsequent plots, the average of ENC3 and ENC4 is used to represent the vertical displacement of the center column. 

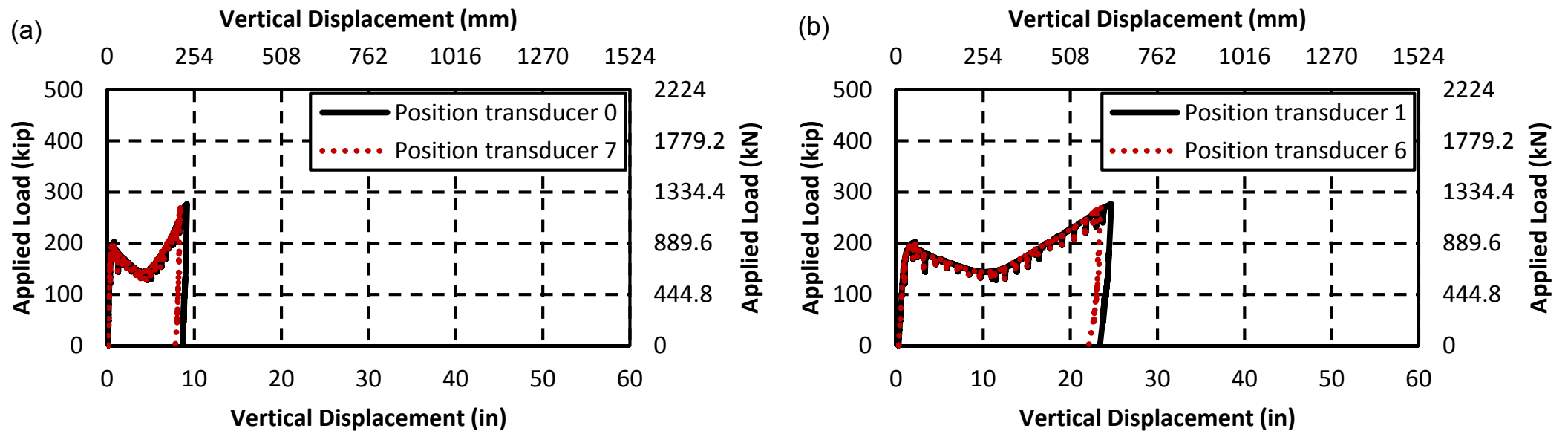

(c) Vertical Displacement (mm)
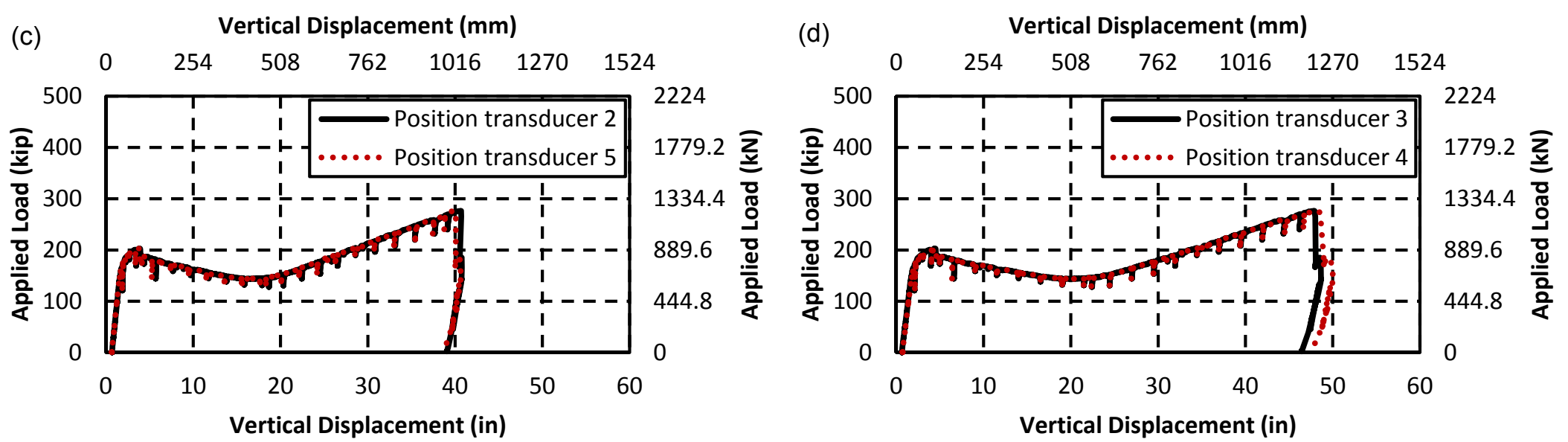

Figure 4.18 Vertical load versus vertical displacements of SMF specimen at (a) $1 / 4$ span of beams (ENC 0 and ENC 7), (b) mid-span of beams (ENC 1 and ENC 6), (c) $3 / 4$ span of beams (ENC 2 and ENC 5), and (d) center column (ENC 3 and ENC 4) 
Figure 4.18(d) indicates that the load reached an initial peak of $203 \mathrm{kip}(903 \mathrm{kN})$ at a center column displacement of 4.4 in $(112 \mathrm{~mm})$. The load started to decrease as the vertical displacement increased further. At the time that the initial peak load was reached, a northward movement of the north footing was detected (see Figure 4.19). The footing initially moved approximately 0.25 in $(6.4 \mathrm{~mm})$. As the displacement of the center column increased up to 20 in $(508 \mathrm{~mm})$, additional northward movement of the footing was observed. When the load was $144 \mathrm{kip}(641 \mathrm{kN})$, the movement of the north footing stopped, reaching a maximum northward displacement of about 0.77 in $(19.6 \mathrm{~mm})$. The vertical load reached a maximum of $277 \mathrm{kip}$ $(1232 \mathrm{kN})$ at a center column displacement of 48 in $(1219 \mathrm{~mm})$, when one of the outermost bottom bars near the north face of the center column fractured (see Figure 4.16). All bottom layer bars ruptured instantaneously as additional displacement of the center column was attempted.

Figure 4.20 depicts the deflection profile of the beams (ENC0 through ENC7, see Figure 3.12) at different load values. In the figure, dotted lines are used to connect the measured deflections, while it is noted that straight lines do not accurately represent the deflected shape of the beams.

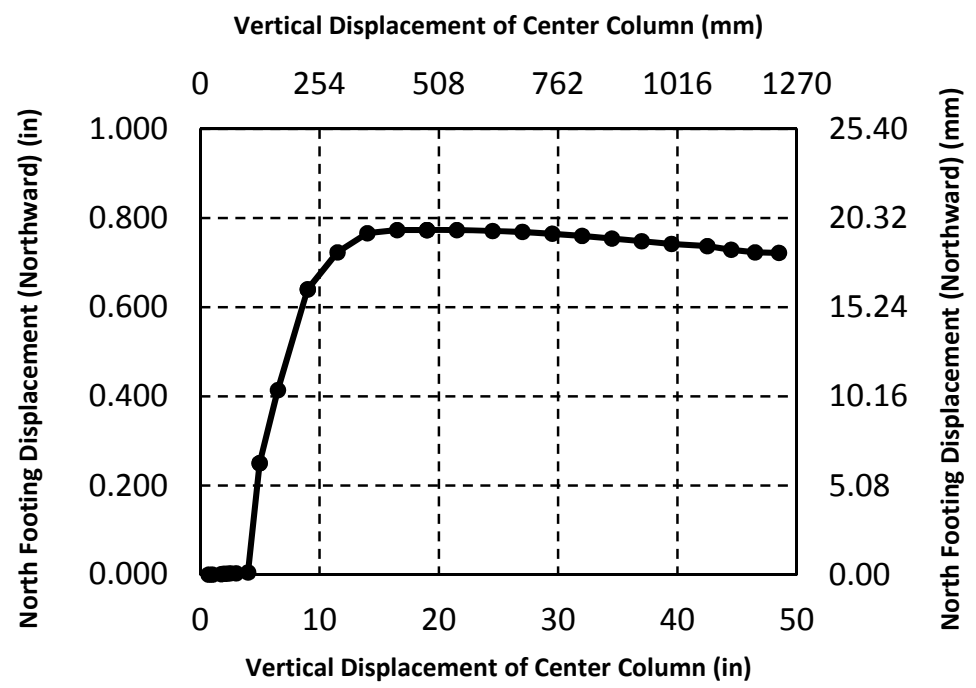

Figure 4.19 North footing displacement versus vertical displacement of center column 


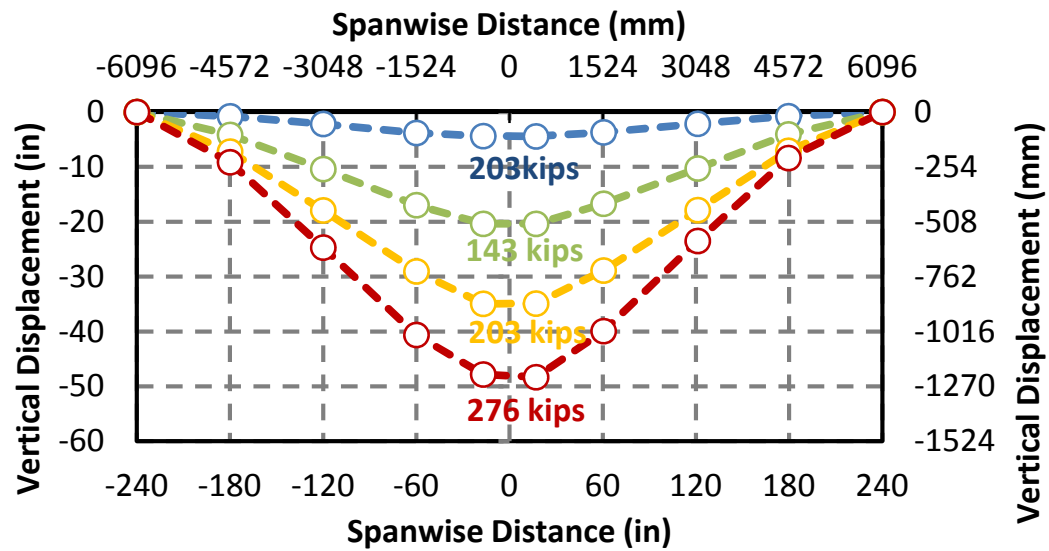

Figure 4.20 Vertical deflection profiles of beams corresponding to indicated vertical loads for SMF specimen

The plots in Figure 4.21 show the horizontal movement at the tops of the end columns (SCOL T and NCOL T, see Figure 3.12), where the rollers were placed to restrain the movement, and at the beam mid-height (SCOL M and NCOL M, see Figure 3.12) versus the vertical displacement of the center column. In the plots, positive values represent inward movement of the end columns. Due to the horizontal movement of the north footing, horizontal displacements of the north column were larger than those of the south column. The maximum outward displacements at the top and beam mid-height of the south column were about $0.13 \mathrm{in}(3.3 \mathrm{~mm})$ and 0.29 in $(7.4 \mathrm{~mm})$, respectively. When the north footing started to move, the displacements of the south column ceased to increase while the displacements at the top and beam mid-height of the north column continued to increase. The maximum outward displacements at the top and beam midheight of the north column were about $0.15 \mathrm{in}(3.8 \mathrm{~mm})$ and 0.71 in $(18.0 \mathrm{~mm})$, respectively. As the vertical displacement of the center column increased, the end columns tended to be pulled inward due to catenary action. The south column at the beam mid-height was pulled inward (toward the center column) about 0.1 in $(2.5 \mathrm{~mm})$ relative to the original position, whereas the north column at the beam mid-height was pushed outward (away from the center column) about $0.23 \mathrm{in}(5.8 \mathrm{~mm})$ due to the movement of the north column footing.

\subsubsection{Rotation Measurements}

Figure 4.22(a) shows the vertical load plotted against the rotations measured at the beam ends near the north and south columns (inclinometers NN INC and SS INC, respectively, see Figure 3.12), while Figure 4.22(b) shows the vertical load plotted against the rotations measured at the beam ends near the north and south sides of the center column (NM INC and SM INC, respectively, see Figure 3.12). Rotations of the north and south beams matched closely until the final stages of loading. The average of the two rotation measurements at the beam ends near the end columns (NN INC and SS INC) at failure was about $0.183 \mathrm{rad}\left(10.5^{\circ}\right)$, and the average of the two rotation measurements at the beam ends near the center column (NM INC and SM INC) at failure was about $0.195 \mathrm{rad}\left(11.2^{\circ}\right)$. Figure 4.23 presents the measured rotations of the beam ends versus the vertical displacement of the center column. The rotations were essentially linearly 
proportional to the vertical displacement of the center column until the displacement reached 30 in $(762 \mathrm{~mm})$.

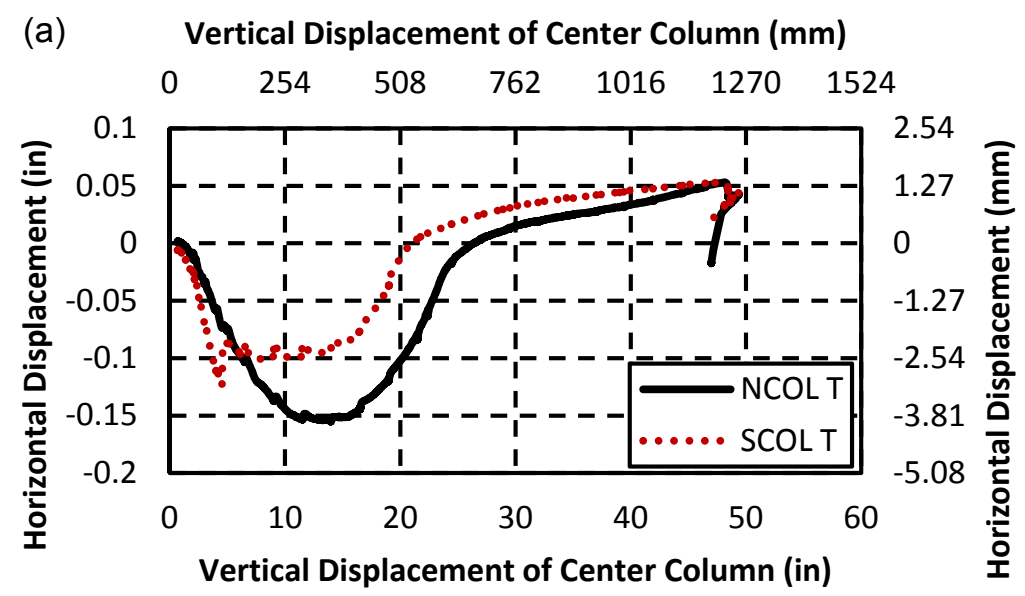

(b) Vertical Displacement of Center Column (mm)
$\begin{array}{lllllll}0 & 254 & 508 & 762 & 1016 & 1270 & 1524\end{array}$

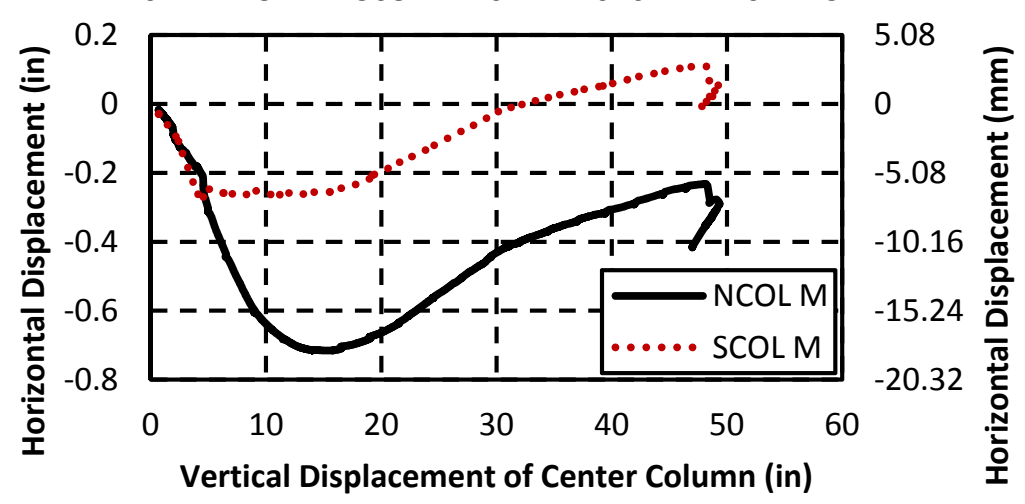

Figure 4.21 Horizontal displacement of end columns at (a) top (SCOL T, NCOL T), and (b) beam midheight (SCOL M, NCOL M) versus vertical displacement of center column for SMF specimen 

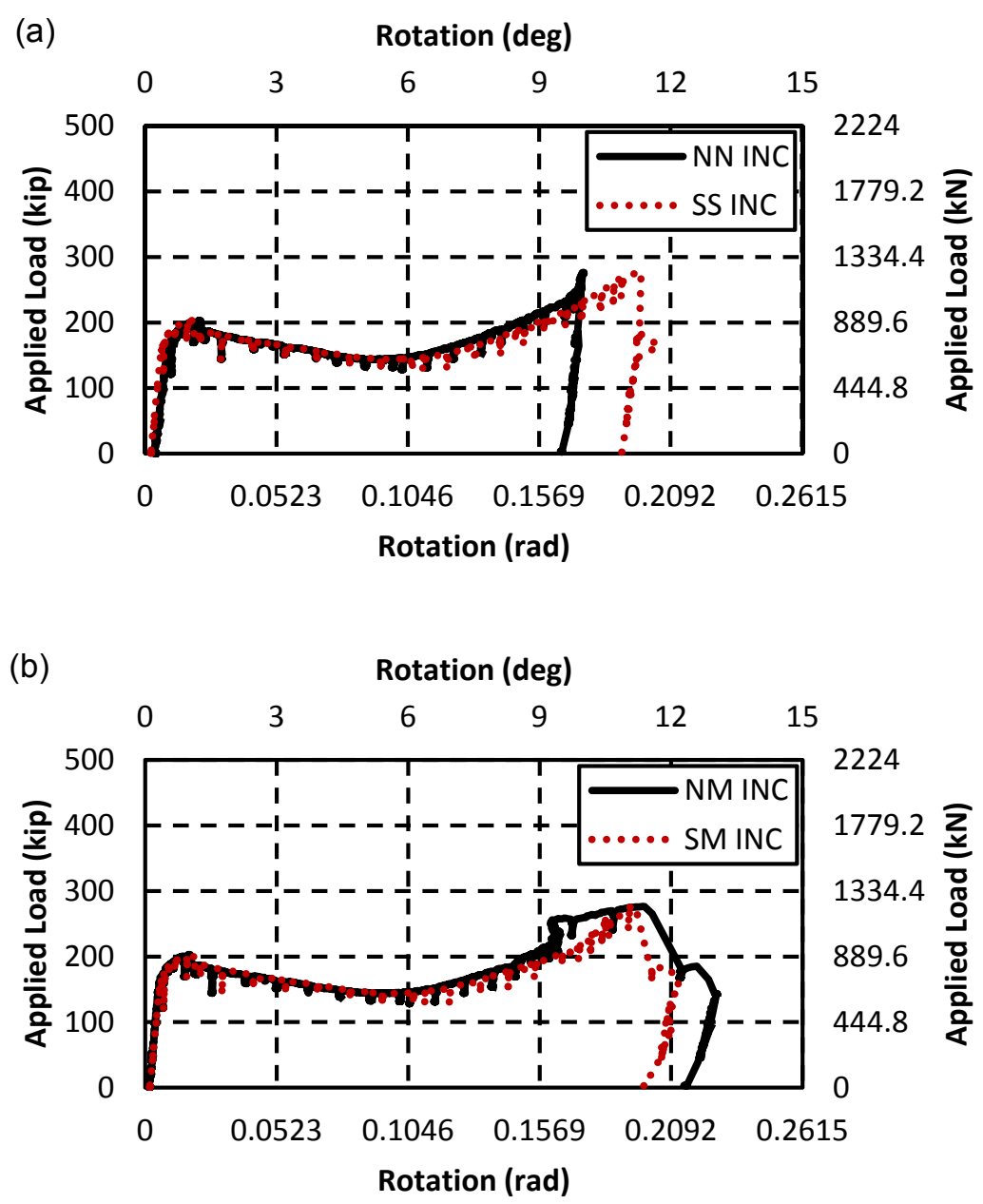

Figure 4.22 Vertical loads versus beam end rotations for SMF specimen: (a) near end columns and (b) near center column 
(a) Vertical Displacement of Center Column ( $\mathrm{mm}$ )

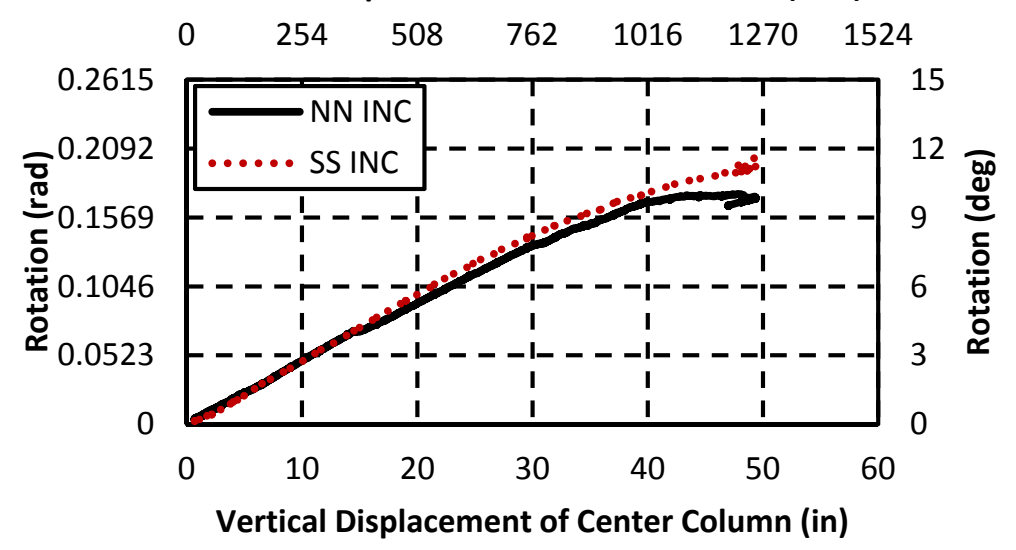

(b)

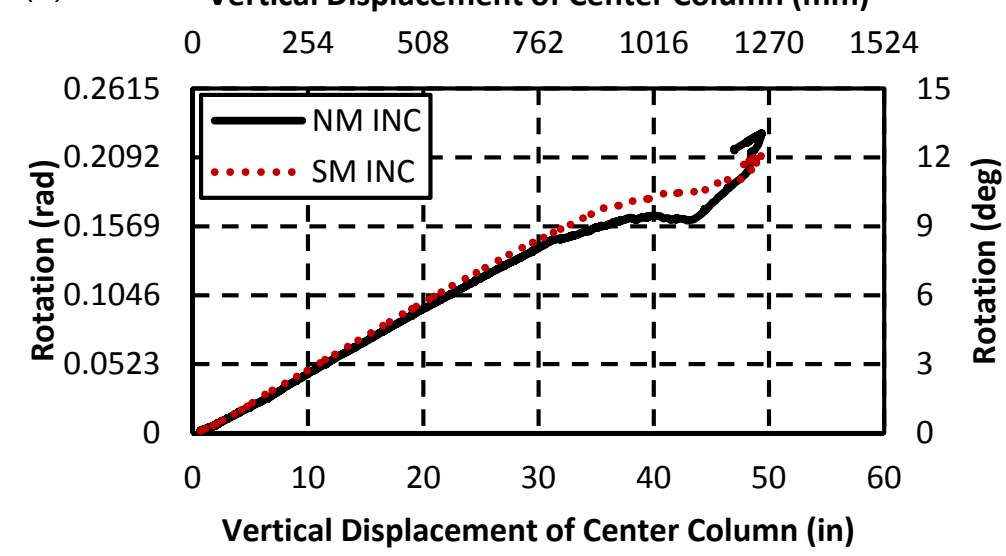

Figure 4.23 Beam end rotation versus vertical displacement of center column for SMF specimen: (a) near end columns and (b) near center column

\subsubsection{Strain Measurements}

Concrete surface strains were estimated using Whittemore gage readings which recorded the relative displacement between the targets cemented on the concrete surface as shown in Figure 4.24(a). The horizontal gage length between the Whittemore gage targets was 8 in $(203 \mathrm{~mm})$, and the vertical spacing was 10 in $(254 \mathrm{~mm})$. Reinforcing bar strains were measured by electrical resistance strain gages attached to steel bars embedded into concrete. The strain gage locations are shown in Figure 4.24(b). In the figure, the cross sections where strain gages were installed are labeled as S1 through S3 in the south column, N1 through N3 in the north column, and B1 through B10 in the beams.

Gages at Sections B3 and B8 provide information about the reinforcement strains at mid-span of the beams. Figure 4.25 shows negative (compressive) strains in both top and bottom reinforcing 
bars before the vertical displacement exceeded 25 in $(635 \mathrm{~mm})$, which indicates that a compressive axial force had developed in the beams. The transition of beam axial forces from compression to tension occurred as the vertical displacement of the center column increased from 25 in $(635 \mathrm{~mm})$ to 30 in $(762 \mathrm{~mm})$. Positive (tensile) strain in all reinforcements at the midspan sections indicates the development of catenary action in the beams as the vertical displacement of the center column exceeded 30 in $(762 \mathrm{~mm})$. When the vertical displacement of the center column exceeded 30 in $(762 \mathrm{~mm})$, reinforcement strains at sections B3 and B8 exceeded the nominal yield strain of the steel (0.002) in tension. Enlargements of the strain development in the early stages of loading are shown on the right hand side of the plots.

Gages at Sections S1 and N1 provided information about the reinforcement strains at the base of the end columns. Figure 4.26(a) shows strains in the longitudinal reinforcing bars located near the interior face at these sections, indicating that these bars were all in tension initially and gradually changed to compression after reaching a peak tensile strain. On the other hand, Figure 4.26(b) shows that the reinforcing bars near the outer face were in compression initially and gradually changed to tension. These sign changes in the measured strains indicate a reversal of the in-plane curvature of the end columns, which was associated with the development of tensile axial forces in the beams due to catenary action. A sudden drop in strain was observed in each plot when the vertical displacement was close to 4.4 in $(112 \mathrm{~mm})$, which was due to the movement of the north footing. Some of the exterior reinforcing bars at Sections S1 and N1 yielded in tension, with strains exceeding the nominal yield strain of the steel (0.002) at a center column displacement of about 30 in $(762 \mathrm{~mm})$.

At sections B1 and B10, strain readings on the top reinforcing bars exceeded the nominal yield strain (0.002) in tension at a vertical displacement of the center column of about 2 in $(51 \mathrm{~mm})$. Soon after the vertical displacement exceeded about 5 in $(127 \mathrm{~mm})$, these gages failed. Strains in the outermost bottom layer of reinforcement at Sections B1 and B10 exceeded the nominal yield strain in compression at a center column displacement of about 4 in $(102 \mathrm{~mm})$, while positive (tensile) strains were measured for reinforcements located in the second bottom layer. Strain measurements on the reinforcing bars located in the outermost bottom layer at Sections B5 and B6 exceeded the nominal yield strain in tension at a vertical displacement of about 1.5 in $(38 \mathrm{~mm})$. The maximum recorded tensile strain was about 0.007 at gage W5B when the vertical displacement of the center column was close to 40 in $(1016 \mathrm{~mm})$. Strains in the reinforcements located in the outermost top layer exceeded the nominal yield strain in compression at a vertical displacement of about 3 in $(76 \mathrm{~mm})$. The maximum recorded compressive strain was about 0.004 at gage E5T when the vertical displacement of the center column was close to $10 \mathrm{in}(254 \mathrm{~mm})$. Positive (tensile) strains were measured for reinforcements located in the second top layer. Most gages at sections B1 and B10 stopped working before the deflection reached 10 in $(254 \mathrm{~mm})$.

Strain gage measurements at bar-cutoff sections (B2, B4, B7, and B9) are presented in Figure 4.27. The strain measurements at bar-cutoff sections B2 and B9 show that the top reinforcing bars yielded in tension when the bottom reinforcing bars were still in compression. Similarly, at bar-cutoff sections B4 and B7, the bottom reinforcing bars yielded in tension when the top reinforcements were still in compression. This spreading of yielding in the longitudinal bars is the reason that the displacement profile in Figure 4.20 exhibits curvature along the beam spans, rather than consisting simply of straight line segments between plastic hinges at the beam ends. 
(a)

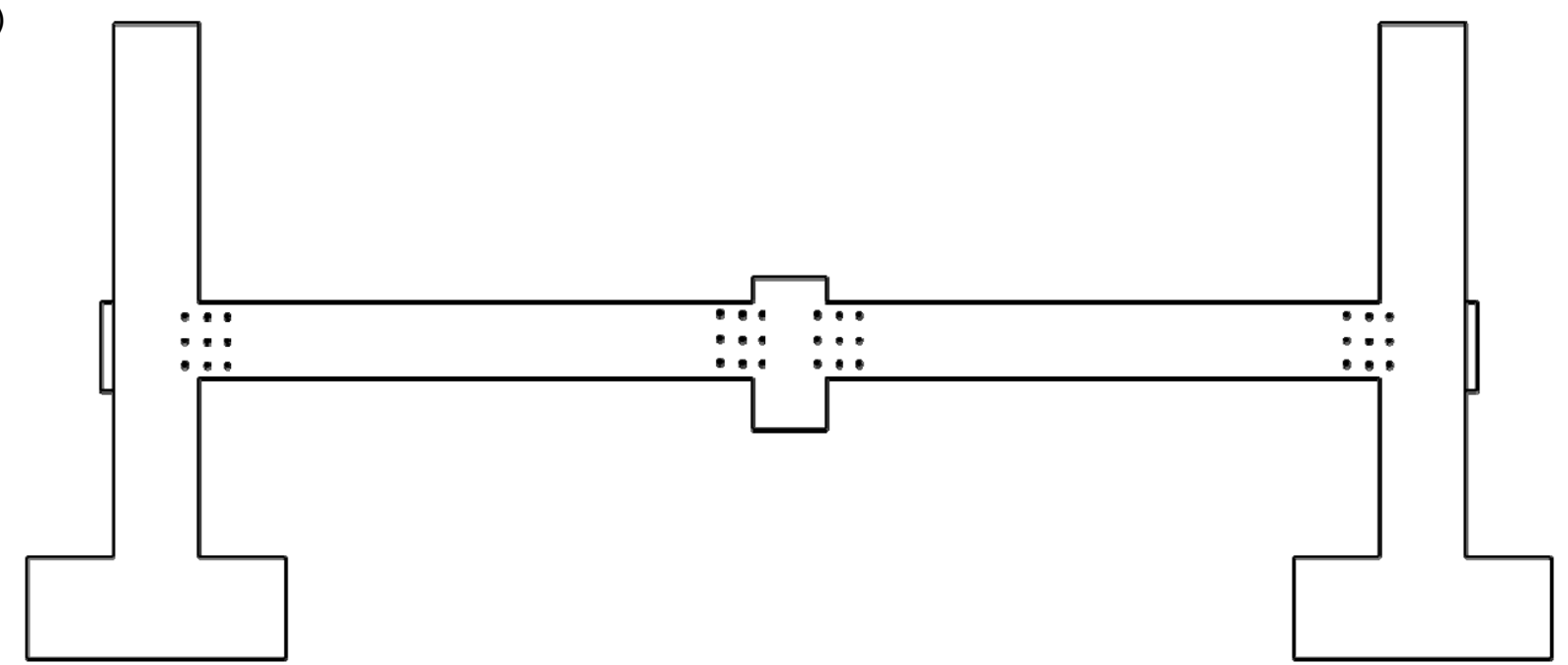

(b)

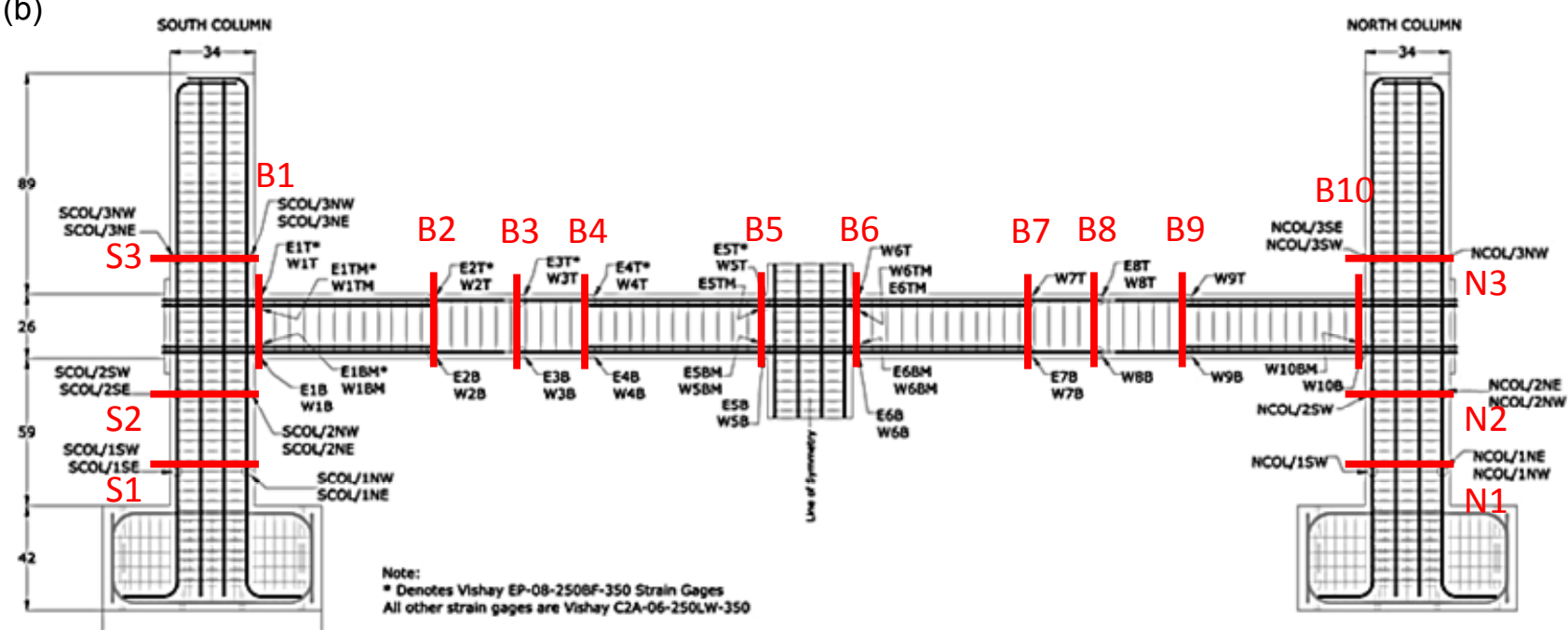

Figure 4.24 Stain measurements for SMF specimen: (a) Whittemore gage target locations and (b) reinforcing bar strain gage locations 
(a) Vertical Displacement of Center Column (mm)
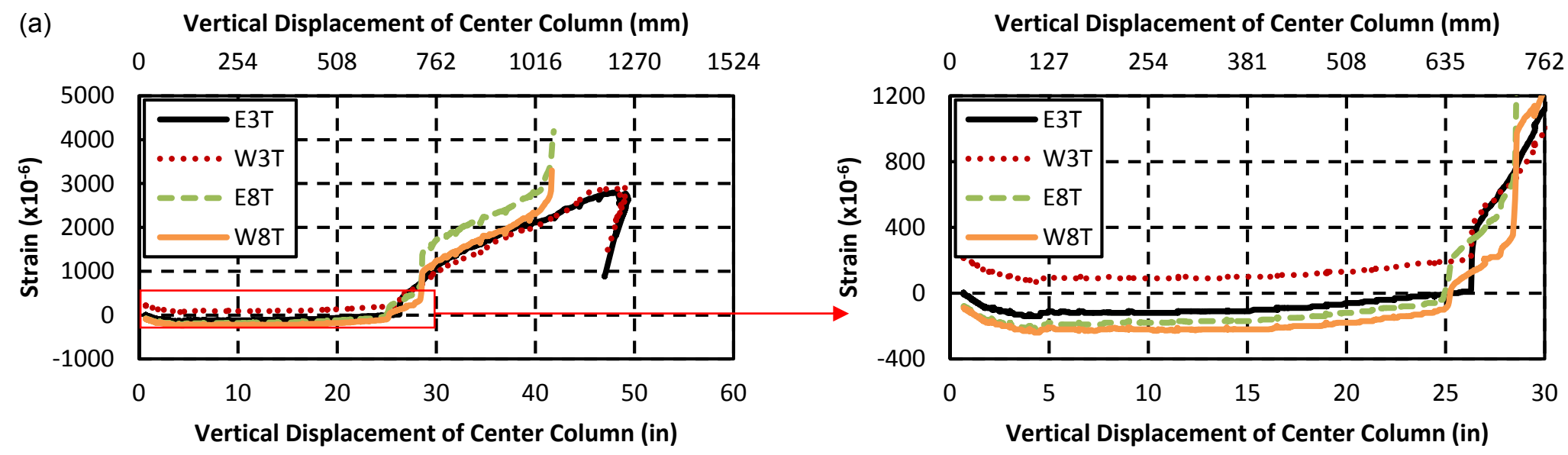

(b)
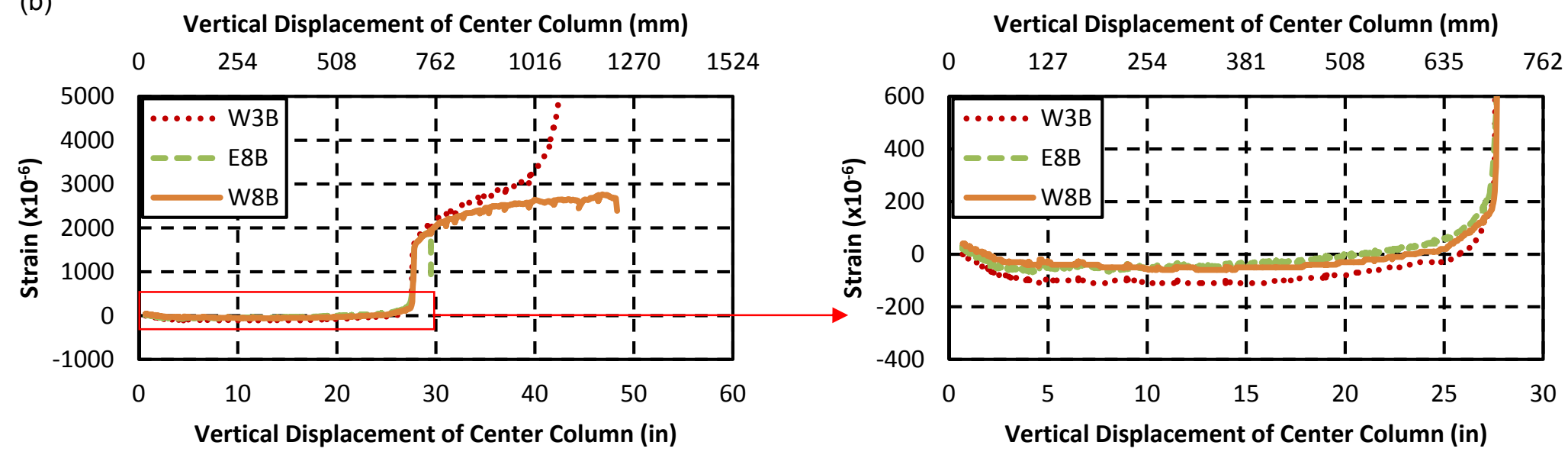

Figure 4.25 Mid-span (Sections B3 and B8) strain gage measurements versus vertical displacement of center column for SMF specimen: (a) top reinforcing bars and (b) bottom reinforcing bars 
(a) Vertical Displacement of Center Column ( $\mathrm{mm}$ )

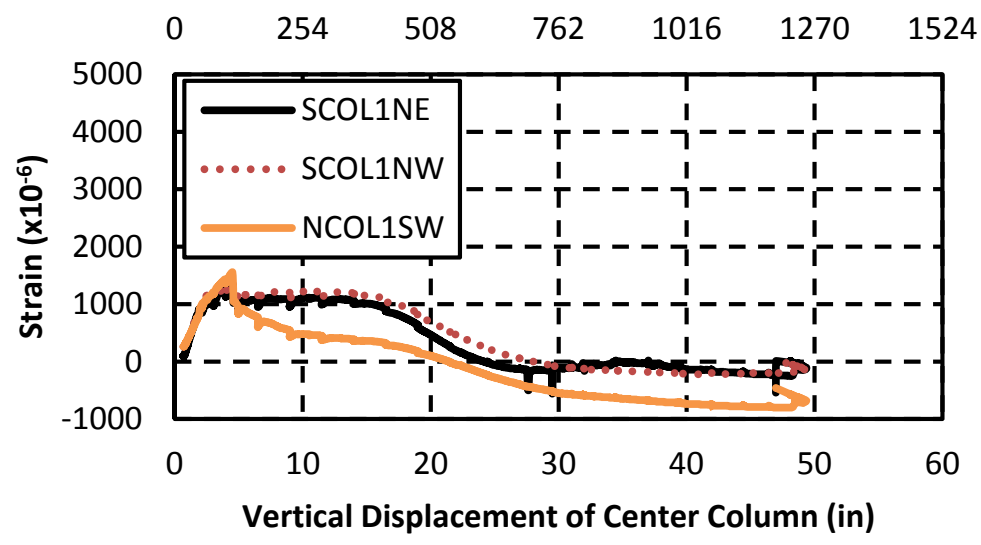

(b)

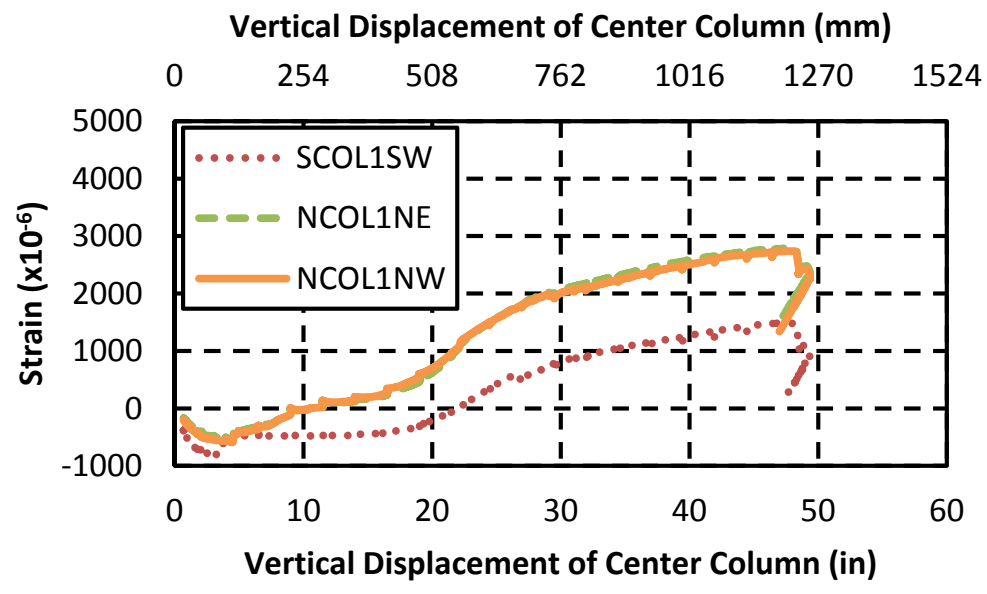

Figure 4.26 Column reinforcement strains at sections S1 and N1 versus vertical displacement of center column for SMF specimen: (a) interior reinforcing bars and (b) exterior reinforcing bars 
(a)

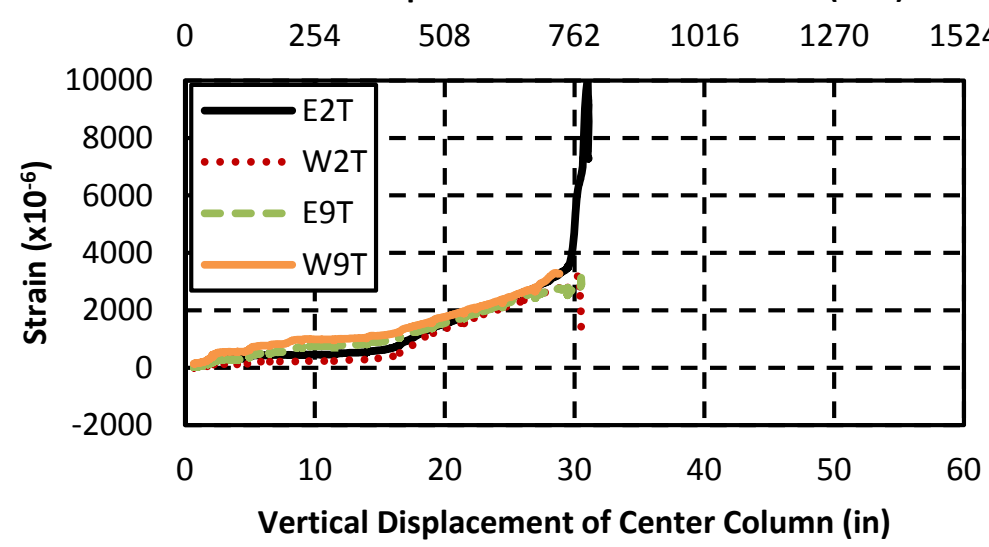

(c)

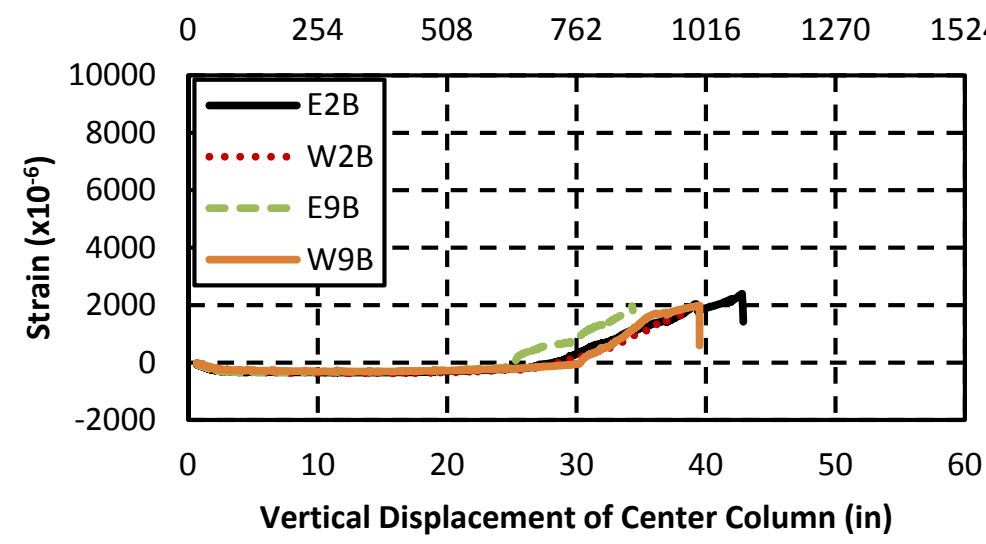

(b)

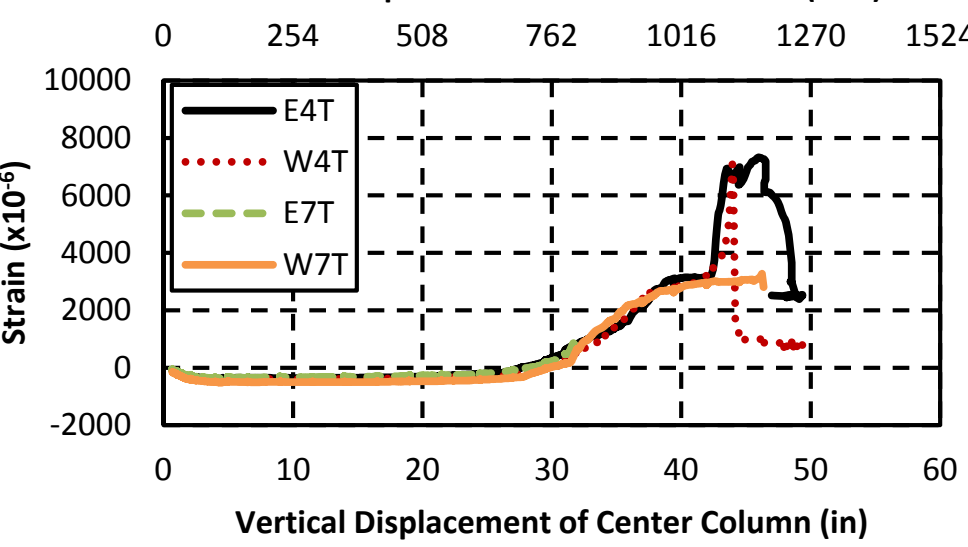

(d)

\section{Vertical Displacement of Center Column ( $\mathrm{mm}$ )}

$\begin{array}{lllllll}0 & 254 & 508 & 762 & 1016 & 1270 & 1524\end{array}$

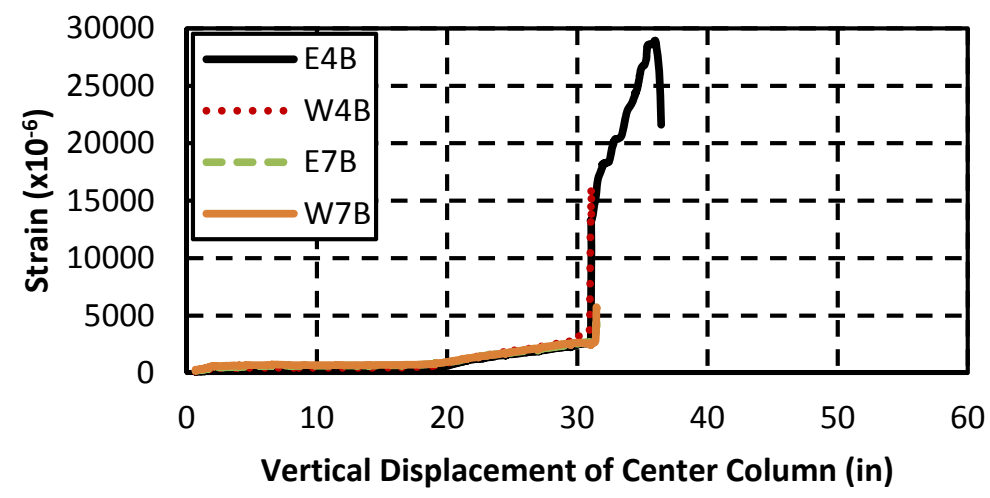

Figure 4.27 Beam reinforcement strains at bar-cutoff sections versus vertical displacement of center column for SMF specimen: (a) top bars at sections B2 and B9, (b) top bars at sections B4 and B7, (c) bottom bars at sections B2 and B9, and (d) bottom bars at sections B4 and B7 
Plots of concrete surface strain measurements along beam-end sections near the end columns are presented in Figure 4.28. Strain distributions correspond to applied vertical loads of $150 \mathrm{kip}$, $200 \mathrm{kip}, 182 \mathrm{kip}, 163 \mathrm{kip}$, and $145 \mathrm{kip}(667 \mathrm{kN}, 890 \mathrm{kN}, 810 \mathrm{kN}, 725 \mathrm{kN}$, and $645 \mathrm{kN})$. These loads correspond to center column vertical displacements of $1.7 \mathrm{in}, 4.0 \mathrm{in}, 6.5 \mathrm{in}, 11.5 \mathrm{in}$, and $21.5 \mathrm{in}(43 \mathrm{~mm}, 102 \mathrm{~mm}, 165 \mathrm{~mm}, 292 \mathrm{~mm}$, and $546 \mathrm{~mm})$. In these figures, enlargements of the cross sectional strain distributions during the early stage of loading are shown on the right-hand side of the plots. Similar plots are shown in Figure 4.29 for the beam-end sections near the center column. In Figure 4.28, the neutral axis was shifted to the tension side in the initial stages of loading. This verified the presence of compressive axial forces in the beams. Due to crushing of concrete at the beam ends, not enough data were obtained to characterize the strain distribution after the vertical displacement exceeded 21.5 in $(546 \mathrm{~mm})$.

(a)

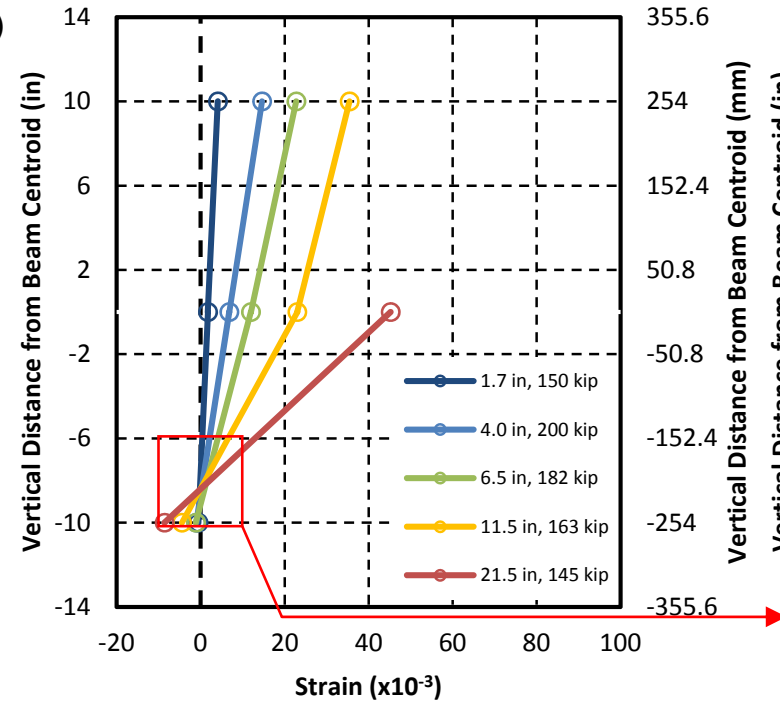

(b)

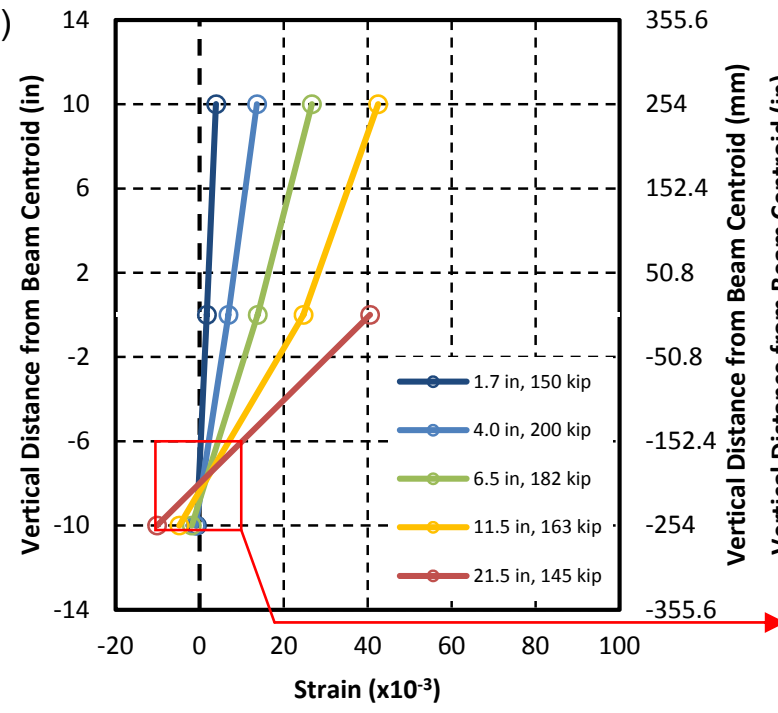

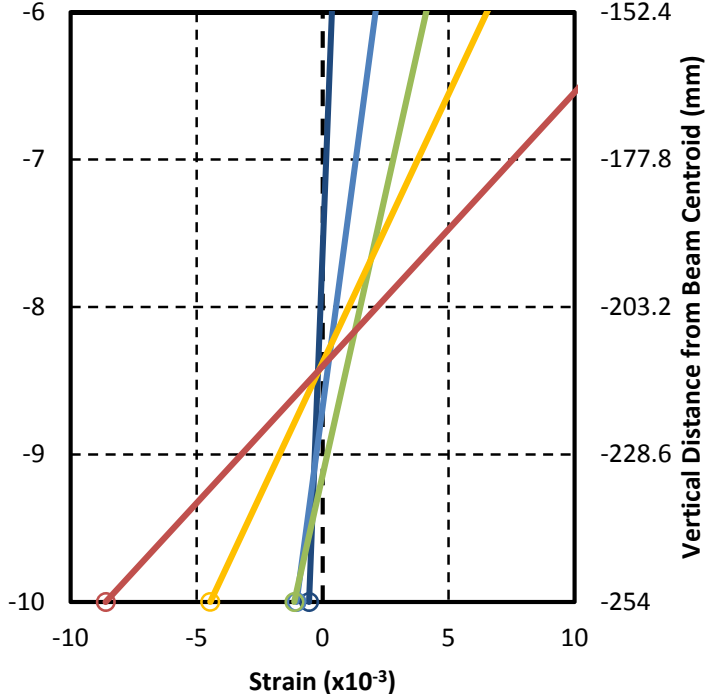

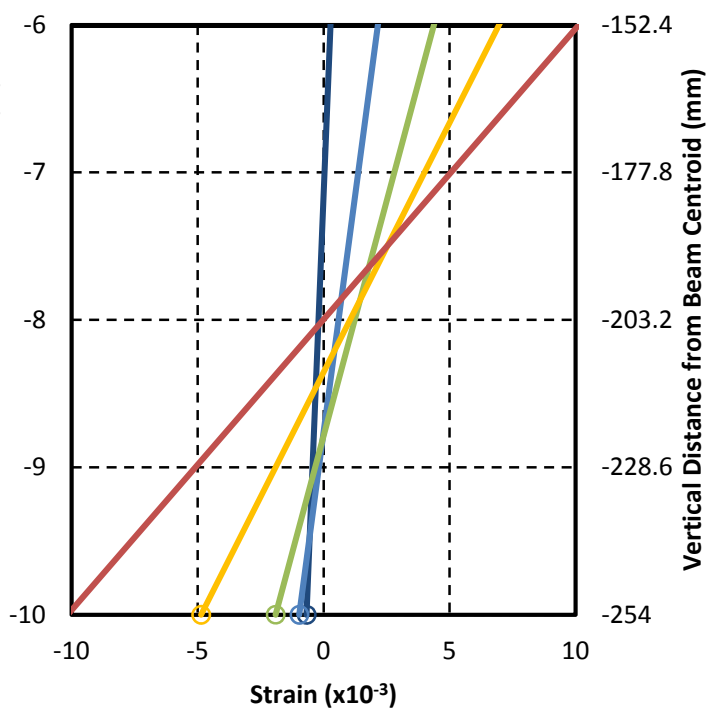

Figure 4.28 Concrete surface strain distributions of SMF specimen at beam ends: (a) near north end column and (b) near south end column 
(a)
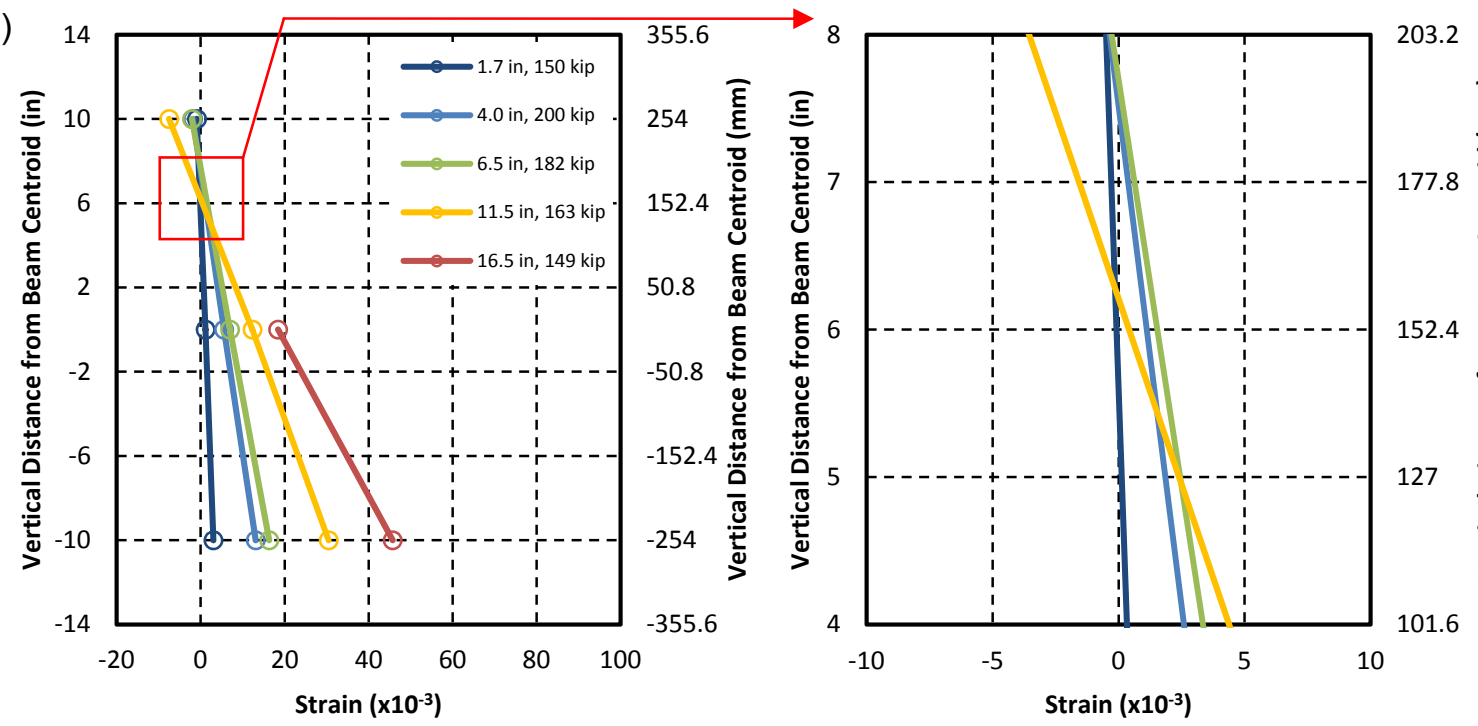

(b)

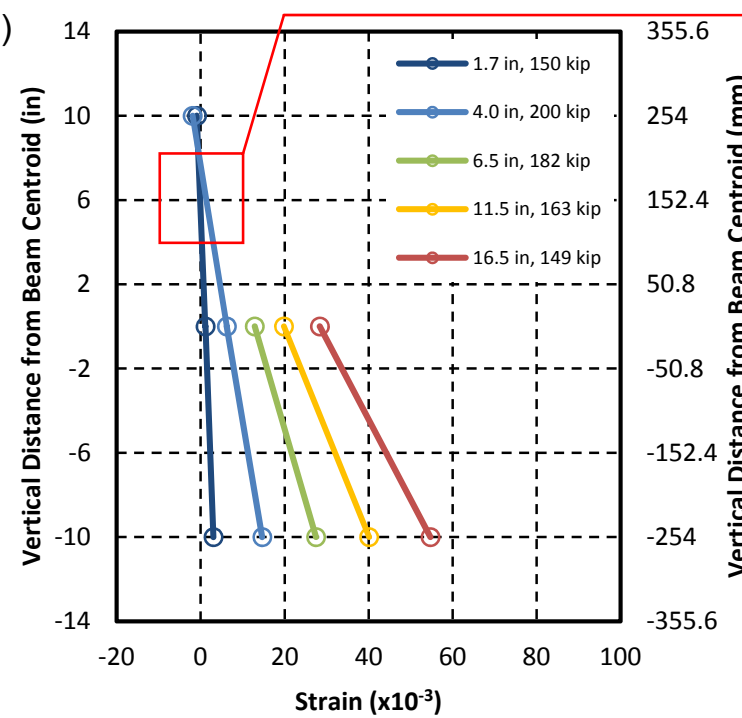

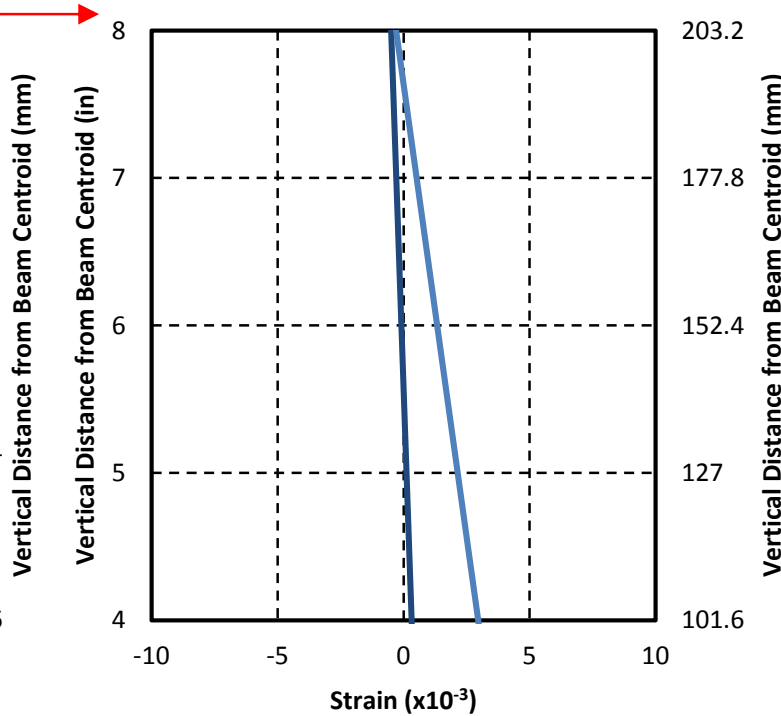

Figure 4.29 Concrete surface strain distributions of SMF specimen at beam ends: (a) near north side of center column and (b) near south side of center column

\subsection{SUMMARY AND DISCUSSION OF TEST RESULTS}

This chapter presented the experimental results of two reinforced concrete beam-column assemblies tested under a simulated column removal scenario. The assemblies represented portions of the moment resisting frames of two ten-story prototype buildings designed and detailed in accordance with the ACI 318 requirements for Seismic Design Category (SDC) C and SDC D. For the lateral force resisting system, intermediate moment frames (IMFs) and special moment frames (SMFs) were selected for the SDC C and D buildings, respectively. The center 
column of each three-column assembly was subjected to monotonically increasing downward vertical displacement until failure. The experimental results included the photographic documentation of crack formation and modes of failure, as well as response measurements taken using various instruments. The instruments used were displacement transducers, inclinometers, position transducers, strain gages, an Optotrak coordinate measurement system, Whittemore gages, dial gages, and load cells.

For both the IMF and SMF specimens, minor flexural cracks developed in the beams during the early stages of loading. However, these cracks did not cause a significant decrease in the overall stiffness of the beams. This was due to the restraint to horizontal movements of the beams provided by the end columns, which induced the development of arching action in the beams. Similar behavior was previously observed in axially restrained two-span beam tests ( $\mathrm{Su}$ et al. 2009). Pronounced degradation of the beam stiffness was observed in both specimens when yielding of the beam bottom reinforcing bars near the center column and the top reinforcing bars near the end columns commenced. As a result, while the rate of vertical displacement of the center column remained constant, the load level increased gradually at a lower rate. For the IMF specimen the load reached a peak value of $66.5 \mathrm{kip}(296 \mathrm{kN})$ with a corresponding center column displacement of about 5 in $(127 \mathrm{~mm})$, and for the SMF specimen the load reached a peak value of $203 \mathrm{kip}(903 \mathrm{kN})$ with a corresponding center column displacement of about 4.4 in $(112 \mathrm{~mm})$. For both specimens, after reaching the initial peak load, the load began to drop with increasing vertical displacement of the center column. The load leveled off and started to increase again when the vertical displacement of the center column exceeded the depth of the beam. Catenary forces developed in the beams as full-depth cracks developed. The catenary force development was evidenced by tensile strains in both top and bottom reinforcing bars at mid-span of the beams. Both specimens failed due to fracture of beam-bottom reinforcing bars near the center column at an ultimate load greater than the initial peak load reported above. The ultimate load of the IMF specimen was $123 \mathrm{kip}(547 \mathrm{kN})$, with a corresponding center column displacement of 43.0 in $(1092 \mathrm{~mm})$, while the ultimate load of the SMF specimen was 277 kip $(1232 \mathrm{kN})$, with a corresponding center column displacement of $48.0 \mathrm{in}(1219 \mathrm{~mm})$. The ultimate load of the SMF specimen was thus 2.25 times greater than that of the IMF specimen, reflecting the more stringent seismic design and detailing of the SMF specimen. However, the ultimate load of the IMF specimen exceeded the initial peak load by a factor of 1.85 , whereas the ultimate load of the SMF specimen exceeded the initial peak load by a factor of only 1.36 .

The behavior described above can be summarized as a three-stage process (Figure 4.30): (1) an arching action stage, in which compressive arching forces developed due to horizontal restraint at the beam ends, providing additional stiffness and load-carrying capacity; (2) a plastic hinging stage, in which flexural bending caused reinforcing bars to yield in tension, and concrete to soften and crush in compression, causing a reduction in load-carrying capacity; and (3) a catenary action stage, in which tensile catenary forces were mobilized as the deflection of the center column exceeded the depth of the beam, supplying additional load-carrying capacity. While beam-end rotations continued to increase during the third stage, the overall load carrying capacity of the assembly was dominated by the development of catenary action, which prevented a further drop in load. As described above, the ultimate failure of the assemblies resulted from fracture of the bottom reinforcing bars at the beam ends near the center column. While strain measurements in the top and bottom reinforcing bars show that yielding did occur even at mid- 
span of the beams, fracture of the reinforcing bars occurred only near the center column. These fractures occurred due mainly to concentrated rotation of the beams near the beam-column interface (see Figures 4.1, 4.2, 4.15 and 4.16). The results of these tests suggest that the rotational capacity of concrete beams at the beam-column joints controls the development of catenary (or tensile) forces.

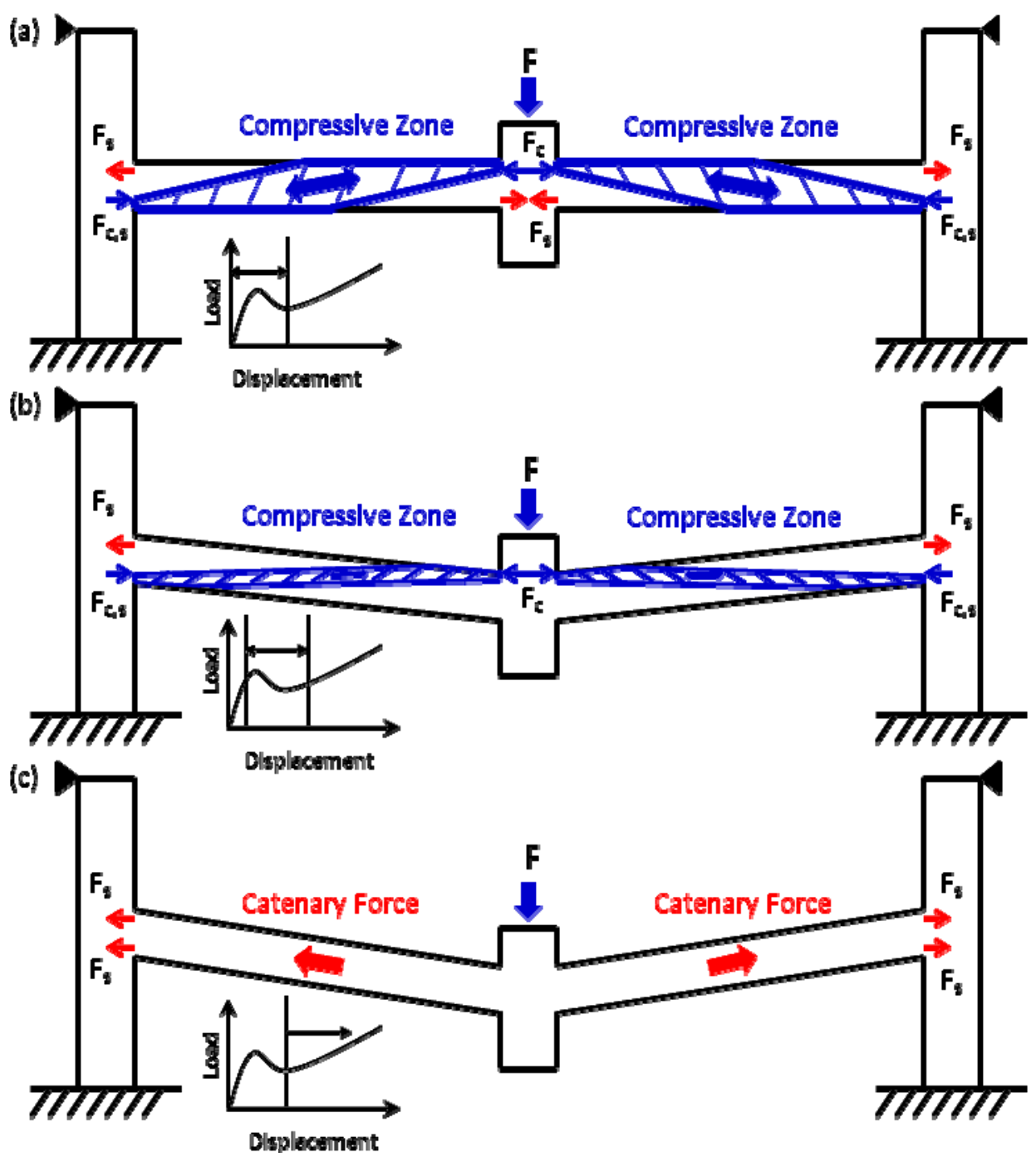

Figure 4.30 Three stages of load transfer: (a) arching action, (b) plastic hinge formation, and (c) catenary action ( $F_{s}$ : force in steel, $F_{c}$ : force in concrete, $F_{c, s}$ : force in concrete and steel)

Table 4.1 summarizes the rotational capacities based on the tests conducted in this study and on ASCE/SEI 41-06 (ASCE 2006), which is based on prior seismic test data (FEMA 2000). As the table indicates, the rotations at peak load based on the experimental results in this study were about 0.185 rad for the IMF specimen, corresponding to a center column displacement of 44.5 in $(1130 \mathrm{~mm})$ at failure, and $0.200 \mathrm{rad}$ for the SMF specimen, corresponding to a center column displacement of 48.0 in $(1219 \mathrm{~mm})$ at failure. These values are obtained by dividing the center 
column displacement at failure by the centerline-to-centerline beam span of 240.0 in (6096 mm). The permitted plastic rotation angles (or rotation capacities) of the IMF and SMF beam columncolumn-joint assemblies based on seismic testing data are $0.026 \mathrm{rad}$ and $0.025 \mathrm{rad}$, respectively, corresponding to the collapse prevention criterion according to Table 6-7 of ASCE/SEI 41-06 (ASCE 2006). These results show that the rotational capacities of these beam-column-joints under monotonic column displacement are about 7 8 times as large as those based on seismic test data generated under cyclic loading condition. This difference may be attributed to (1) degradation of strength and stiffness of the beam-column joint regions due to different loading effects, cyclic loading versus monotonic loading, and (2) the presence of large axial tension in the beams due to the development of catenary action under a column removal scenario. Thus, if the acceptance criteria based on seismic test data are used for column removal scenarios, a very conservative design of beam-column joints would result.

Table 4.1 Comparison of rotation capacities of IMF and SMF beam-column joints based on seismic data and monotonic column displacement

\begin{tabular}{|c|c|c|}
\hline \multirow{2}{*}{ Connection Type } & \multicolumn{2}{|c|}{ Rotation Capacities (rad) } \\
\cline { 2 - 3 } & $\begin{array}{c}\text { Seismic Data } \\
\text { (ASCE/SEI 41-06) }\end{array}$ & $\begin{array}{c}\text { Monotonic Loading } \\
\text { (This Study) }\end{array}$ \\
\hline IMF & 0.026 & 0.185 \\
\hline SMF & 0.025 & 0.200 \\
\hline
\end{tabular}

\subsection{REFERENCES}

American Society of Civil Engineers (ASCE). (2006). "Seismic rehabilitation of existing buildings." ASCE/SEI 41-06, Reston, VA.

Federal Emergency Management Agency (FEMA). (2000). "Prestandard and commentary for the seismic rehabilitation of buildings." FEMA 356, Washington, DC.

Su, Y., Tian, Y., and Song, X. (2009). "Progressive collapse resistance of axially-restrained frame beams." ACI Structural Journal, 106(5), 600-607. 


\section{Chapter 5 \\ COMPUtATIONAL MOdELING AND ANALYSIS OF TeSt SPECIMENS}

\section{$5.1 \quad$ INTRODUCTION}

This chapter presents a computational study of the response of the Intermediate Moment Frame (IMF) and Special Moment Frame (SMF) reinforced concrete beam-column assemblies. The objectives of the analyses are to: (1) develop and validate detailed finite element models of the assemblies that can reproduce the behavior and failure modes of the test specimens, (2) develop and validate reduced finite element models of the assemblies that can accurately predict the response and failure modes of the test specimens, and (3) gain insight into the behavior and failure modes of moment resisting frames, including the process of member force redistribution due to loss of structural members and the development of tie forces within structural members to enhance continuity, ductility, and maintain structural integrity.

The finite element analyses presented in this study are conducted using explicit time integration in LS-DYNA (Hallquist 2007), a general-purpose finite element software package. The analyses account for both geometrical and material nonlinearities, including fracture using element erosion. In all analyses, the center column is pushed down under displacement control until failure occurs. Displacements are increased at a slow rate to ensure a static response (no dynamic amplification), similar to the test conditions. Comparisons between the computational and experimental results are presented to validate the detailed and reduced models developed herein.

Section 5.2 provides an overview of the material models used in the analyses. Section 5.3 presents a description of the detailed and reduced models used in this study. Section 5.4 provides the analysis results for both the IMF and SMF specimens. Section 5.5 presents a summary and discussion of the analysis results.

\subsection{MATERIAL MODELS}

\subsubsection{Reinforcement}

The primary material model used in the analyses presented in this study was an isotropic elasticplastic model (MAT_PLASTICITY_COMPRESSION_TENSION or MAT_124 in LS-DYNA). In this model, effective stress versus plastic strain curves are defined, along with a plastic strain to failure. Once the failure strain is reached, the element is eroded, simulating fracture of the steel bar. One advantage of using this model is that the compressive and tensile stress-strain curves can be defined individually, which is desirable in developing a modified stress-strain relationship incorporating bond-slip effects for the reduced models (see Section 5.2.4). While this model was developed for solid and shell elements only, it has been extended to support beam elements by the software vender for the purposes of this study. 
For various sizes of reinforcing bars used in the test specimens, the material model parameters were developed based on the engineering stress-strain curves obtained from standard tensile tests of reinforcing bars used for fabrication of the test specimens (see Chapter 3). For both the IMF and SMF specimens, the tensile tests provided data for beam longitudinal reinforcement (No. 8 and No. 9 bars), column longitudinal reinforcement (No. 9 and No. 10 bars), and ties and stirrups (No. 4 bars). Due to the lack of data for the softening branch of stress-strain curves beyond the ultimate stress, a linear descending branch of the stress-strain relationship was assumed (see Figure 5.2).

For beam elements representing reinforcing bars in the detailed models (Section 5.3.1), the engineering stress-strain curve cannot be converted directly to the true stress versus effective plastic strain curve because the cross-sectional area of the beam element remains constant (true stress $\sigma^{t}$ is equal to engineering stress $\sigma^{E}$ in this case). To determine the input curves, iterative finite element analyses of the tensile strength tests were carried out. Effective plastic strains were adjusted until quantitative agreement of the measured and calculated engineering stress-strain behavior was attained.

Figure 5.1 shows examples of finite element models of a No. 9 reinforcing bar used in the IMF specimen. The length was determined by the gage length of 8 in $(203 \mathrm{~mm})$ used in the tensile tests. In Example (a) a single beam element was used. The input curves were determined by iterative finite element analysis until a close match between the engineering stress-strain curve from the tensile strength test and from the analysis was attained as shown in Figure 5.2. The results of Examples (b) and (c) using two and four beam elements, respectively, and the same input curve used in Example (a) are also plotted in Figure 5.2. The curves agreed well with the test results except for the softening branches. Since the softening behavior was essentially associated with the necking of the bar, the beam element with constant cross-sectional area cannot capture the necking behavior. Plasticity tended to be localized in one element, which is affected by the mesh size. To avoid this type of spurious localization, the softening portion of the input stress-strain curve was adjusted based on the element size. In this manner, consistency with the experimental rupture strain can be achieved as shown in Figure 5.3.

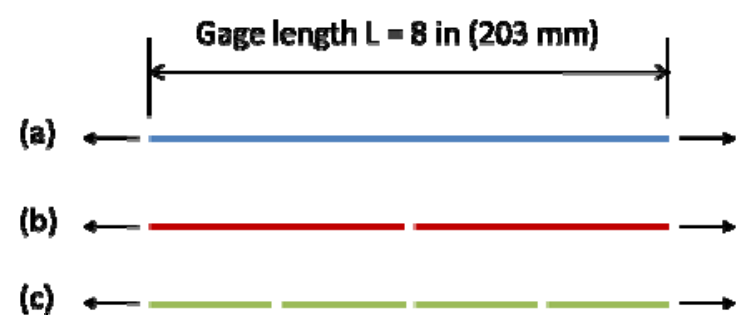

Figure 5.1 Example finite element models of No. 9 reinforcing bar: (a) beam element with 8 in (203 mm) mesh size, (b) beam element with 4 in (102 mm) mesh size and (c) beam element with 2 in (51 mm) mesh size 

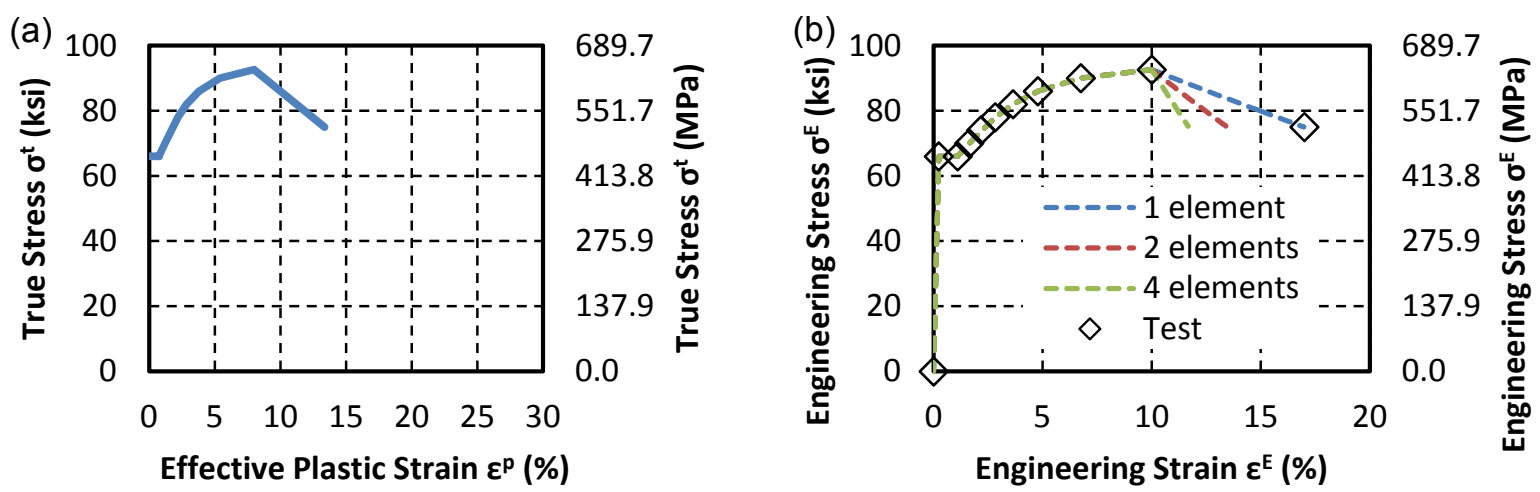

Figure 5.2 (a) Input stress-strain curve and (b) engineering stress-strain curves for a No. 9 reinforcing bar obtained from a standard tensile test and from finite element analyses using different sizes of beam elements
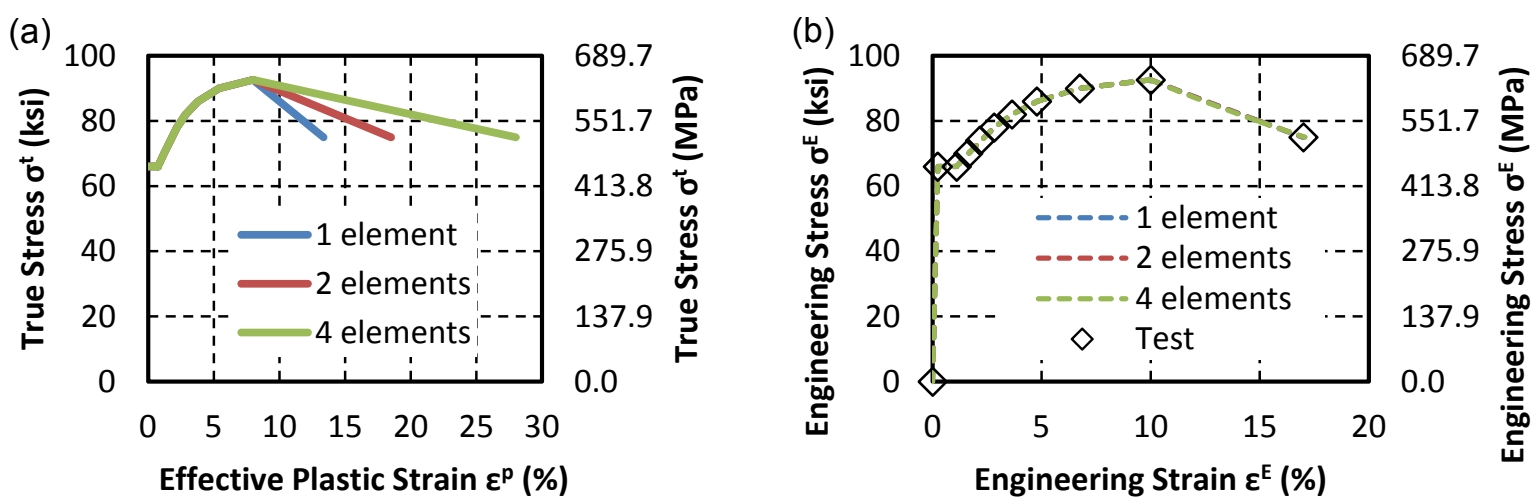

Figure 5.3 (a) Input stress-strain curves and (b) engineering stress-strain curves for a No. 9 reinforcing bar obtained from a standard tensile test and from finite element analyses using different sizes of beam elements

\subsubsection{Concrete}

For the solid elements used in the detailed models (Section 5.3.1), a continuous surface cap model (MAT_CSCM_CONCRETE or MAT_159 in LS-DYNA) was used as the material model for concrete. In this model, a smooth and continuous intersection is formulated between the failure surface and the hardening cap. The main features of the model are isotropic constitutive equations, a yield surface formulated in terms of three stress invariants with translation for prepeak hardening, a hardening cap that expands and contracts, and damage-based softening with erosion and modulus reduction. This model can capture confinement effects and softening behavior both in tension and compression. By using a regulation technique, it can achieve convergent softening behavior with reasonable mesh refinement.

To demonstrate the capability of the concrete model to handle confinement effects, a single element example is shown in Figure 5.4. Boundary conditions and load conditions are imposed to simulate a lateral confinement to the concrete element block. The element is pushed down by 
applying a controlled displacement to the top four nodes. Stress-strain curves are compared for the cases with zero confinement pressure and with 150 psi $(1034 \mathrm{kPa})$ confinement pressure.

Figure 5.4 shows that the confined concrete has higher compressive strength. More details about this model can be found in a report published by the Federal Highway Administration (FHWA 2007).

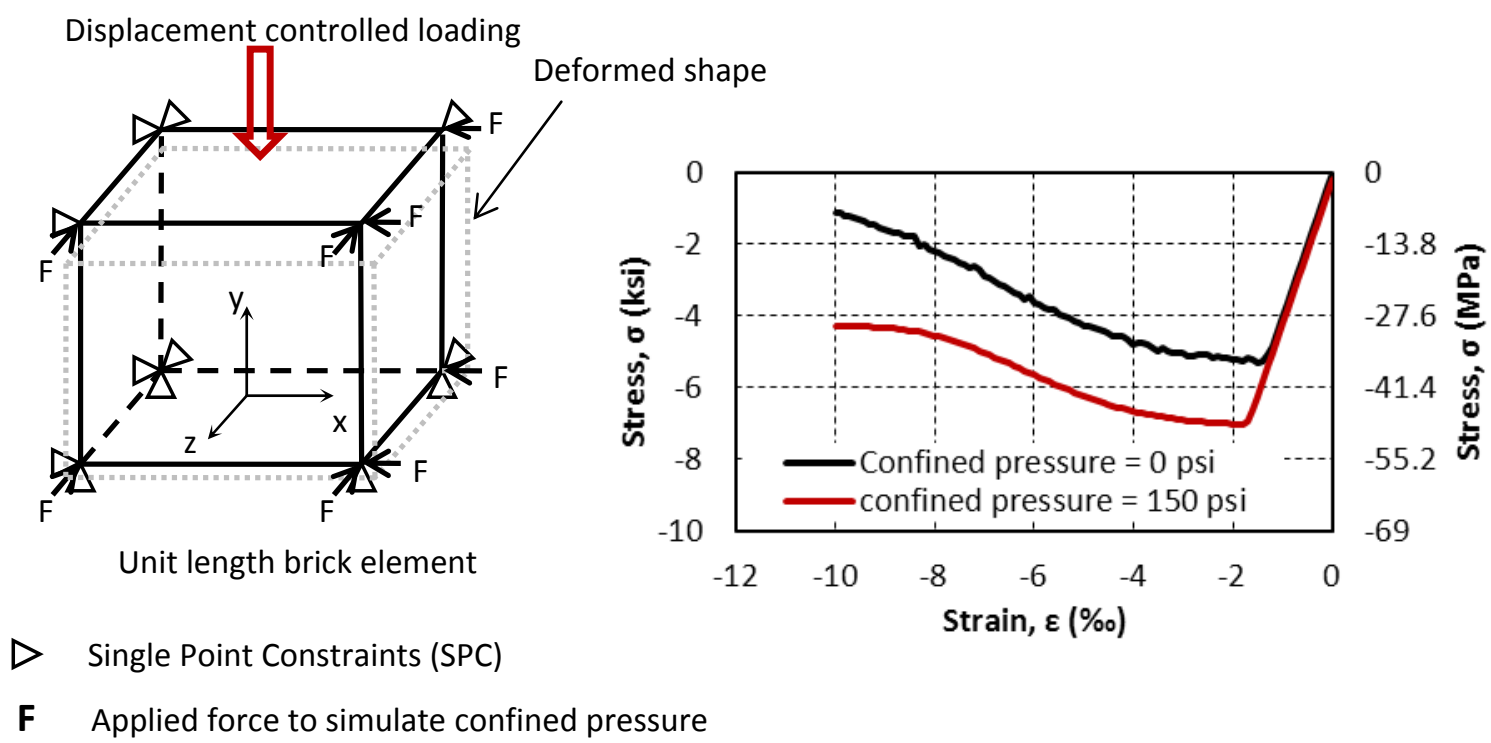

Figure 5.4 Compressive stress-strain curves of concrete with and without confinement

For the beam elements representing concrete in the reduced models (Section 5.3.2), two material models (MAT_PLASTICITY_COMPRESSION_TENSION or MAT_124, and MAT_RC_BEAM or MAT_174) were considered. Important features of each of the material models are listed in Table 5.1. Because the current version of LS-DYNA does not support the use of different types of materials to define concrete and reinforcement with type 1 beam formulation (Hughes-Liu beam with cross-section integration), MAT_124 was selected as the concrete material model for critical beam elements representing beam segments with highly nonlinear behavior expected. MAT_124 is generally suitable for defining a uniaxial stress-strain relationship under monotonic loading condition. It is noted in Table 5.1 that MAT_124 does not provide a regulation on softening behavior by itself. Therefore, a modification of the input stressstrain curve based on mesh size is required. For noncritical beam elements, MAT_174 was used in place of MAT_124.

The softening branch of the stress-strain curve for concrete could not be obtained experimentally due to limitations on the stiffness of the machine used for compression testing of the concrete cylinders. In order to develop input stress-strain curves for concrete to be used in the reduced models, a basic stress-strain curve was generated first from available information such as the compressive strength $f_{c}^{\prime}$ and the strain $\varepsilon_{c l}$ corresponding to the compressive strength. Subsequently, the basic stress-strain curve was modified based on the mesh size. 
Table 5.1 Features of two material models used for concrete

\begin{tabular}{|l|c|c|}
\hline \multicolumn{1}{|c|}{ Feature } & MAT_124 & MAT_174 \\
\hline Can be used for concrete and reinforcing bars & Y & Y \\
\hline Can define failure & Y & N \\
\hline Compressive and tensile behavior can be defined separately & Y & N \\
\hline Regulation for mesh size sensitivity & N & Y \\
\hline Support user defined compressive and tensile curves & Y & N \\
\hline
\end{tabular}

The compressive stress-strain relationship for unconfined concrete was estimated as follows:

1. The ascending portion can be calculated by various equations in the literature, such as the one proposed by Popovics (1973):

$$
\sigma_{c}=-\frac{\frac{E_{c i} \varepsilon_{c i}}{E_{c 1} \varepsilon_{c 1}}-\left(\frac{\varepsilon_{c i}}{\varepsilon_{c 1}}\right)^{2}}{1+\left(\frac{E_{c i}}{E_{c 1}}-2\right) \frac{\varepsilon_{c i}}{\varepsilon_{c 1}}} f_{c}^{\prime}
$$

where $\sigma_{c}$ is the compressive stress, $\varepsilon_{c i}$ is the compressive strain, $E_{c i}$ is the tangent modulus calculated based on the CEB-FIP model code (CEB 1991), and $E_{c l}$ is the secant modulus from the origin to the peak compressive stress (see Figure 5.5).

2. The descending portion was approximated by a straight line (Figure 5.5). The cutoff strain $n \varepsilon_{c l}$ depends on the concrete strength, and the coefficient $n$ was estimated from Table 5.2, which is from the CEB-FIP model code (CEB 1991).

Table 5.2 Coefficient $\boldsymbol{n}$ of concrete cutoff strain from CEB-FIP model code (CEB 1991)

\begin{tabular}{|c|c|}
\hline Compressive strength of concrete & Cutoff strain coefficient, $\mathbf{n}$ \\
\hline $2900 \mathrm{psi}(20 \mathrm{MPa})$ & 3 \\
\hline $5800 \mathrm{psi}(40 \mathrm{MPa})$ & 2 \\
\hline $8700 \mathrm{psi}(60 \mathrm{MPa})$ & 1.5 \\
\hline $11600 \mathrm{psi}(80 \mathrm{MPa})$ & 1.2 \\
\hline
\end{tabular}

When experimental data are not available, Equation (5.1) may be used to develop a stress-strain curve. To reduce the mesh size effects, a constant fracture energy approach was used. To maintain constant fracture energy, the shaded area in Figure 5.5 needs to be adjusted by modifying the cutoff strain (through adjustment of the coefficient $n$ ) according to the element characteristic length $L_{c h a r}$. The compressive fracture energy $G_{f, c}$ can be estimated as 100 times the tensile fracture energy $G_{f, t}$ (see Table 5.3). 
Confinement effects were calculated using a modified Kent and Park model proposed by Scott et al. (1982), which was based on experimental data from monotonically loaded full-sized column samples. The enhancement of concrete strength and ductility as a result of the confinement of rectangular-shaped transverse reinforcement were taken into account in this model.

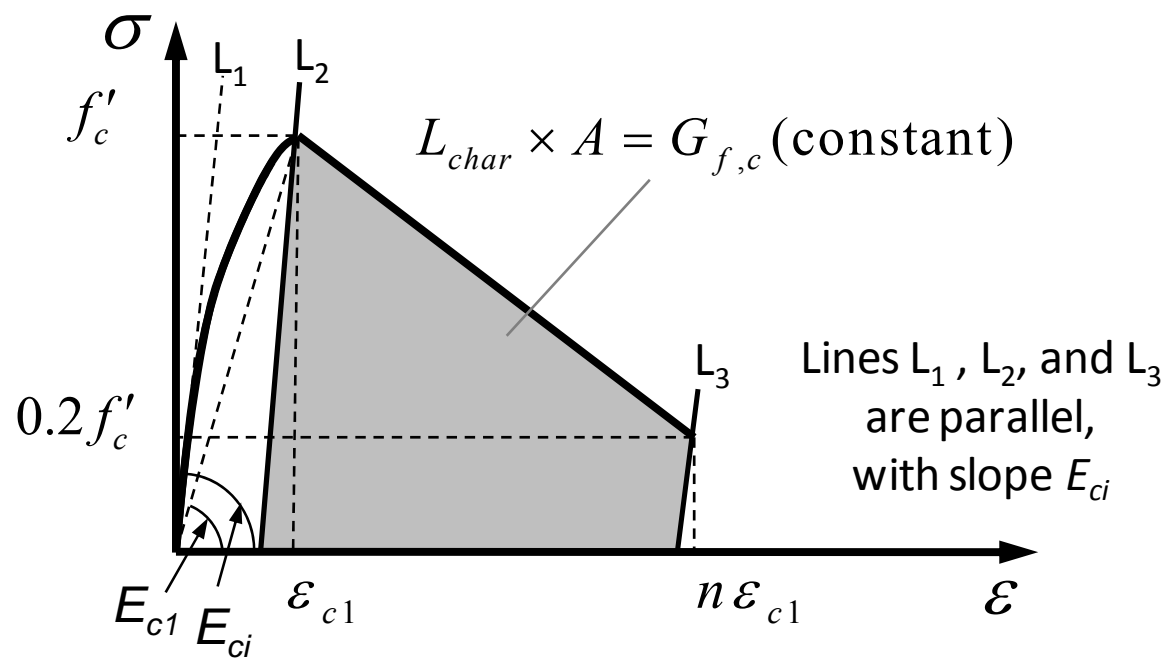

Figure 5.5 Compressive stress-strain relationship of unconfined concrete

The tensile stress-strain relationship for concrete was estimated as follows:

1. For uncracked concrete subject to tension, a bilinear curve defined by the following equations in the CEB-FIP model code (CEB 1991) was used to estimate the ascending branch of the tensile stress-strain curve:

$$
\sigma_{c t}=\left\{\begin{array}{cl}
E_{c i} \varepsilon_{c t} & \text { for } \quad 0<\varepsilon_{c t} \leq 0.9 \frac{f_{t}}{E_{c i}} \\
f_{t}-0.1 f_{t} \frac{0.00015-\varepsilon_{c t}}{0.00015-0.9 \frac{f_{t}}{E_{c i}}} & \text { for } 0.9 \frac{f_{t}}{E_{c i}}<\varepsilon_{c t} \leq 0.00015
\end{array}\right.
$$

where $E_{c i}$ is the tangent modulus of elasticity, $f_{t}$ is the tensile strength, $\sigma_{c t}$ is the tensile stress, and $\varepsilon_{c t}$ is the tensile strain (see Figure 5.6).

2. For cracked concrete, a straight line was used to describe the descending branch of the stress-strain curve. The ultimate crack strain $\varepsilon_{u}^{c r}$ was calculated based on tensile fracture energy $G_{f, t}($ see Table 5.3) in this smeared crack model as:

$$
\varepsilon_{u}^{c r}=\frac{2 G_{f, t}}{f_{t} h}
$$

where $h$ is the crack bandwidth (for beam elements, $h$ is the length of the element). 
Table 5.3 Tensile fracture energy from CEB-FIP model code (CEB 1991)

\begin{tabular}{|c|c|}
\hline Maximum aggregate size, $\boldsymbol{d}_{\max }$ & Fracture energy, $\boldsymbol{G}_{\boldsymbol{f}, \boldsymbol{t}}$ \\
\hline $0.315 \mathrm{in}(8 \mathrm{~mm})$ & $0.143 \mathrm{lbf} \cdot \mathrm{in} / \mathrm{in}^{2}\left(0.025 \mathrm{~N} \cdot \mathrm{mm} / \mathrm{mm}^{2}\right)$ \\
\hline $0.630 \mathrm{in}(16 \mathrm{~mm})$ & $0.171 \mathrm{lbf} \cdot \mathrm{in} / \mathrm{in}^{2}\left(0.030 \mathrm{~N} \cdot \mathrm{mm} / \mathrm{mm}^{2}\right)$ \\
\hline $1.260 \mathrm{in}(32 \mathrm{~mm})$ & $0.331 \mathrm{lbf} \cdot \mathrm{in} / \mathrm{in}^{2}\left(0.058 \mathrm{~N} \cdot \mathrm{mm} / \mathrm{mm}^{2}\right)$ \\
\hline
\end{tabular}

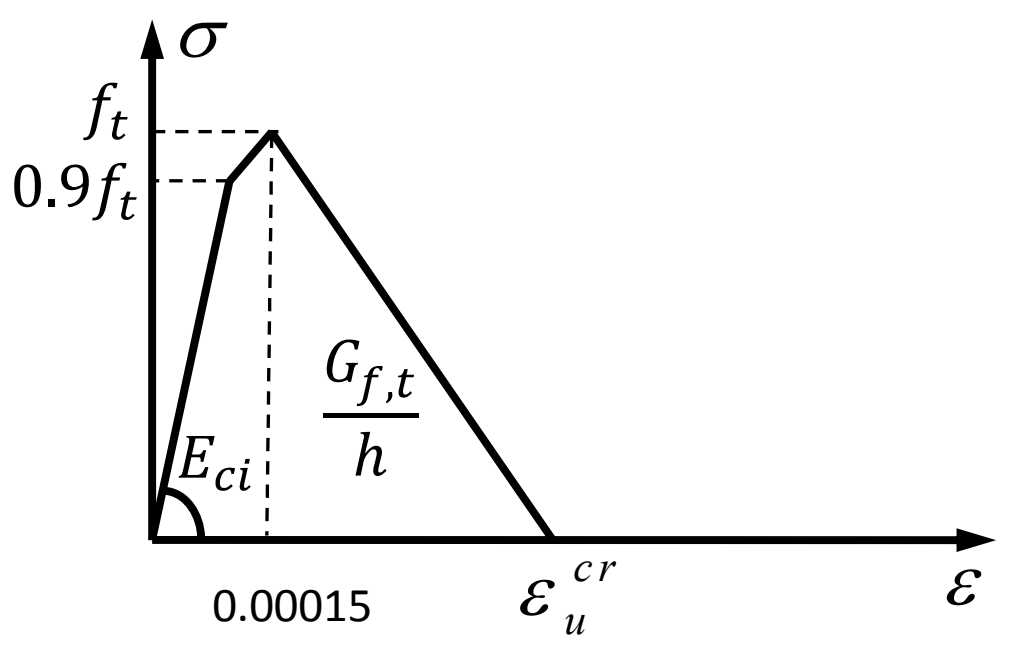

Figure 5.6 Tensile stress-strain relationship of concrete

\subsubsection{Shear in Concrete}

For the detailed models (Section 5.3.1), shear behavior of the concrete material is modeled explicitly using the continuous surface cap model (MAT_159). For the reduced models (Section 5.3.2), although the Hughes-Liu beam element is able to include finite transverse shear strains in its formulation, the shear behavior of the joint panel zones needs to be modeled using separate spring elements. The shear behavior of joint panel zones in the reduced models was represented using rigid links connected by rotational springs with a symmetric multi-linear moment-rotation relationship. The shear stress $(\tau)$ versus shear strain $(\gamma)$ relationship under monotonic load was calculated following the approach proposed by Vecchio and Collins (1986). Figure 5.7 shows a comparison between the calculated shear stress-strain relationship and experimental data (specimen PV20, Vecchio and Collins 1986). The equivalent moment $(M)$ and corresponding joint rotation $(\theta)$ for the rotational springs are estimated as:

$$
M=\tau \cdot V_{\text {joint }}, \theta=\tan ^{-1} \gamma
$$


where $V_{\text {joint }}$ is the gross volume of the joint, which is computed as a product of the column width, depth and beam height. Since no beam shear failure was observed in similar tests conducted recently (Yi et al. 2008, Su et al. 2009, Yu and Tan 2010), a distinct shear spring representing the shear behavior of the beam-joint interface was not included in the reduced models.

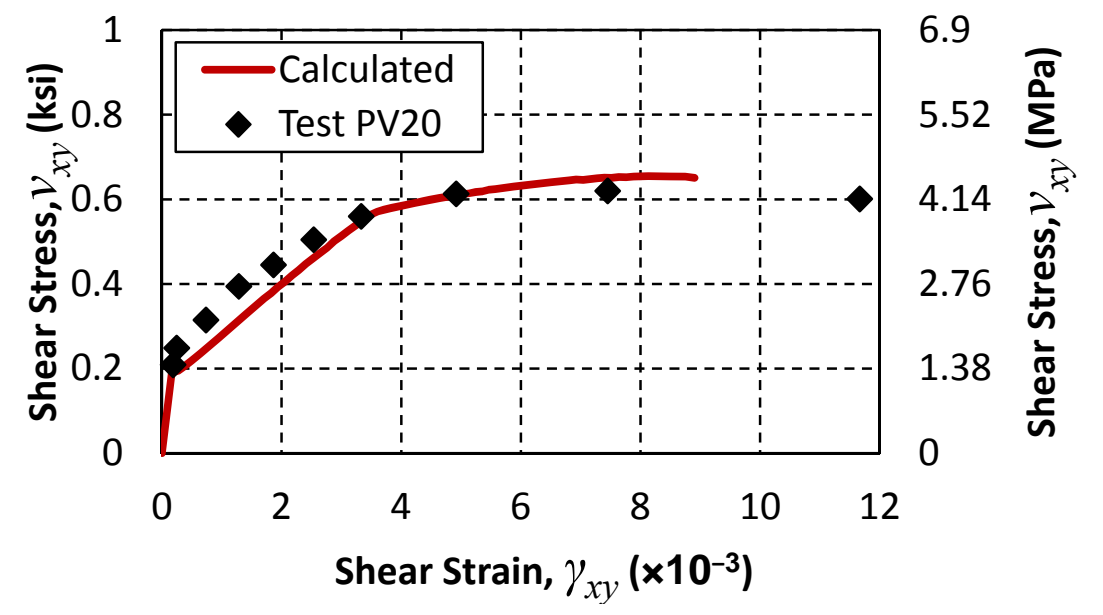

Figure 5.7 Comparison of calculated and observed response (Vecchio et al. 1986)

\subsubsection{Bond-Slip Effects}

The bond-slip effect is an important feature that needs to be considered in developing the computational model. If bond slip is neglected, the model cannot capture the bond failure mode. A fully bonded assumption will also lead to premature bar fracture in certain circumstances. For the detailed models (Section 5.3.1), bond-slip behavior was modeled by defining a onedimensional contact interface (CONTACT_1D in LS-DYNA) between the solid elements representing concrete and the beam elements representing reinforcing bars. The bond-slip relationship is assumed to be bilinear, and bond stress deterioration after reaching the maximum bond stress is considered through setting a positive value of the exponent in the damage curve (see Hallquist 2007).

Recommended values of the maximum bond stress $\tau_{\max }$ and the slip $s_{o}$ under $\tau_{\max }$ can be found in references as the DIANA User's Manual (de Witte 2005) or the CEB-FIP model code (CEB 1991). In this study, $\tau_{\max }$ is defined as $1.9 f_{t}$, where $f_{t}$ is the tensile strength of concrete, $s_{o}$ is equal to 0.0024 in $(0.06 \mathrm{~mm})$, and the value of the exponent in the damage curve is set to 4 (see Hallquist 2007).

For the reduced models (Section 5.3.2), the stress-strain relationship of reinforcing bars of critical beam elements, representing beam segments with highly nonlinear behavior expected, is modified for bond-slip effects as shown in Equation (5.6). It is assumed that the stress-strain relationship without the bond-slip effect is expressed as: 


$$
\varepsilon=f(\sigma)
$$

The modified stress-strain relationship can then be defined as:

$$
\varepsilon^{\prime}=\frac{L-L_{0}}{L_{0}}=\frac{s(\sigma)+f(\sigma) L_{0}}{L_{0}}=\frac{s(\sigma)}{L_{0}}+f(\sigma)=f^{\prime}\left(\sigma, L_{0}\right)
$$

where $s$ is the slip under axial stress $\sigma, L_{0}$ is the original length of the reinforcing bar, and $L$ is the "deformed" length of the reinforcing bar including slip. All stresses and strains are expressed in engineering terms. The input curves for MAT_124 are generated based on the modified stressstrain curves by following the iterative procedure described in Section 5.2.1. The slip $s$ is calculated using an approach proposed by Lowes et al. (2003). An average bond stress of $\tau_{e}$ is assumed if $\sigma_{\mathrm{s}} \leq f_{y}$, where $\sigma_{\mathrm{s}}$ is the stress in the reinforcing bar and $f_{y}$ is the yield strength of the bar. An average bond stress of $\tau_{y}$ is assumed if $\sigma_{\mathrm{s}}>f_{y}$. Expressions for $\tau_{e}$ and $\tau_{y}$ are given in Table 5.4, based on Lowes et al. (2003). If sufficient anchorage length can be provided, which is shown in Figure 5.8(a), bond slip $s$ is defined as the deformation of the reinforcing bar along the anchorage length $L_{y}$.

Table 5.4 Average bond strengths as a function of steel stress (Lowes et al. 2003)

\begin{tabular}{|c|c|c|}
\hline Bar stress $\sigma_{\mathbf{s}}$ & $\begin{array}{c}\text { Average bond strength (psi) } \\
\left(\mathbf{f}_{\mathbf{c}} \text { in psi) }\right.\end{array}$ & $\begin{array}{c}\text { Average bond strength (MPa) } \\
\left(\mathbf{f}_{\mathbf{c}} \text { in } \mathbf{M P a}\right)\end{array}$ \\
\hline Tension $\sigma_{s} \leq \mathrm{f}_{\mathrm{y}}$ & $\tau_{e}=21 \sqrt{f_{c}^{\prime}}$ & $\tau_{e}=1.8 \sqrt{f_{c}^{\prime}}$ \\
\hline Tension $\sigma_{\mathrm{s}}>\mathrm{f}_{\mathrm{y}}$ & $0.6 \sqrt{f_{c}^{\prime}} \leq \tau_{y} \leq 4.8 \sqrt{f_{c}^{\prime}}$ & $0.05 \sqrt{f_{c}^{\prime}} \leq \tau_{y} \leq 0.4 \sqrt{f_{c}^{\prime}}$ \\
\hline
\end{tabular}

For the convenience of modeling with more generalized stress-strain curves obtained from tensile tests, the calculation of slip $s$ is simplified from an integrated form (Lowes et al. 2003) to a discretized form. Let $\left(\left[\varepsilon_{S}\right]_{n},\left[\sigma_{s}\right]_{n}\right)$ denote a point on a discretized, monotonically-increasing stress-strain curve, where $n=1,2,3, \ldots$, and $\left[\varepsilon_{s}\right]_{1}=\left[\sigma_{s}\right]_{1}=0$. Letting $s_{n}$ denote the value of slip associated with the point $\left(\left[\varepsilon_{s}\right]_{n},\left[\sigma_{s}\right]_{n}\right)$, where $s_{1}=0$, and letting $d_{b}$ denote the diameter of the reinforcing bar, values of slip corresponding to each point on the stress strain curve can be calculated as follows:

$$
S_{n+1}=\left\{\begin{array}{cc}
{\left[\varepsilon_{s}\right]_{n+1}\left[\sigma_{s}\right]_{n+1} \frac{d_{b}}{8 \tau_{e}}} & \text { for }\left[\sigma_{s}\right]_{n+1} \leq f_{y} \\
s_{n}+\left(\left[\varepsilon_{s}\right]_{n+1}+\left[\varepsilon_{s}\right]_{n}\right)\left(\left[\sigma_{s}\right]_{n+1}-\left[\sigma_{s}\right]_{n}\right) \frac{d_{b}}{8 \tau_{y}} & \text { for }\left[\sigma_{s}\right]_{n+1}>f_{y}
\end{array}\right.
$$

For the case with insufficient anchorage length (see Figure 5.8b), bond slip $s^{\prime}$ can be obtained by

$$
s^{\prime}=s\left(\sigma_{s}\right)-s\left(\sigma_{s}^{\prime}\right)
$$

Figure 5.9 illustrates modeling the tensile behavior of a reinforcing bar of a critical beam element. Assuming that the original length of the steel bar is $L_{0}$, the deformed length $L$ including bond slip is calculated as: 


$$
L=L^{\prime}+S_{1}+S_{2}
$$

where $L^{\prime}$ is the deformed length caused by bar elongation, and $s_{1}$ and $s_{2}$ are the amounts of bond slip at each end. In Equation (5.9), $s_{1}$ and $s_{2}$ can be computed based on their anchorage conditions, and $L^{\prime}$ can be computed based on the stress-strain relationship of the reinforcing bar. A more sophisticated calculation of $L^{\prime}$ would need to consider the tension stiffening effect by using a modified stress-strain relationship for the embedded reinforcing bar in concrete, as suggested in the CEB-FIP model code (CEB 1991). For simplicity, the tension stiffening effect is not included in this study, as its effect is considered negligible compared to the bond-slip effect.

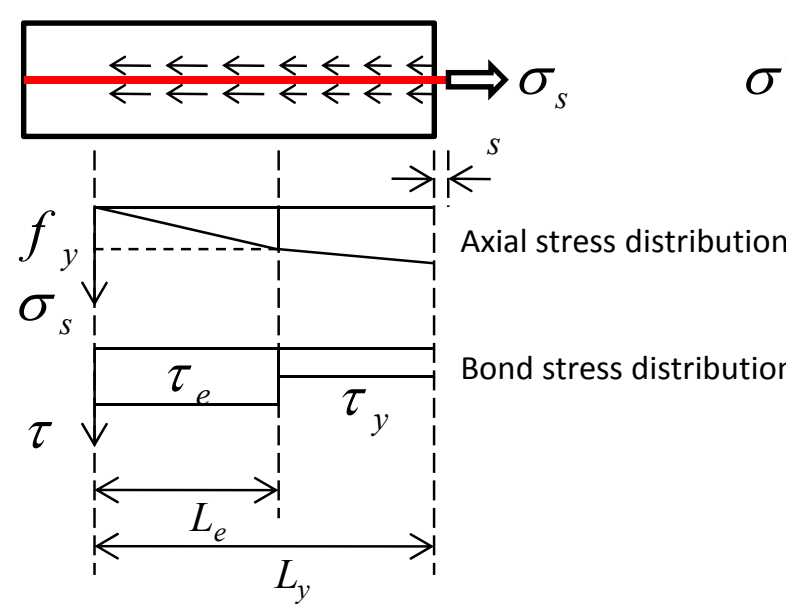

(a)

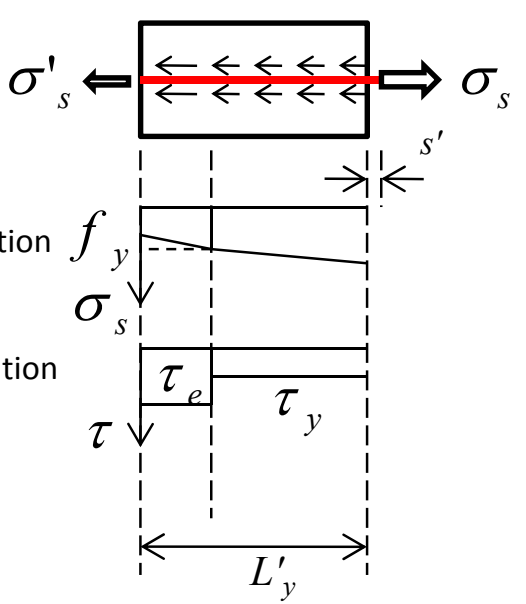

(b)

Figure 5.8 Bond stress distribution (a) with full anchorage and (b) without full anchorage

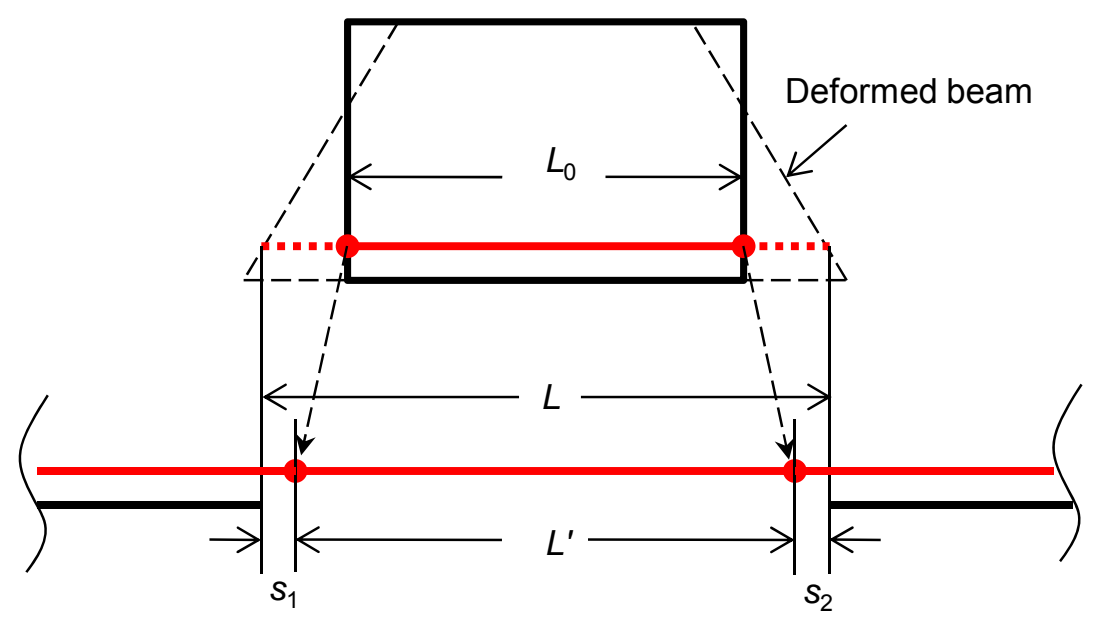

Figure 5.9 Bond-slip effects of reinforcement fiber at critical beam elements 


\subsection{FINITE ELEMENT MODELS}

Two finite element models of each specimen tested in Chapter 4 were developed to study the response characteristics of the beam-column assemblies. The first was a detailed model with approximately 70,000 solid and beam elements for the IMF specimen and about 60,000 elements for the SMF specimen (fewer elements due to the relative larger mesh size). The second was a reduced model with about 80 beam and zero-length elements for both IMF and SMF specimens. The following sections provide detail descriptions of the both models.

\subsubsection{Detailed Models}

An overview of the detailed models used in the analysis of the IMF and SMF specimens is shown in Figure 5.10. Solid elements in the right-hand portion of each model are removed to show the embedded reinforcing bars. The detailed models consist of solid elements representing the concrete and the steel plate at the top of the center column, beam elements representing longitudinal and transverse reinforcing bars, and rigid elements representing the steel rollers. Enlarged views of portions of the detailed model are shown in Figure 5.11. The characteristic length of the solid elements used to represent concrete is between 1.75 in to 2 in $(44 \mathrm{~mm}$ to $51 \mathrm{~mm}$ ) for the IMF specimen, and 1.2 in to 3 in $(30 \mathrm{~mm}$ to $76 \mathrm{~mm}$ ) for the SMF specimen. The aspect ratio of solid elements is in a range of 1 to 2.3 for the IMF specimen and 1 to 2.8 for the SMF specimen. The length of the beam elements representing beam longitudinal reinforcement is 4 in $(102 \mathrm{~mm})$, while the beam elements representing transverse and column longitudinal reinforcement range in length from 3.25 in to 4 in $(83 \mathrm{~mm}$ to $102 \mathrm{~mm})$ for the IMF specimen and 3.5 in to $5 \mathrm{in}(89 \mathrm{~mm}$ to $127 \mathrm{~mm})$ for the SMF specimen.

Bond slip is modeled between beam-longitudinal reinforcing bars and surrounding concrete as described in Section 5.2.4. Two sets of nodes are required to define the contact, with the concrete nodes specified as master nodes and the reinforcement nodes specified as slave nodes. Bond slip is not considered for the transverse and column longitudinal reinforcement. Beam elements representing these reinforcing bars are constrained within the solid elements using the CONSTRAINED_LAGRANGE_IN_SOLID card. Beam elements can be eroded when a prespecified failure strain is reached, representing the fracture of reinforcing bars. Solid elements are not eroded in this analysis in order to avoid excessive loss of stiffness.

Very fine meshing of solid elements would be required to directly capture the progress of concrete cracking, which could also cause a nonobjective (divergent) response due to localization. Since simulation of cracking is not a focus of this study, the level of refinement of the solid element mesh described above is considered reasonable. While cracks are not modeled explicitly, concrete cracking can be reflected by contours of the damage index computed by the concrete material model. Mechanical bar couplers are assumed to have a higher ultimate strength than the longitudinal reinforcing bars and thus modeled using elastic elements. End nodes of the beam longitudinal reinforcements within the end columns are constrained by the surrounding concrete nodes using the CONSTRAINED_INTERPOLATION card, simulating the effect of mechanical anchorage devices (see Section 3.2). 
All nodes are fixed at the bases of the end columns. The steel rollers which are used to restrain the horizontal movement near the top of the end columns are modeled by non-deformable cylinders (RIGIDWALL_GEOMETRIC_CYLINDER in LS-DYNA). Contact between the concrete column and the steel roller is automatically considered as a feature of the rigid wall interface in LS-DYNA. In the test, a steel plate was placed on the top of the center column to avoid local damage to concrete. This plate is represented using solid elements with an elastic material model. All top surface nodes of the steel plate are pushed downward following a prescribed time-displacement curve.
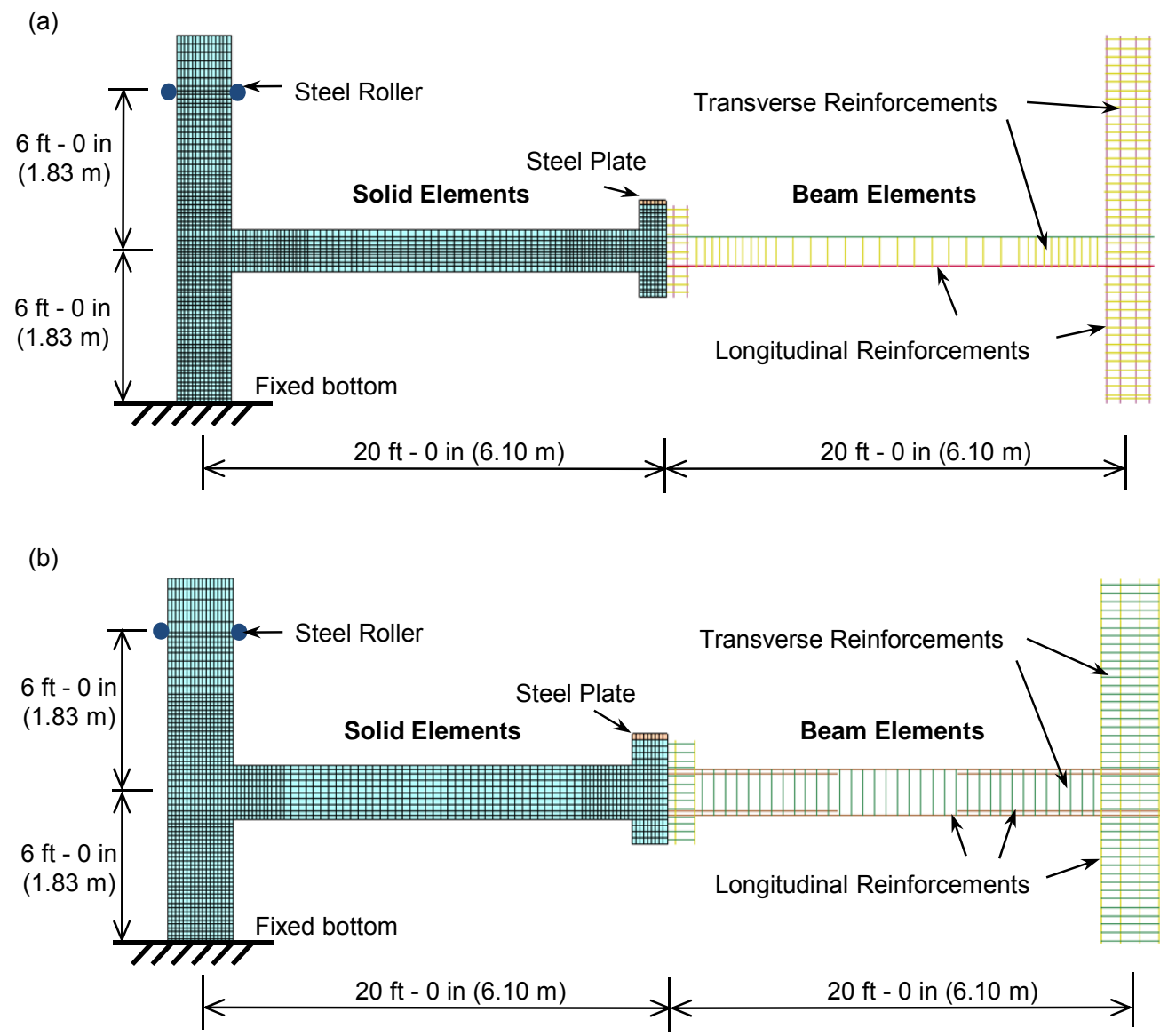

Figure 5.10 Overview of detailed model of (a) IMF and (b) SMF specimen 


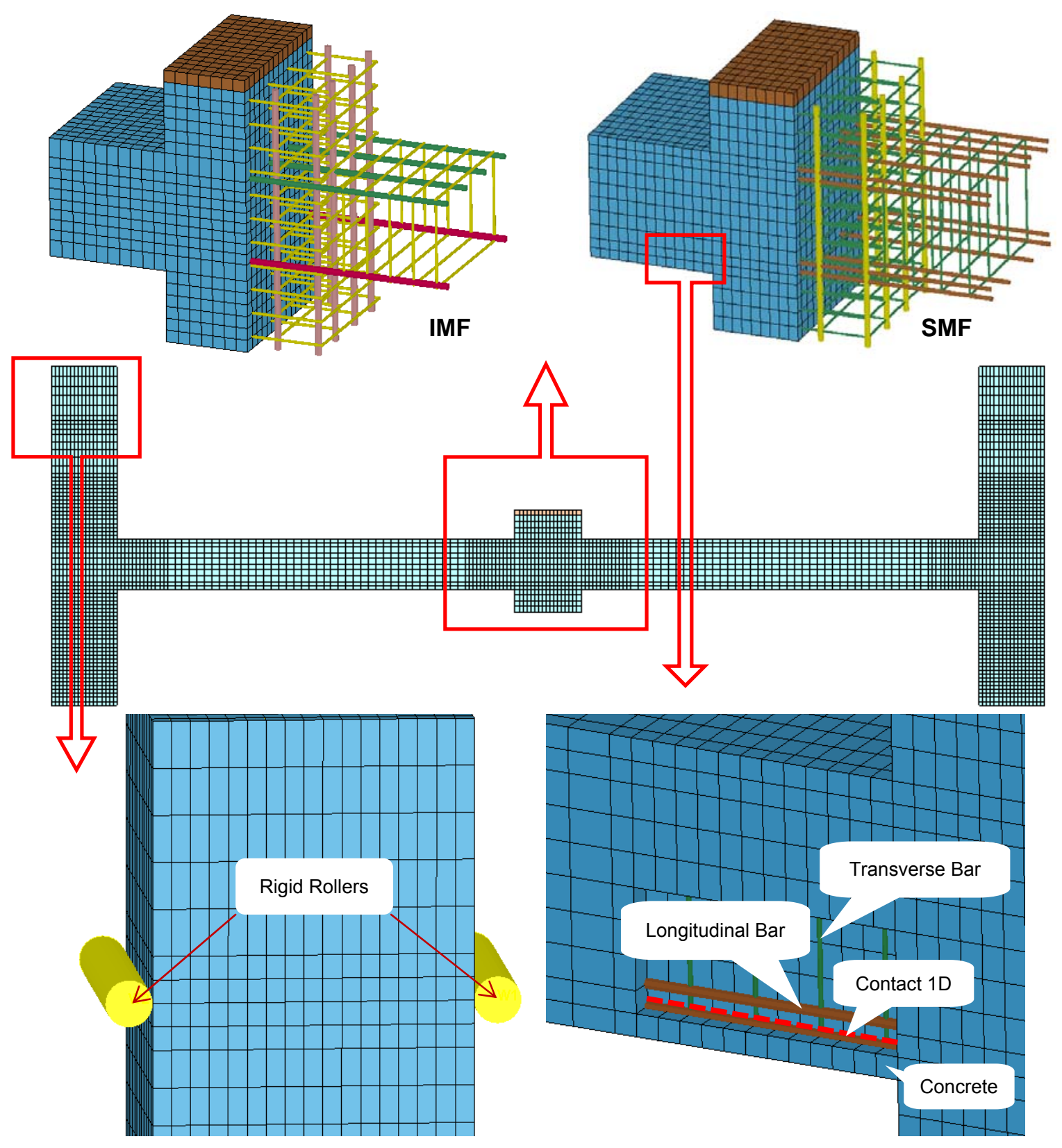

Figure 5.11 Enlarged views of portions of the detailed model

\subsubsection{Reduced Models}

The reduced models of the IMF and SMF specimens are shown in Figure 5.12. Both models make use of Hughes-Liu beam elements (Hallquist 2007) to represent the beams and columns. The Hughes-Liu beam elements use cross section integration with each integration point assigned to a discretized cross-sectional geometry component (fiber). Integration of the cross section is performed at mid-length of each beam element. Because integration is performed at only one section along the axis of each beam, a fairly small mesh size is required at critical 
locations (such as beam ends) in order to obtain acceptable accuracy. However, very small mesh sizes will cause a non-objective material response as well as computational inefficiency. In this study, the mesh size of critical elements is selected as one half of the beam depth. Ten beam elements in total were used to model each beam with varying section properties. The beam elements used cross section integration with the proper cross-sectional geometry defined for each section type. Uniaxial stress-strain relationships for concrete and reinforcing bars are defined as discussed in Section 5.2.

The beam-column joints were modeled by a deformable rectangular frame with rigid sides and nonlinear springs located at the corners (Figure 5.13). Zero-length discrete beam elements were used to connect the rigid links at their ends. Independent curves can be defined for all degrees of freedom (three translational and three rotational DOFs) of these zero-length elements using the MAT_GENERAL_NONLINEAR_6DOF_DISCRETE_BEAM card in LS-DYNA. The in-plane moment-rotation relationship is presented in Section 5.2.3, accounting for joint panel shear behavior. Beams and columns were connected to the joints by interpolating beam (or column) nodal DOFs from the translational DOFs of a pair of joint nodes, one at each end of the rigid element, using the CONSTRAINED_INTERPOLATION card in LS-DYNA. The column bases were modeled as fixed.
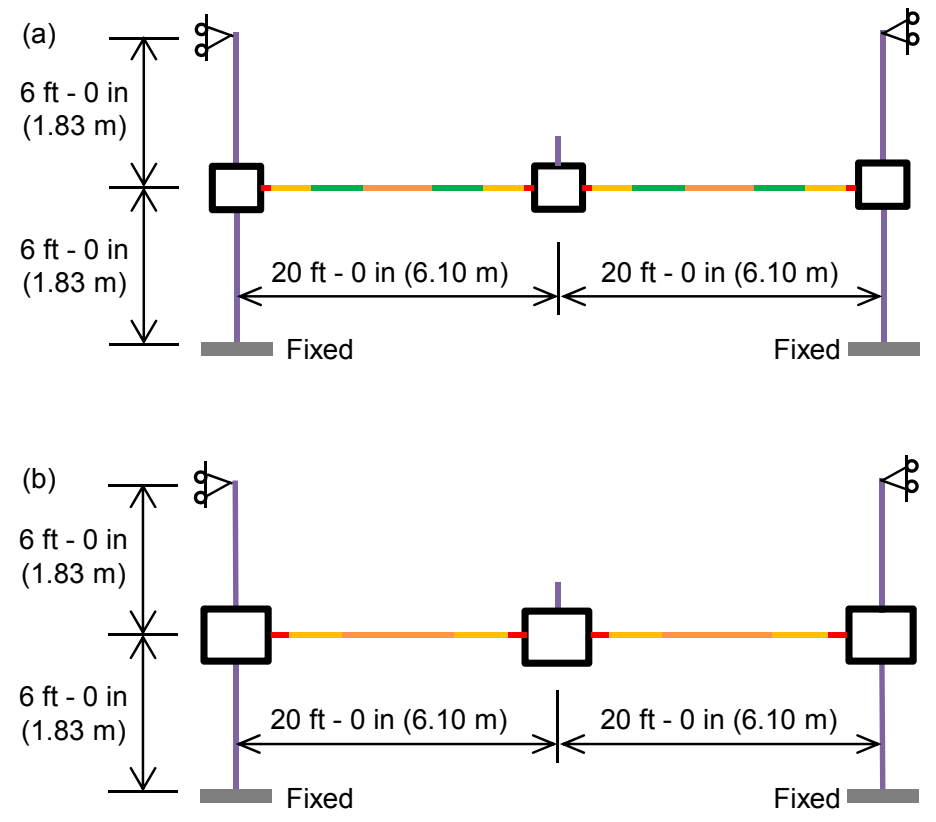

Figure 5.12 Overview of reduced model of (a) IMF and (b) SMF specimens 


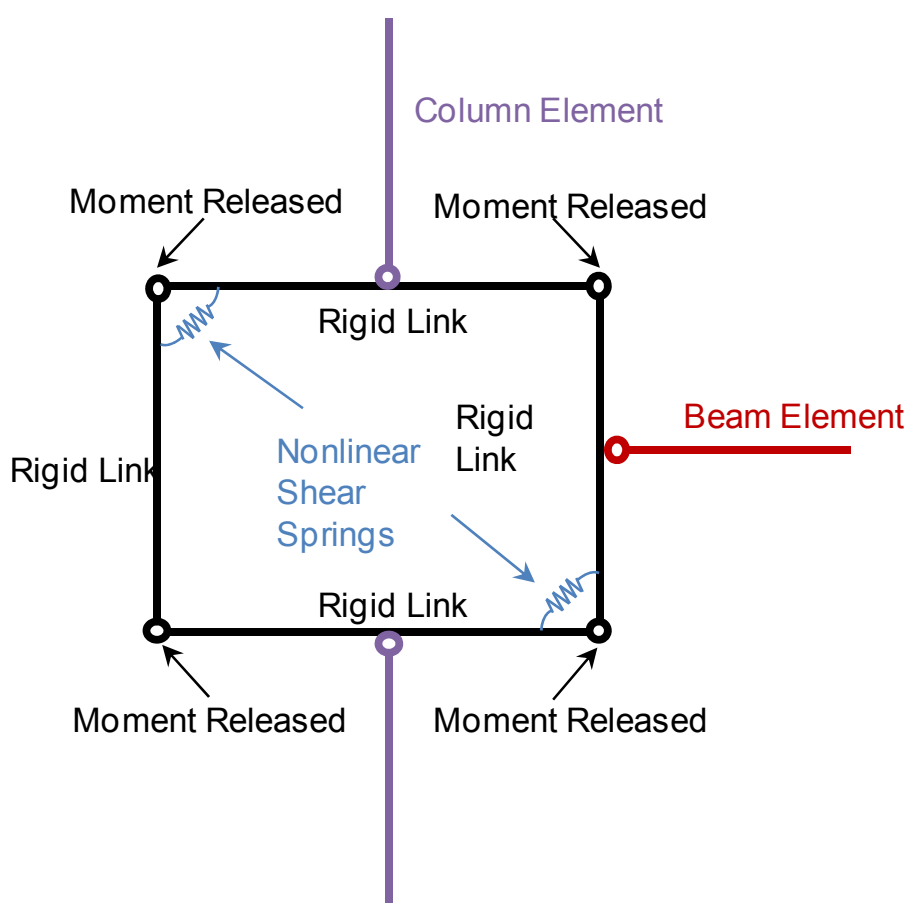

Figure 5.13 Detailed view of beam-column joint in reduced model of IMF specimen

\subsection{ANALYSIS RESULTS}

The IMF and SMF test specimens were analyzed using both the detailed and reduced models. The gravity load (self-weight) of the specimen was applied first, which was followed by displacement-controlled loading applied at the top of the center column. The analysis results of the detailed and reduced models are presented in the following sections.

\subsubsection{IMF Specimen}

The final deflected shapes of the IMF specimen based on the detailed and reduced models are shown in Figure 5.14. In the detailed model, beam elements representing bottom reinforcing bars near the center column exceeded the fracture strain and were eroded (see Figure 5.15) at a center column vertical displacement of 42.2 in $(1072 \mathrm{~mm})$. In the reduced model, strains of the integration points representing the bottom reinforcing bars in the critical elements near the center column exceeded the fracture strain at a center column displacement of about 42.8 in (1087 mm). Such a failure mode is consistent with that observed in the experiment (see Figure 4.2) at a measured center column vertical displacement of 43 in $(1092 \mathrm{~mm})$. 

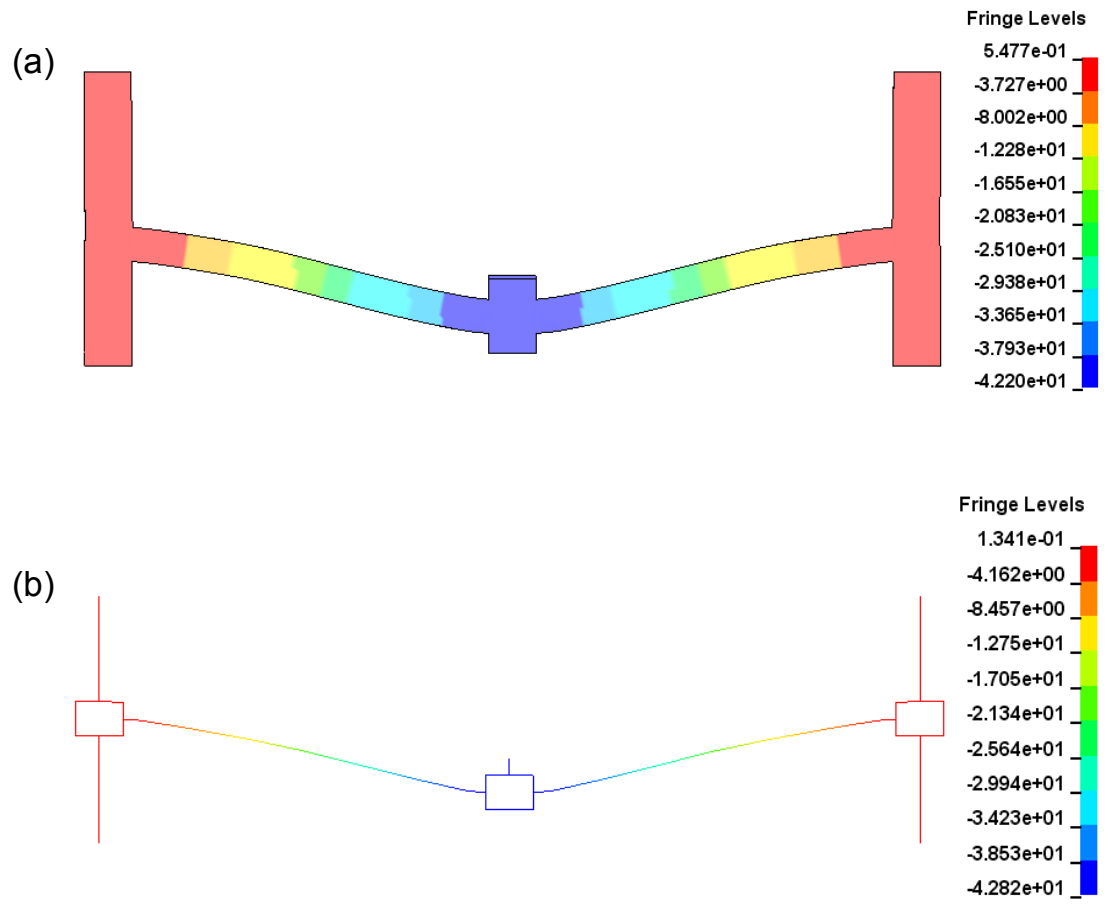

Figure 5.14 Deflected shape of IMF specimen: (a) detailed model at a center column vertical displacement of 42.2 in (1072 $\mathrm{mm})$ and (b) reduced model at a center column vertical displacement of 42.8 in (1087 $\mathrm{mm})$ (contours represent vertical displacements in inches)

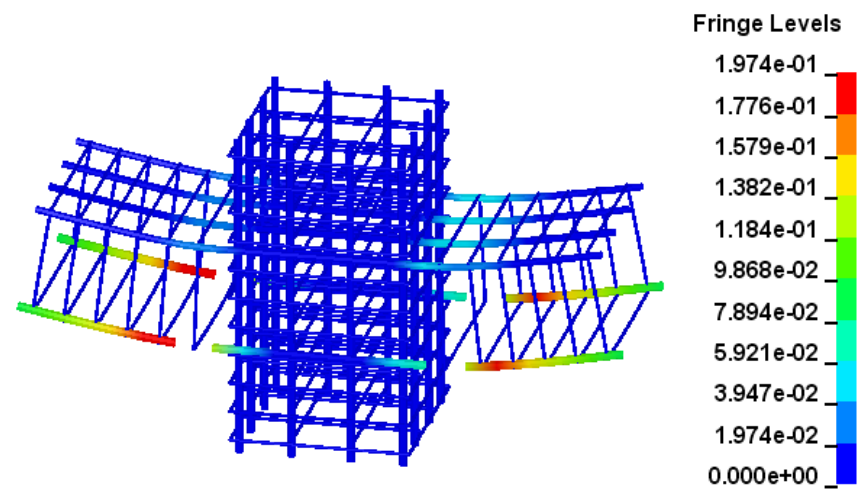

Figure 5.15 Failure mode of IMF detailed model (contours represent plastic strains)

Concrete damage distributions at two levels of vertical displacement of the center column are shown in Figure 5.16 along with the observed crack patterns. The contours depict the degree of damage of the concrete, with a value of 0 representing no damage and a value of 1 representing complete damage. At a displacement of 24 in $(610 \mathrm{~mm})$, about at the onset of catenary action (see Section 4.4), the analysis shows that the damage is concentrated at the beam ends and the longitudinal reinforcing bar cutoff points in the beam. Inclined damage contours are seen at 
exterior beam-column joints and the lower half of the columns, which represent the formation of diagonal shear cracks. At the final stage of the response, with a displacement of about 42 in $(1076 \mathrm{~mm})$, damage is widespread along the entire length of the beams. The computed damage distributions are in agreement with the observed crack patterns.

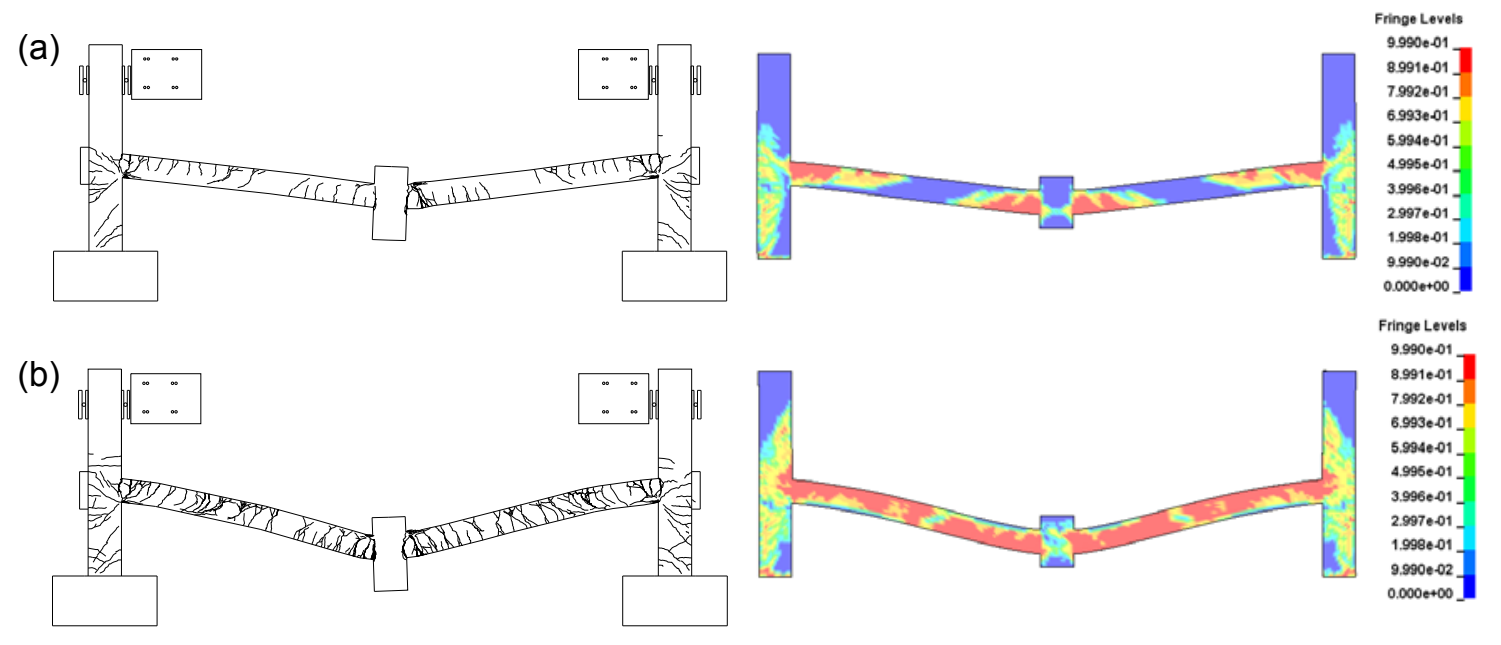

Figure 5.16 Concrete damage index contours compared with observed crack patterns at center column displacement of (a) 24 in $(610 \mathrm{~mm})$ and (b) 42 in $(1067 \mathrm{~mm})$ for IMF specimen (contours represent damage index: 0 = no damage, 1 = complete damage)

Figure 5.17 shows plots of (a) the applied vertical load and (b) the measured horizontal displacement of the end columns at beam mid-height versus the measured vertical displacement of the center column. Curves computed from the detailed and the reduced models are also shown in the figures and generally good agreement with the experimental curve is observed. The applied load on the center column began to decrease after reaching a peak at a vertical displacement of about 5 in $(127 \mathrm{~mm})$. The applied load leveled off after the center column was pulled down to a displacement of about 20 in $(508 \mathrm{~mm})$, then increased again with increasing displacement until the specimen failed at a displacement of about 42.8 in $(1087 \mathrm{~mm})$. Similar to the experimental observations, the end columns at beam mid-height initially moved outward and subsequently moved inward when the displacement of the center column was about 10 in $(254 \mathrm{~mm})$. This change in the direction of movement of the end columns indicates a change in the beam axial force from compression to tension. 

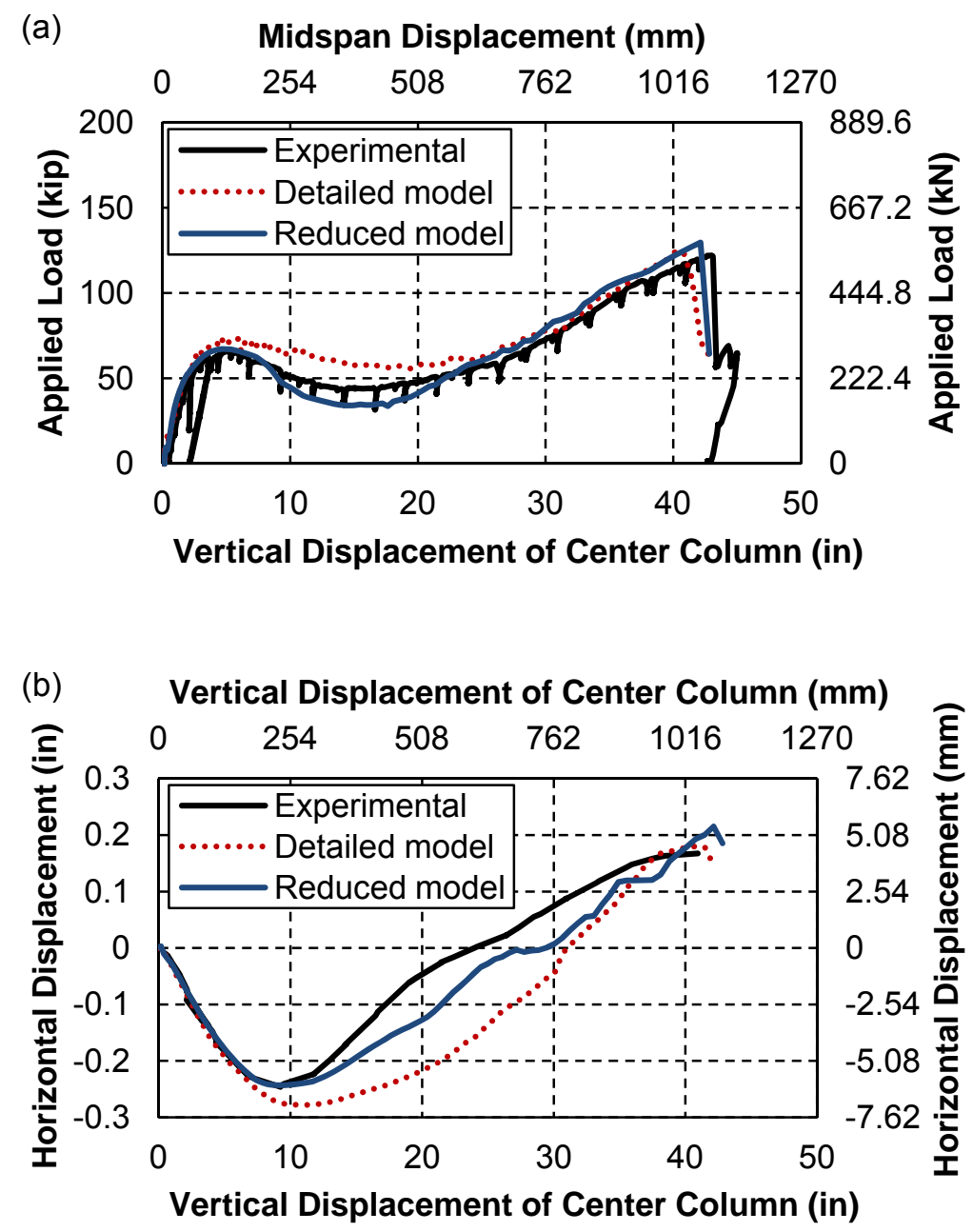

Figure 5.17 (a) Applied vertical load and (b) horizontal displacement of end column at beam mid-height versus vertical displacement of center column for IMF specimen

Computed axial stresses in longitudinal reinforcing bars at the beam mid-span from the detailed model are shown in Figure 5.18, which indicates a shift in the beam axial force from compression to tension. Figure 5.18(a) shows that both top and bottom reinforcing bars were predominantly in compression in the early stages of loading, when the vertical displacement of the center column was less than 4.6 in $(117 \mathrm{~mm})$. The stresses in the bars gradually changed to tension as the center column displacement was increased. Figure 5.18(b) shows the state of stress of these reinforcing bars when the vertical displacement was 42 in (1067 mm). Detailed and reduced model calculations of beam axial force versus the center column displacement are shown in Figure 5.19, in which the change from compression to tension is evident.

A diagonal compression zone extending from the bottom corner of the beam near the end column to the upper corner near the center column is seen in Figure 5.20, which shows the minimum principal stress contours for concrete at a center column displacement of 4.6 in $(117 \mathrm{~mm})$. The 
plot indicates the development of "arching action" in the beams (see Section 4.4), which was also reported by Su et al. (2009) in their experimental work.

Similar to the experimental results, the computational models indicate that as the displacement of the center column increased, yielding initiated in the bottom reinforcing bars of the beams near the center column, followed by yielding of the top reinforcing bars near the end columns. With further increase in the displacement, yielding of both the top and bottom reinforcing bars propagated from the beam ends toward mid-span.

(a)

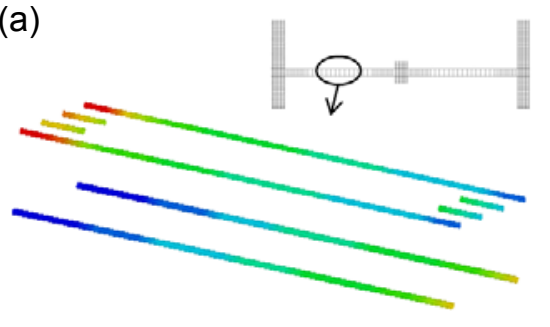

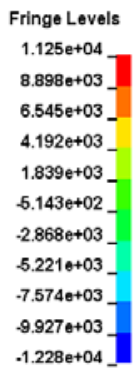

(b)

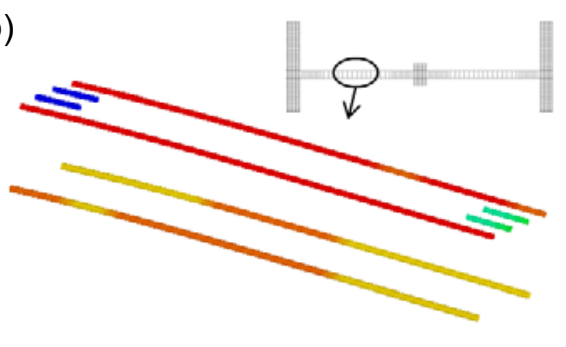

Fringe Levels

$7.883 \mathrm{e}+04$

$6.860 \mathrm{e}+04$

$5.838 \mathrm{e}+04$

$4.815 \mathrm{e}+04$

$3.793 \mathrm{e}+04$

$2.770 \mathrm{e}+04$

$1.747 \mathrm{e}+04$

$7.249 \mathrm{e}+03$

$-2.977 \mathrm{e}+03$

$-1.3200+04$

$-2.343 \mathrm{e}+04$

Figure 5.18 Axial stresses in reinforcing bars along a beam segment near mid-span at center column displacements of (a) 4.6 in $(117 \mathrm{~mm})$ and (b) 42 in $(1067 \mathrm{~mm})$ for IMF specimen (contours represent stress in psi)

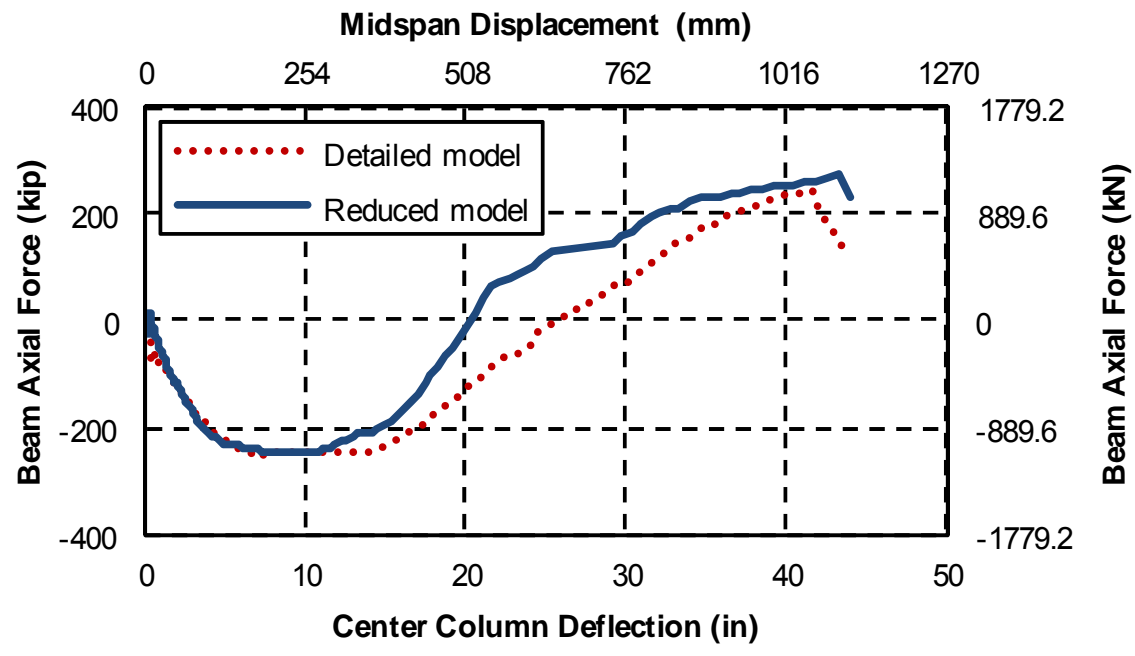

Figure 5.19 Beam axial force versus vertical displacement of center column for IMF specimen 


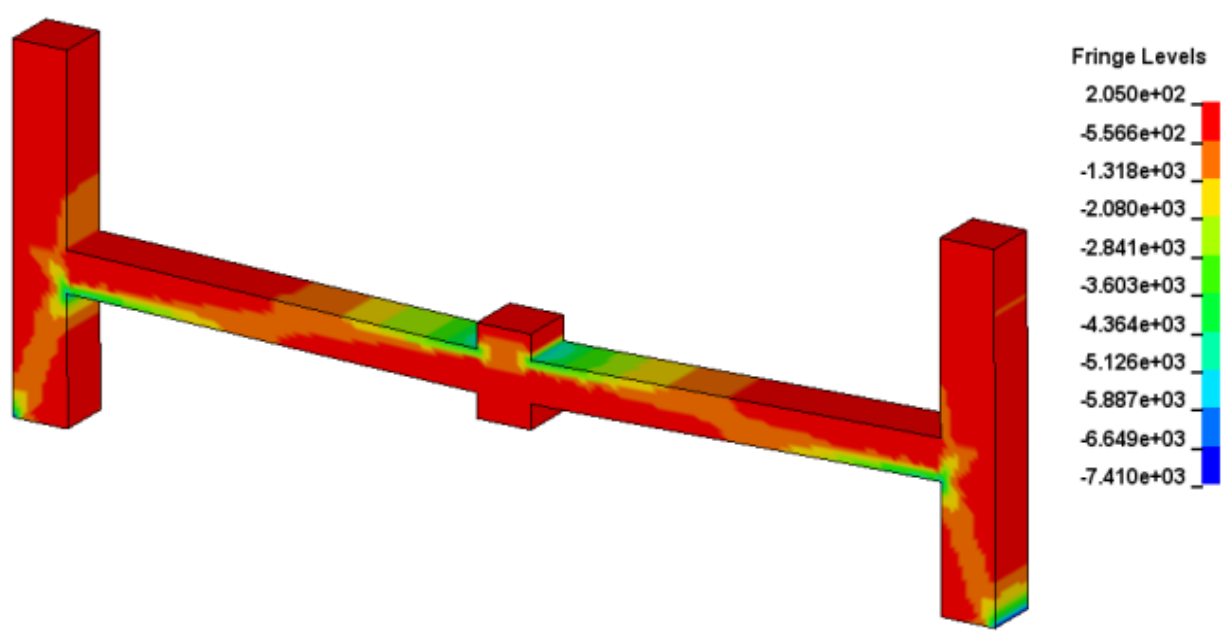

Figure 5.20 Minimum principal stress contours of concrete at a center column displacement of 4.6 in (117 $\mathrm{mm}$ ) for IMF specimen (Contours represent stress in psi)

\subsubsection{SMF Specimen}

Figure 5.21 shows the final deformed shapes of the SMF specimen based on the detailed and reduced models. This specimen experienced a movement of the north footing during the test as described in Section 4.3.3. This movement of the footing was considered in the analysis by applying the measured displacement in Figure 4.19 as a prescribed displacement at the base of the north column. In the detailed model, beam elements representing bottom reinforcing bars near the north side of the center column exceeded the fracture strain and were eroded (see Figure 5.22) at a center column displacement of $48.2 \mathrm{in}(1224 \mathrm{~mm})$. In the reduced model, strains of the integration points representing bottom reinforcing bars in the critical elements near the north side of the center column exceeded the fracture strain at a center column displacement of 47.0 in $(1194 \mathrm{~mm})$. This failure mode is consistent with that observed in the experiment (see Figure $4.16)$ at a measured center column displacement of 48 in (1219 $\mathrm{mm})$.

Concrete damage distributions at two levels of center column displacement are shown in Figure 5.23 along with the observed crack patterns. At a displacement of 24.5 in $(622 \mathrm{~mm})$, the analysis shows that the damage is concentrated at beam ends and at the longitudinal reinforcing bar cutoff points. Inclined damage contours are seen at the exterior beam-column joints and within the lower half of the columns. At the final stage of the response, with a displacement of about 48.2 in $(1224 \mathrm{~mm})$, damage is widespread along the entire length of the beams. The computed damage distributions are in good agreement with the observed crack patterns. 


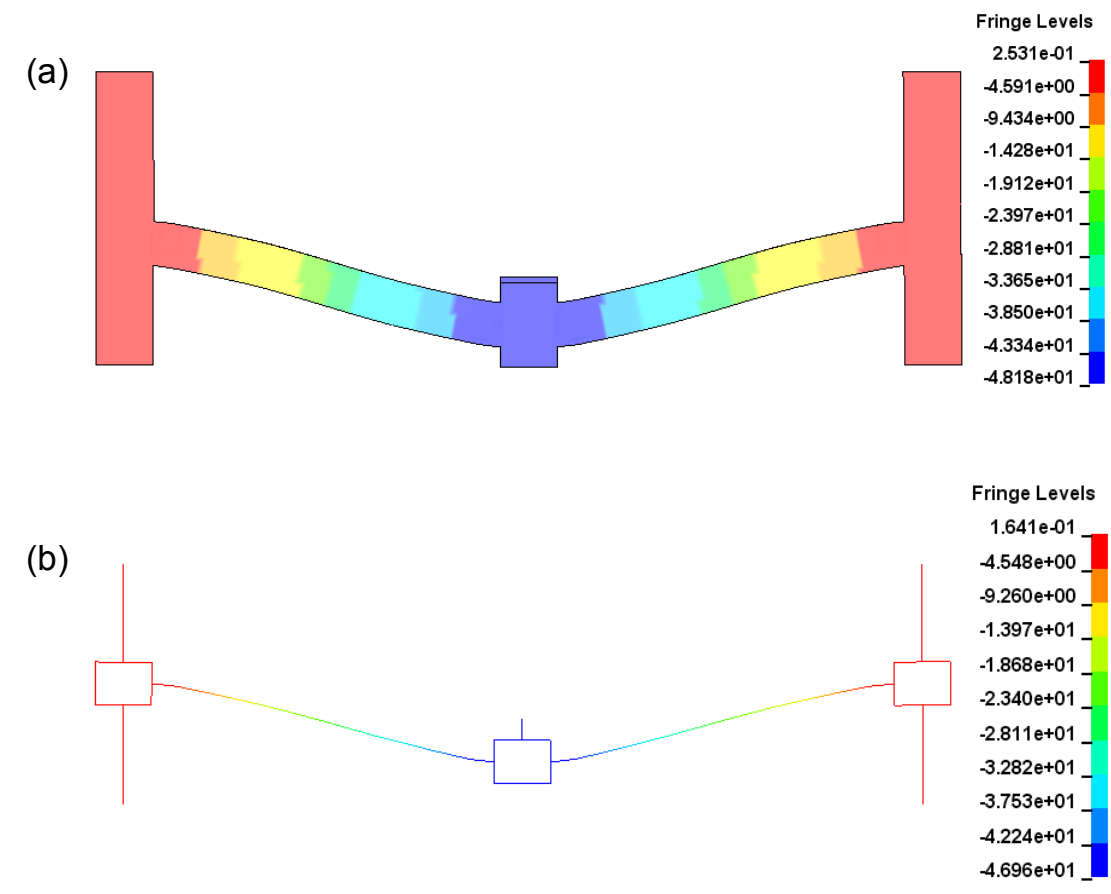

Figure 5.21 Deflected shape of SMF specimen: (a) detailed model at a center column vertical displacement of 48.2 in (1224 mm) and (b) reduced model at a center column vertical displacement of 47.0 in (1194 mm) (Contours represent vertical displacements in inches)

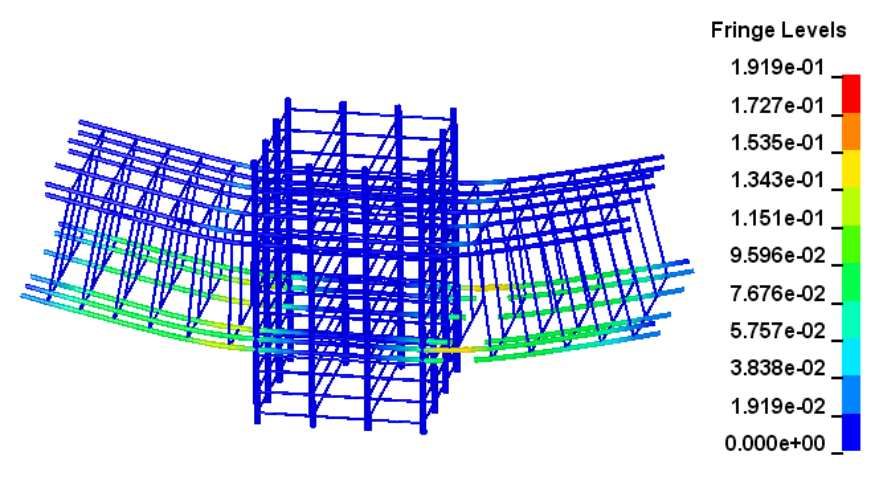

Figure 5.22 Failure mode of the SMF detailed model (Contours represent plastic strains) 
(a)

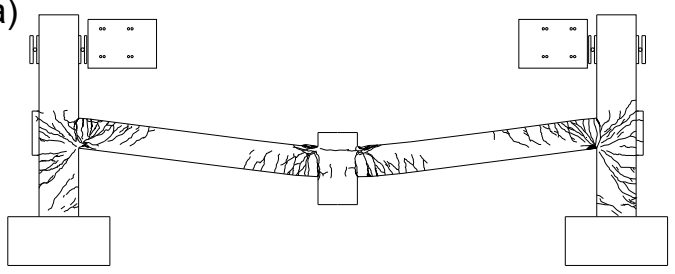

(b)

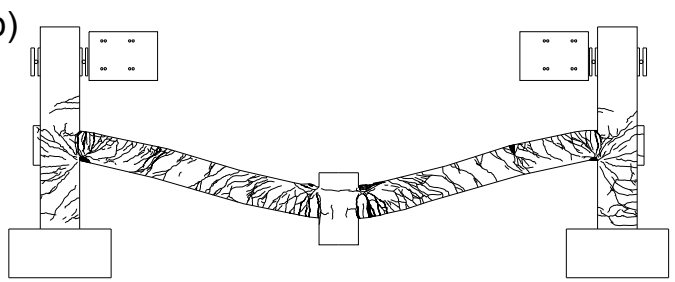

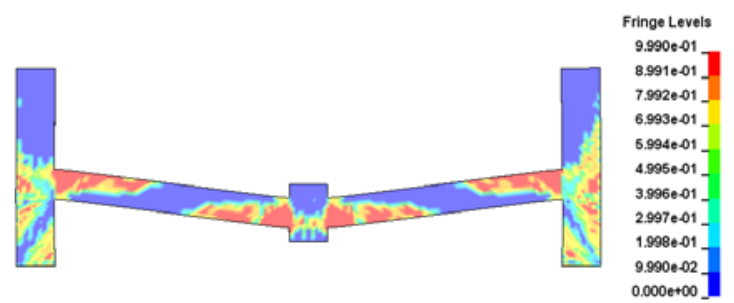

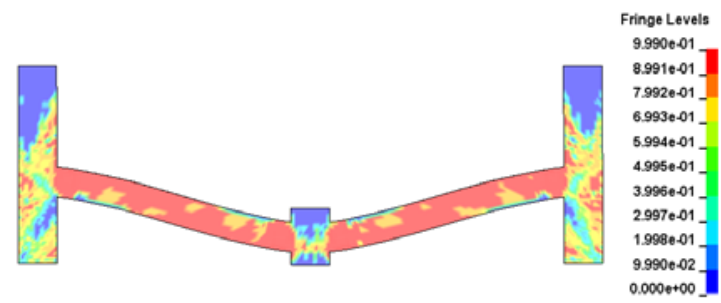

Figure 5.23 Concrete damage index contours compared with observed crack patterns at center column displacement of (a) 24.5 in (622 mm) and (b) 48.2 in (1224 mm) for SMF specimen (contours represent damage index: 0 = no damage, 1 = complete damage)

Figure 5.24 shows plots of (a) the applied vertical load, (b) the horizontal displacement of the south column at beam mid-height, and (c) the horizontal displacement of the north column at beam mid-height versus the vertical displacement of the center column. Curves computed from the detailed and reduced models are also shown in the figures. Similar to the experimental results, the computational models indicate that as the displacement of the center column increased, yielding initiated in the bottom reinforcing bars of the beams near the center column, followed by yielding of the top reinforcing bars near the end columns. After reaching a peak load of about $200 \mathrm{kip}(890 \mathrm{kN})$ at a vertical displacement of 4 in $(102 \mathrm{~mm})$, the load began to decrease as the center column displacement increased. At the same time, yielding of both the top and bottom reinforcing bars propagated from the beam ends toward mid-span. The load leveled off at a center column displacement of about $25 \mathrm{in}(635 \mathrm{~mm})$. As the displacement was further increased, the load began to increase again with the development of catenary action until the specimen failed at a displacement of 47 in (1194 mm). As shown in Figure 5.24(b), the south column initially moved outward at beam mid-height and subsequently began to move inward when the displacement of the center column was about 10 in $(254 \mathrm{~mm})$. This change in direction of the movement of the end columns indicates a change in the beam axial force from compression to tension. Movement of the north column at beam mid-height, which is shown in Figure 5.24(c), was not symmetric to that of the south column due to the movement of the north footing; however, a similar trend can be seen. 

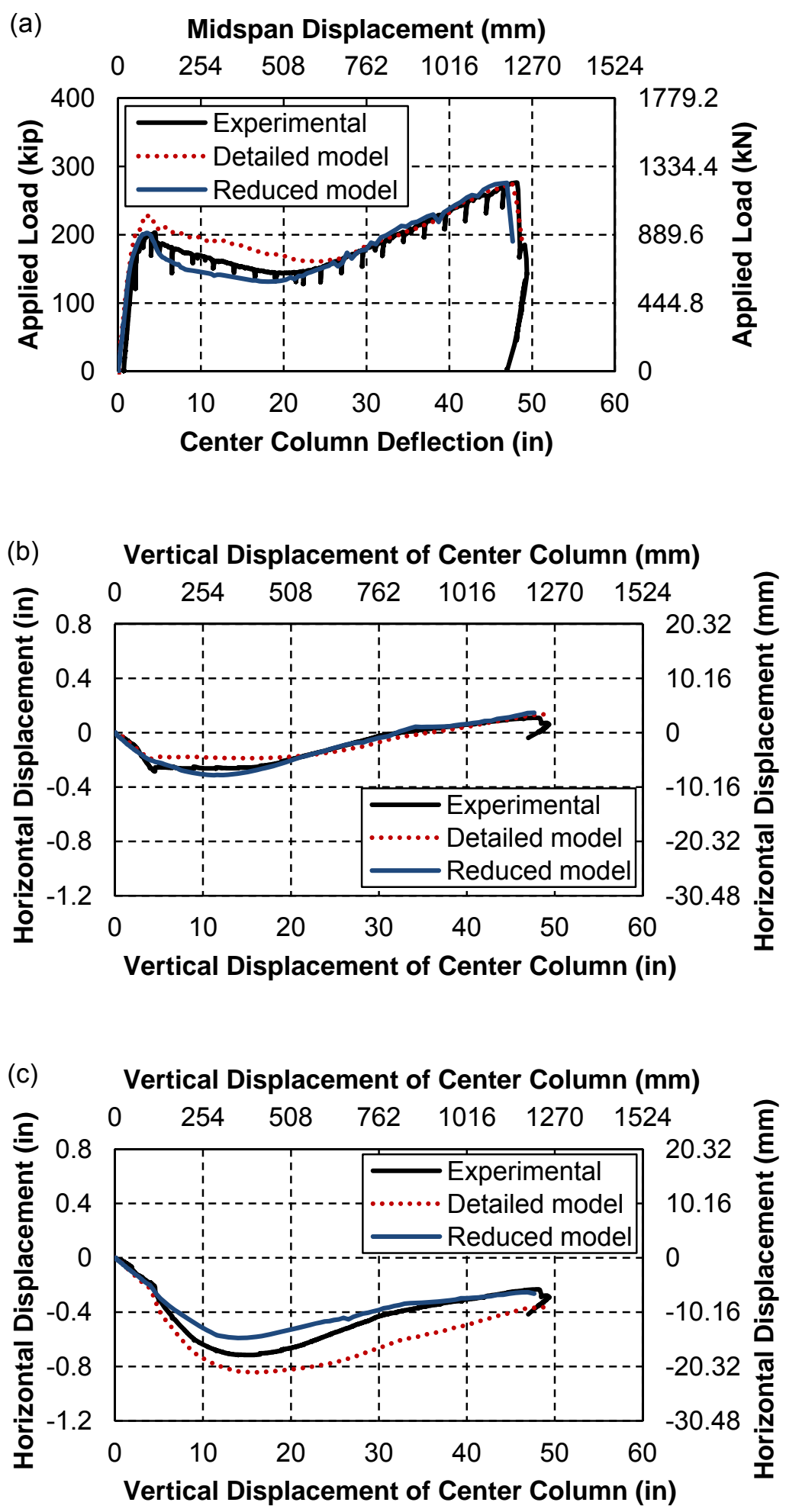

Figure 5.24 (a) Vertical load, (b) horizontal displacement of south column at beam mid-height and (c) horizontal displacement of north column at beam mid-height versus center column displacement for SMF specimen 
Computed axial stresses in longitudinal reinforcing bars at the beam mid-span from the detailed model are shown in Figure 5.25, which indicates a shift in the beam axial force from compression to tension. Figure 5.25(a) shows that both top and bottom reinforcing bars were predominantly in compression when the vertical displacement of the center column was 4.4 in (112 mm), while Figure 5.25(b) shows that tensile stress eventually developed in the longitudinal reinforcements when the vertical displacement was increased to 48 in $(1219 \mathrm{~mm})$.

Detailed and reduced model calculations of beam axial force versus the center column displacement are shown in Figure 5.26. Similar to the IMF specimen, the analysis results show that the compressive axial force continued to increase beyond the initial peak vertical load. A diagonal compression zone extending from the bottom corner of the beam near the end column to the upper corner near the center column is seen in Figure 5.27 at a center column displacement of $4.4 \mathrm{in}(112 \mathrm{~mm})$, indicating the development of "arching action" in the beams.

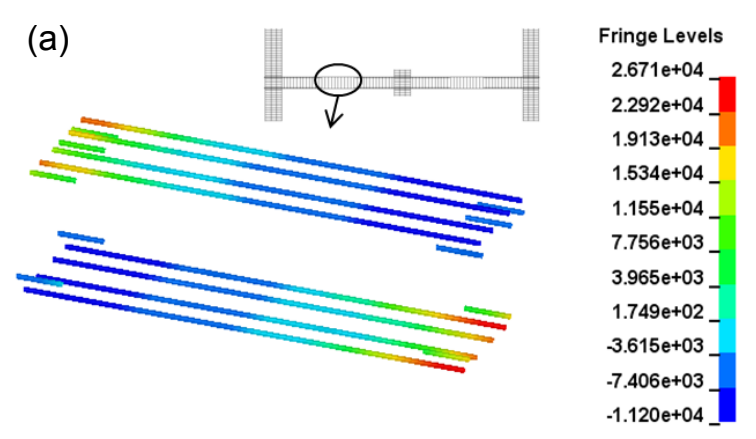

(b)

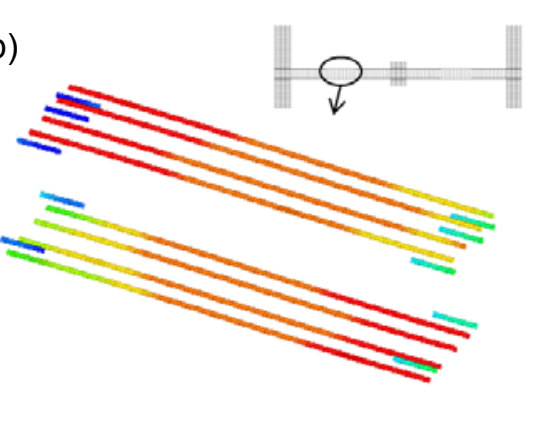

Fringe Levels

$8.883 \mathrm{e}+04$

$7.877 e+04$

$6.871 \mathrm{e}+04$

$5.865 \mathrm{e}+04$ _

$4.859 \mathrm{e}+04$

$3.853 \mathrm{e}+04$

$2.847 \mathrm{e}+04$

$1.841 \mathrm{e}+04$

$8.355 \mathrm{e}+03$

$-1.704 \mathrm{e}+03$

$-1.176 \mathrm{e}+04$

Figure 5.25 Axial stresses in reinforcing bars along a beam segment near mid-span beam at center column displacement of (a) $4.4 \mathrm{in}(112 \mathrm{~mm})$ and (b) $48 \mathrm{in}(1219 \mathrm{~mm})$ for SMF specimen (Contours represent stress in psi)

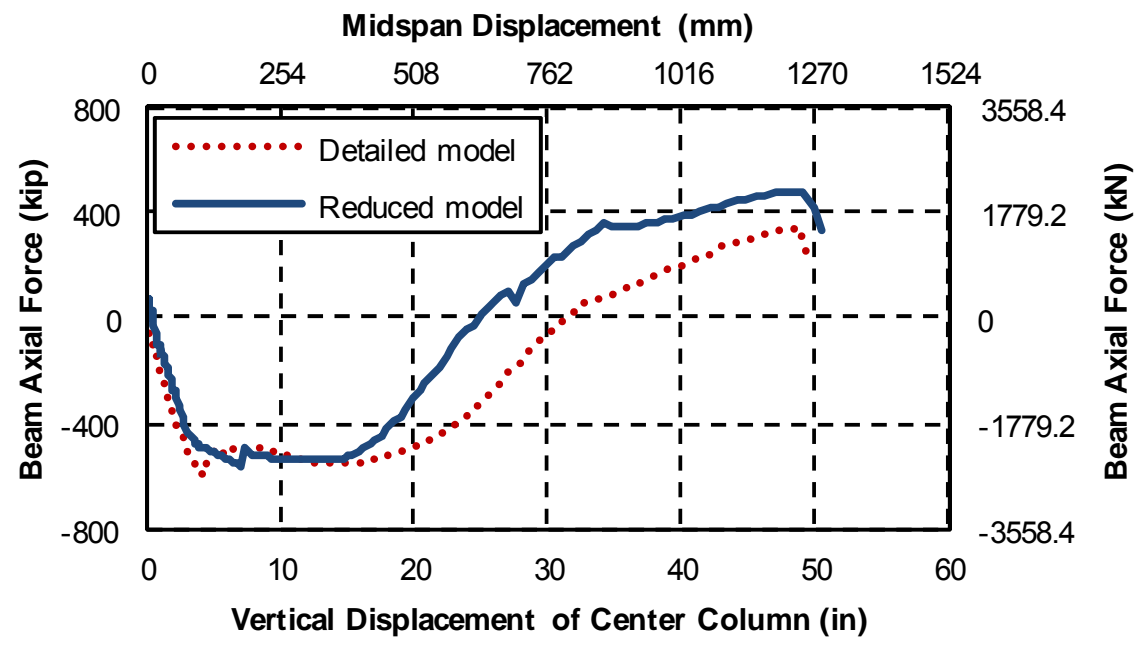

Figure 5.26 Beam axial force versus vertical displacement of center column for SMF specimen 


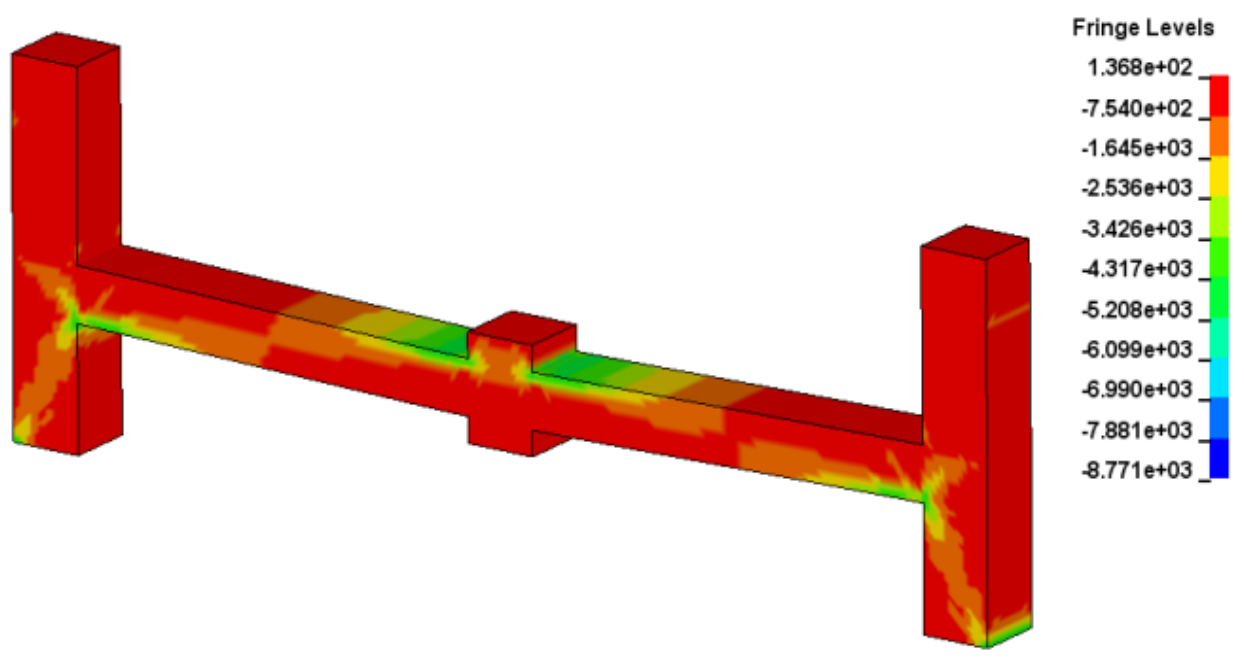

Figure 5.27 Minimum principal stress contours of concrete at a center column displacement of 4.4 in (112 mm) for SMF specimen (Contours represent stress in psi)

\subsection{SUMMARY}

This chapter presented a computational assessment of the performance of beam-column assemblies designed and detailed for Seismic Design Categories C and D under the monotonic loading conditions expected in column removal scenarios. Two different modeling approaches were considered in this study: (1) detailed models with a large number of elements, primarily solid and beam elements, and (2) reduced models with much fewer elements, primarily beam and zero-length elements. The analyses conducted using these models provided insight into the behavior and failure modes of the moment resisting concrete frames.

This study indicates good agreement between the experimental results and the computational predictions. Both detailed and reduced models were able to capture the primary response characteristics and failure modes. The reduced models developed in this study will serve as a valuable tool to analyze complete structural systems for assessing the reserve capacity and robustness of building structures.

The analyses also indicated the development of "arching action" in the beams as a result of the restraint of axial elongation of the beams provided by the end columns. Axial compressive forces in the beams diminished as the vertical column displacement approached the depth of the beam. Eventually, the axial compressive forces in the beams changed to tensile forces as a result of the formation of catenary action in the beam. The tensile forces increased with increasing displacement of the center column until the bottom reinforcing bars near the center column fractured and the specimen lost its load-carrying capacity. 


\subsection{REFERENCES}

Comite Euro-International du Beton (CEB). (1991), CEB-FIP Model Code 1990 Design Code, Published by Thomas Telford, London, UK.

FHWA (2007), Evaluation of LS-DYNA Concrete Material Model 159, Publication No. FHWAHRT-05-063, Federal Highway Administration, McLean, VA.

de Witte, F. C. (2005), User's Manual-release 9, TNO DIANA BV, Delft, the Netherlands.

Hallquist, J. (2007), LS-DYNA Keyword User's Manual, Livermore Software Technology Corporation, Livermore, CA, Version 971.

Lowes, L. N., Mitra, N., and Altoontash, A. (2003) "A beam-column joint model for simulating the earthquake response of reinforced concrete frames." Technical Report, No. PEER 2003/10, PEER, Berkeley, CA.

Popovics, S. (1973) "A numerical approach to the complete stress strain curve for concrete." Cement and concrete research, 3(5), 583-599.

Scott, B. D., Park, R., and Priestley, M. J. N. (1982) "Stress-strain behavior of concrete confined by overlapping hoops at low and high strain rates." ACI Journal, 79(1). 13-27.

Su, Y., Tian, Y., and Song, X. (2009). "Progressive collapse resistance of axially-restrained frame beams." ACI Structural Journal, 106(5), 600-607.

Vecchio, F. J. and Collins, M. P. (1986). "The modified compression-field theory for reinforced concrete elements subjected to shear." ACI Journal, 83(2), 219-231.

Yi, W., He, Q., Xiao, Y., and Kunnath, S. K. (2008). "Experimental study on progressive collapse-resistant behavior of reinforced concrete frame structures." ACI Structural Journal,105(4), 433-439.

$\mathrm{Yu}$, J. and Tan, K. H. (2010). "Experimental study on catenary action of RC beam-column subassemblages." Proceedings, $3^{\text {rd }}$ International fib Congress, PCI, Washington, DC. 


\section{Chapter 6 \\ SUMMARY AND CONCLUSIONS}

This report presented an experimental and computational study of two reinforced concrete beamcolumn assemblies, each comprising three columns and two beams. The two beam-column assemblies represent portions of the structural framing system of two ten-story concrete frame buildings. One building was designed for Seismic Design Category C (SDC C) and the other for Seismic Design Category D (SDC D). The beam-column assemblies were taken from the exterior moment resisting frames of these buildings. One test specimen, which was part of the SDC C building, had intermediate moment frames (IMFs) for the lateral force resisting system and the other, which was part of the SDC D building, had special moment frames (SMFs). The specimens were subjected to monotonically increasing vertical displacement of the center column to observe their behavior under a simulated column removal scenario, including the development of catenary action in the beams. The vertical displacement of the center column was increased until the vertical load-carrying capacity of each specimen was depleted.

The overall behavior of each beam-column assembly was analyzed using two levels of modeling complexity: (1) detailed models with solid elements representing concrete and beam elements representing steel reinforcement, and (2) reduced models with beam elements representing beams and columns and rigid links connected by nonlinear rotational springs representing the beam-column joints. The analyses conducted using these models provided insight into the behavior and failure modes of the test specimens, including the development of catenary action in the beams.

Based on the study reported herein, the following conclusions are reached.

1. For both the IMF and SMF specimens, the behavior was dominated by flexure in the early stages of the response. With increased vertical displacement of the center column, resistance was provided through the development of compressive diagonal axial forces or "arching action" due to the restraint on axial elongation of the beams by the end columns. With further increase in the vertical displacement, tensile axial forces developed in the beams and the behavior was dominated by catenary action.

2. The failure of both the IMF and SMF specimens was characterized by: (1) crushing and spalling of concrete at the top of the beams near the center column, (2) development of major flexural cracks (deepening and widening), and (3) fracture of one of the bottom reinforcing bars at a major crack opening near the center column.

3. The test results show that the rotational capacities of both the IMF and SMF beam-tocolumn joints under monotonic column displacement are about seven to eight times as large as those based on seismic test data. The rotations at peak load in this study were about $0.185 \mathrm{rad}$ and $0.200 \mathrm{rad}$ for the IMF and SMF specimens, respectively, whereas the rotational capacities of these connections based on seismic testing data are approximately $0.026 \mathrm{rad}$ and $0.025 \mathrm{rad}$, respectively. 
4. This study indicates generally good agreement between the experimental and the computational results. Both the detailed and reduced models were capable of capturing the primary response characteristics and failure modes of the test specimens.

This study shows that analysis using reduced models consisting of beam and spring elements can accurately predict the response characteristics of both the IMF and SMF beam-column assemblies. Furthermore, the reduced models developed in this study will be valuable in the analysis of complete structural systems for assessing the reserve capacity and robustness of building structures. 